\title{
Identification of Physical Changes to a Steel Frame
}

\author{
A Thesis \\ presented to \\ the Faculty of California Polytechnic State University \\ San Luis Obispo, California
}

In Partial Fulfillment

of the Requirements for the Degree

Master of Science in Architecture with a Specialization in Architectural Engineering

by

Daniel Eric Means

February 2010 
(C) 2010

Daniel Eric Means

ALL RIGHTS RESERVED 


\section{COMMITTEE MEMBERSHIP}

TITLE:

AUTHOR:

DATE SUBMITTED: $\quad$ February 2010

February 2010
IDENTIFICATION OF PHYSICAL CHANGES

TO A STEEL FRAME

Daniel Eric Means

COMMITTEE CO-CHAIR: Graham Archer, Ph.D., P.E.

COMMITTEE CO-CHAIR: Cole McDaniel, Ph.D., P.E.

COMMITTEE MEMBER: Kevin Dong, S.E. 


\author{
ABSTRACT \\ Identification of Physical Changes to a Steel Frame \\ Daniel Eric Means
}

The thesis utilized physical testing and computer modeling to determine the feasibility of identifying a change to the mass or stiffness of a steel frame. Physical testing was performed using an accelerometer, linear shaker, and arbitrary function generator. Two methods of laboratory testing were developed: ambient vibration testing (AVT) and forced vibration testing (FVT). AVT was able to preliminarily identify the natural frequencies and mode shapes of the frame. FVT was able to precisely identify four distinct natural frequencies, mode shapes, and damping ratios. The baseline frame then underwent two physical changes: the addition of mass to its roof, and the addition of braces along one of its sides. FVT was used again to determine the natural frequencies, mode shapes, and damping ratios of the newly changed structure.

An ETABS computer model was developed to represent the frame. This baseline model produced natural frequencies and mode shapes that closely matched the values determined by FVT. The mass and stiffness of this baseline model were then changed multiple times through the addition of mass and braces at various locations on the model. The frequencies and mode shapes were recorded for each change.

Two methods were developed to identify the changes to the steel frame. The first method was able to determine which one of the models best represented a single change to the structure (adding mass to its roof). The second method was able to determine the combination of models that best represented the two concurrent changes to the structure (adding mass to its roof and braces to its sides). Both methods utilized the percent differences of each altered computer model relative to the original, and each method satisfactorily identified its respective physical alteration. 


\section{ACKNOWLEDGEMENTS}

I want to thank Peter Zahm and Hilti for their generous donation of the expansion anchors and concrete drill bit that helped make this project possible. I also want to thank Daisy Chee for her work in recording data early in the testing phase of the project. I want to especially thank Ray Ward for helping me in preparing, fixing, and setting up the frame countless times until the frame was unquestionably secured to the ground. I would like to thank Joey Williams and Dan Lazzarini for their help in the lab, especially with welding the braces to the frame. I would also like to thank Deborah Wilhelm for helping to develop this document. Finally, I want to thank Graham Archer and Cole McDaniel for their time, help, and sincere interest in the development this research. 


\section{TABLE OF CONTENTS}

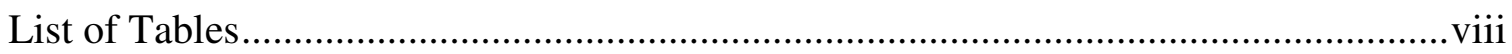

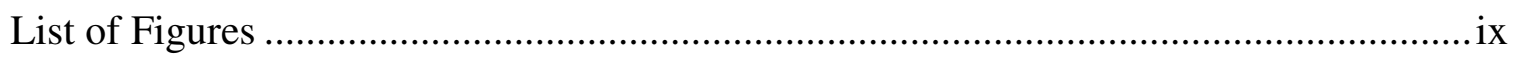

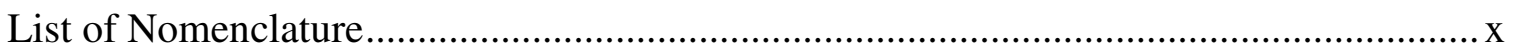

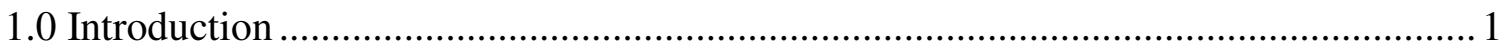

1.1 Purpose

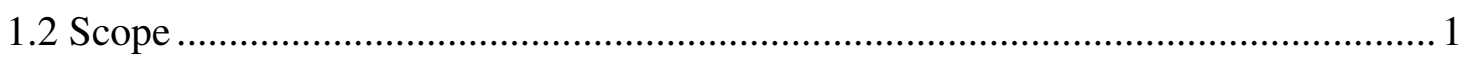

2.0 Literature Review and Theoretical Development ................................................ 2

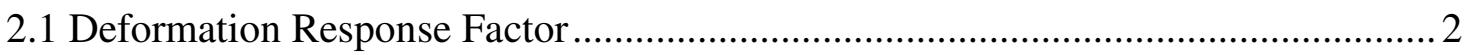

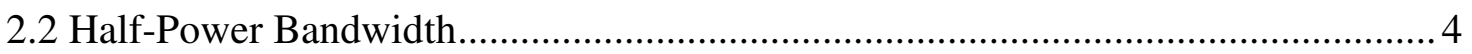

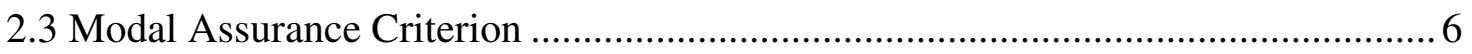

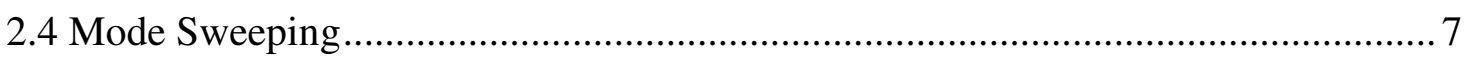

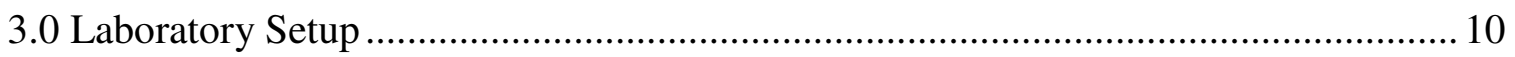

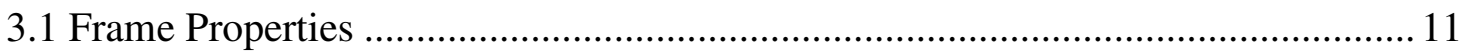

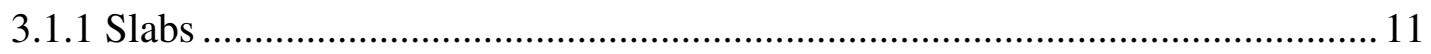

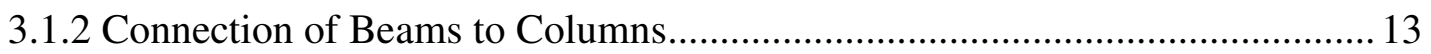

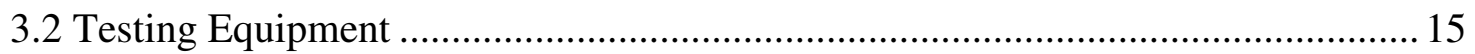

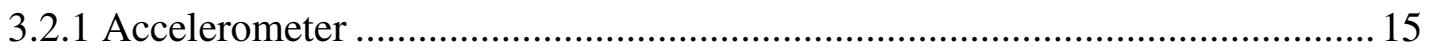

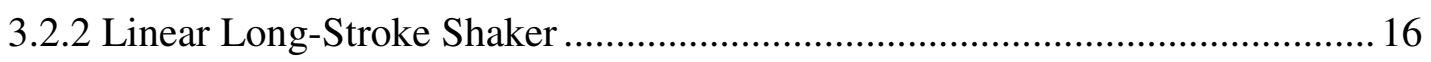

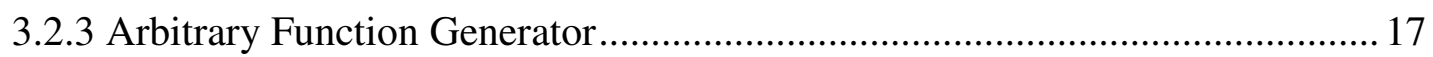

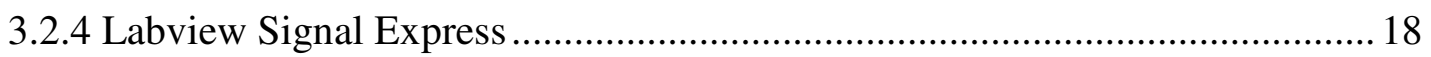

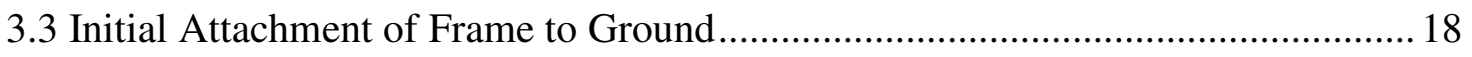

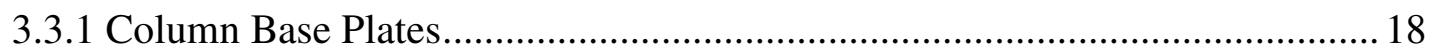

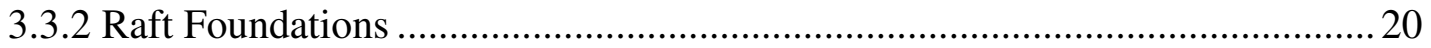

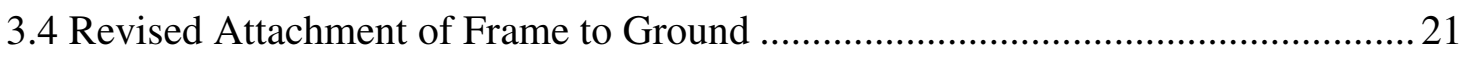

3.4.1 Problems Detecting Natural Frequencies................................................... 21

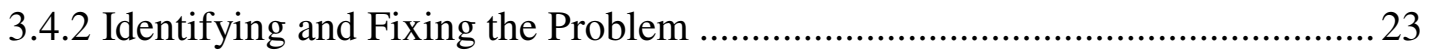

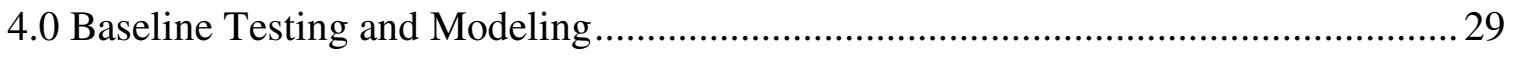

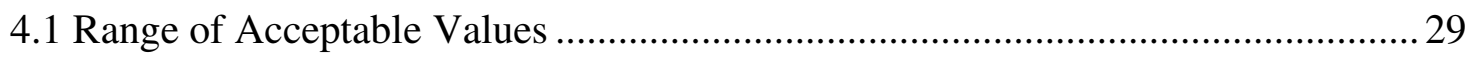

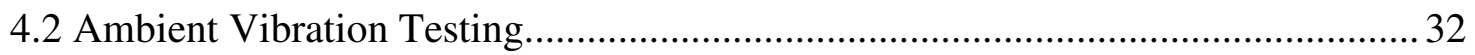

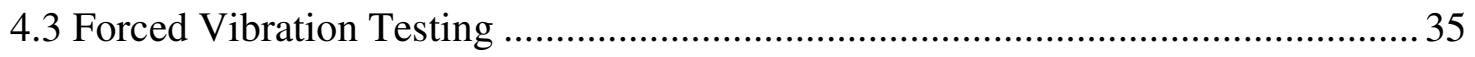

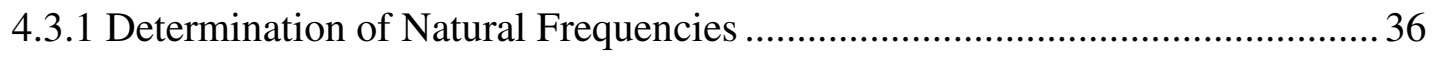

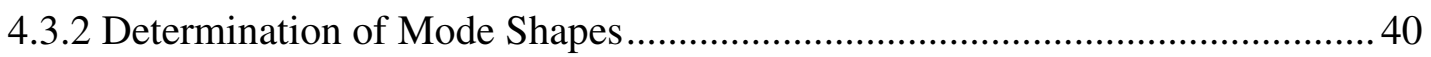

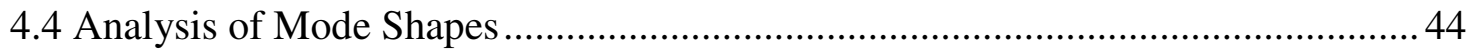

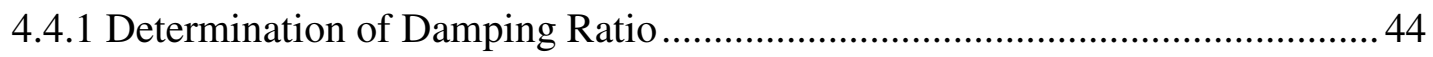

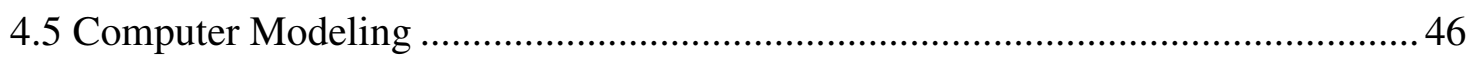

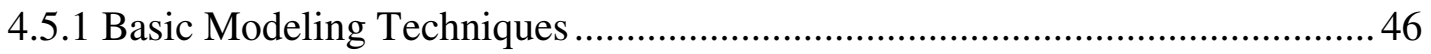


4.5.2 Advanced Modeling Techniques............................................................ 48

4.5.3 Determination of the Adequacy of Computer Model.....................................50

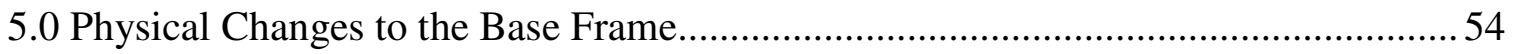

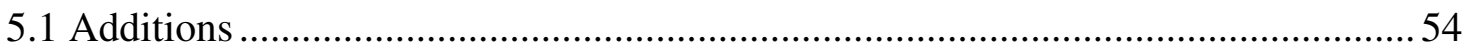

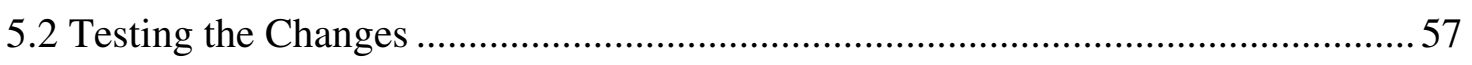

5.3 Establishing Possible Computer Model Solutions .................................................58

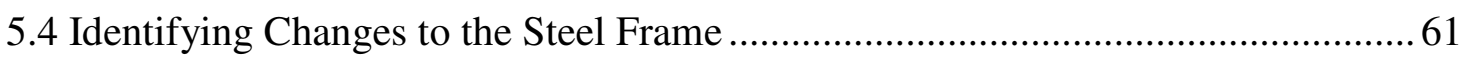

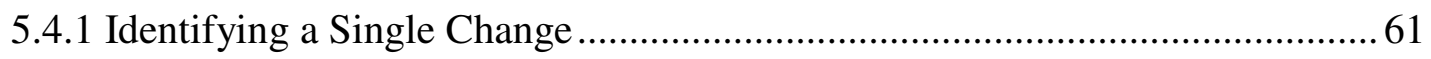

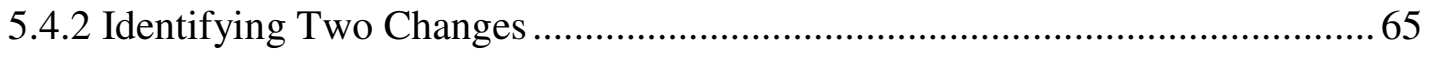

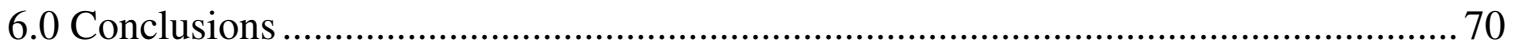

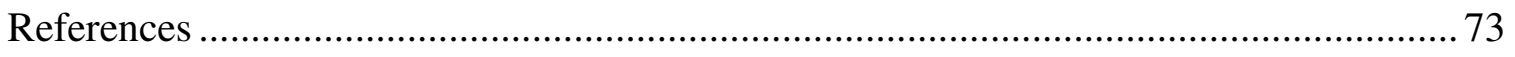

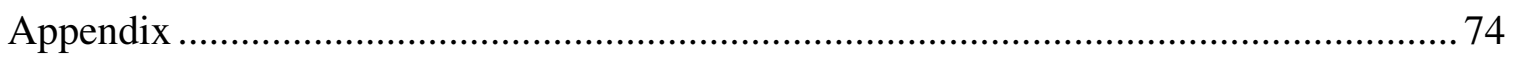

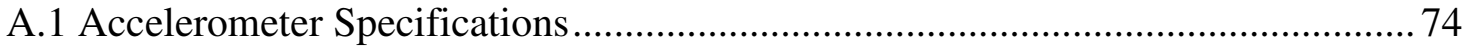

A.2 Baseline Forced Vibration Testing ............................................................... 84

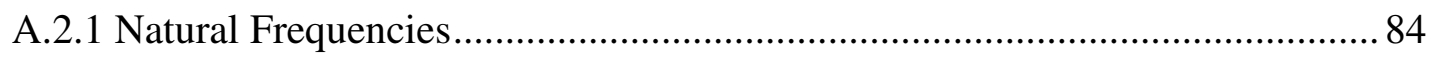

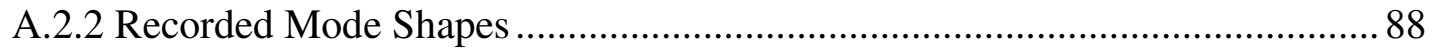

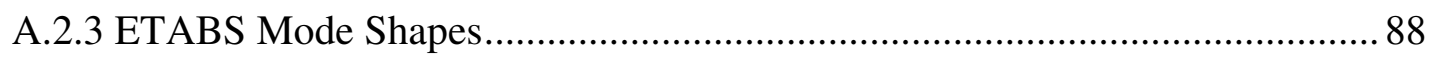

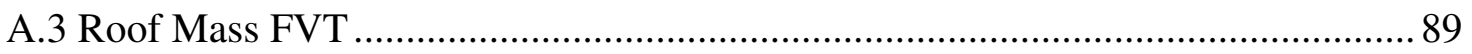

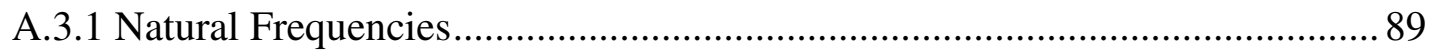

A.3.2 Recorded Mode Shapes ......................................................................... 93

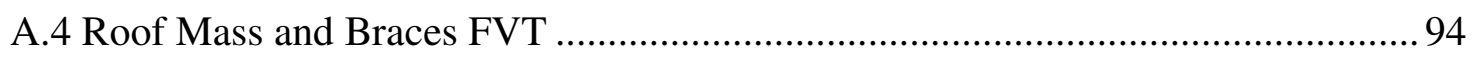

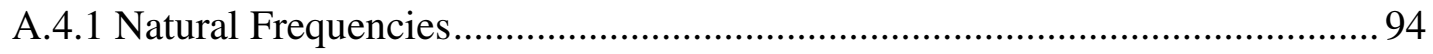

A.4.2 Recorded Mode Shapes ............................................................................. 98

A.5 Properties of Each Singly Altered Model...................................................... 99 


\section{LIST OF TABLES}

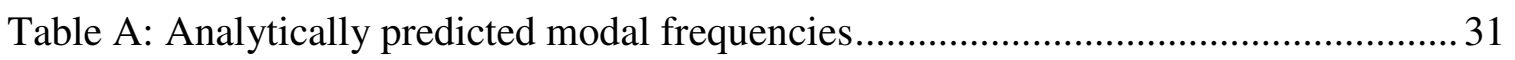

Table B: Potential natural frequencies determined by AVT ....................................... 35

Table C: Natural frequencies determined by FVT ...................................................... 39

Table D: Recorded mode shape values for $6.48 \mathrm{~Hz}$................................................. 41

Table E: Matching mode shapes to natural frequencies............................................... 43

Table F: Damping ratio of each mode shape........................................................... 45

Table G: Percent difference of natural frequencies..................................................51

Table H: MAC with respect to physical structure ............................................................51

Table I: Spring rotational stiffnesses in ETABS model ............................................52

Table J: Natural frequencies of physical structure and computer model .........................53

Table K: Natural frequencies of the altered physical structure ......................................57

Table L: Change in natural frequency due to addition of roof mass ...............................59

Table M: Change in natural frequency due to addition of floor mass.............................59

Table N: Change in natural frequency due to addition of mass to roof and floor.............60

Table O: Changes in natural frequency due to addition of braces ...................................6 60

Table P: Points assigned for range of percent difference................................................. 61

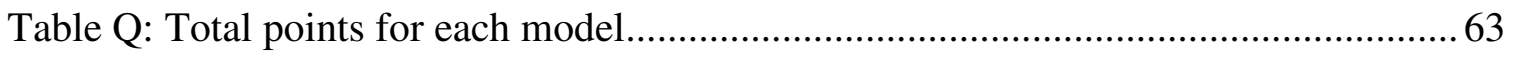

Table R: Total points for each combination of models ............................................ 68 


\section{LIST OF FIGURES}

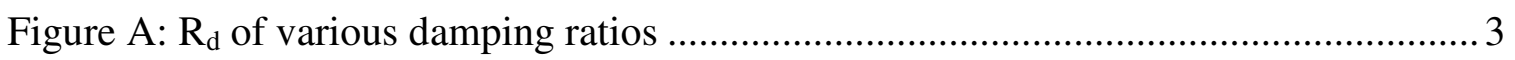

Figure B: Half-power bandwidth ....................................................................... 4

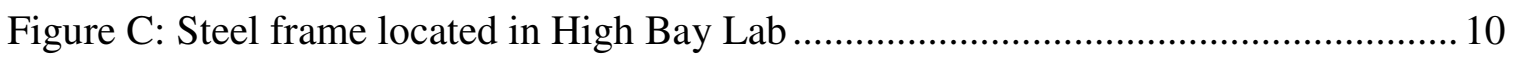

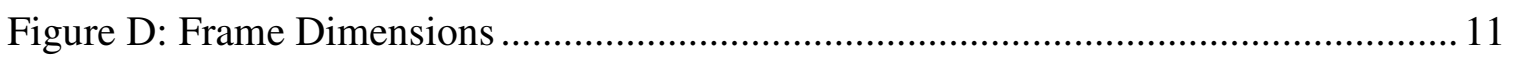

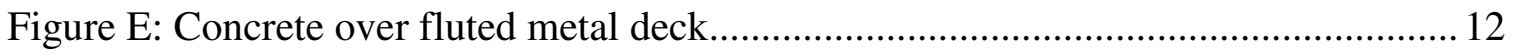

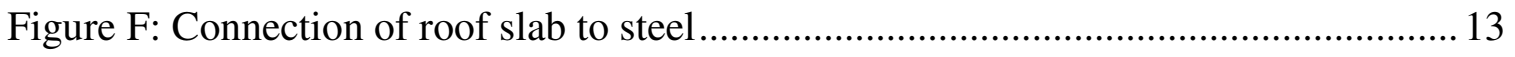

Figure G: Typical long beam-to-column connection .............................................. 14

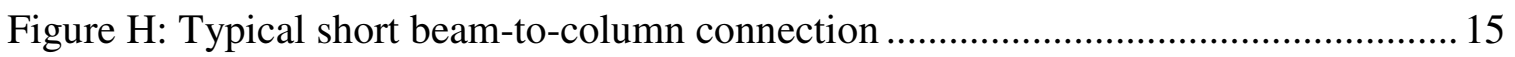

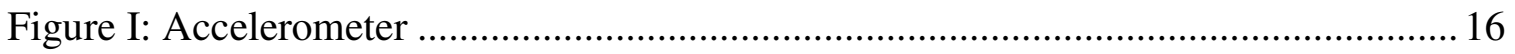

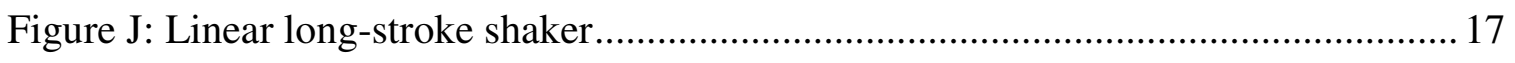

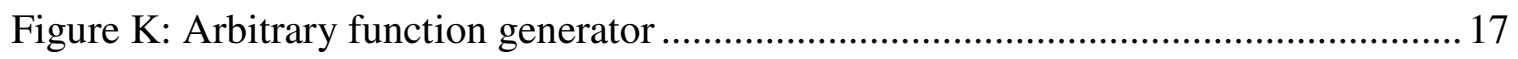

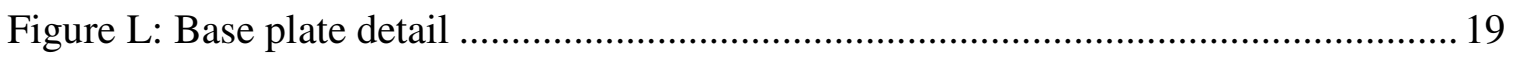

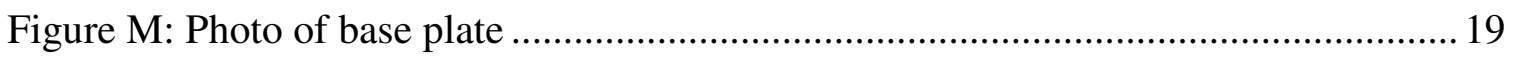

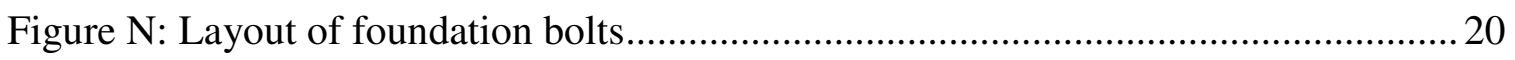

Figure O: Bolts attaching raft to strong-floor.......................................................... 21

Figure P: Initial attachment strong axis acceleration response, $1.0 \mathrm{~V}$............................ 22

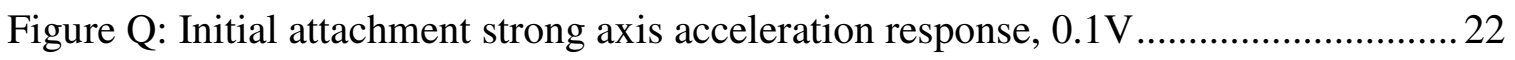

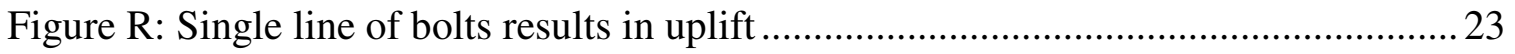

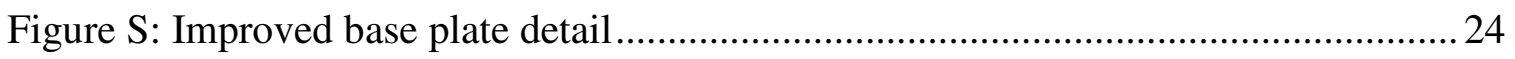

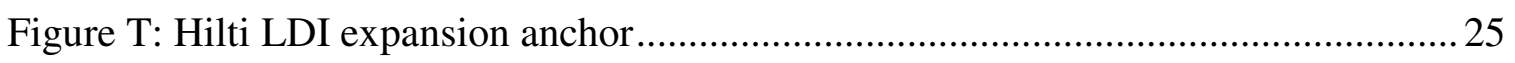

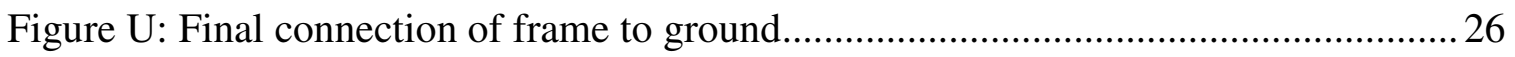

Figure V: Revised attachment strong axis acceleration response, $1.0 \mathrm{~V}$......................... 27

Figure $\mathrm{W}$ : Revised attachment strong axis acceleration response, $0.1 \mathrm{~V}$.........................2 27

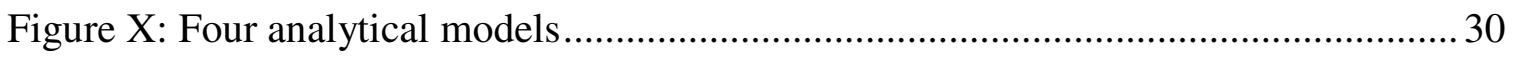

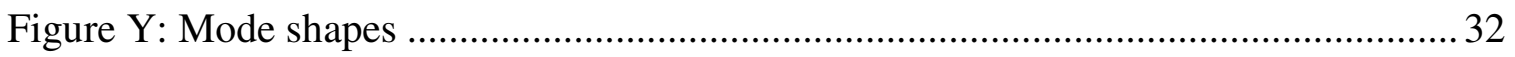

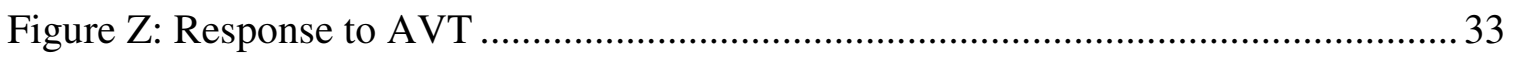

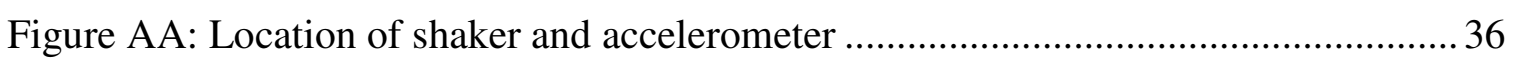

Figure BB: Accelerations of each frequency from $6.48 \mathrm{~Hz}$ loading ............................. 37

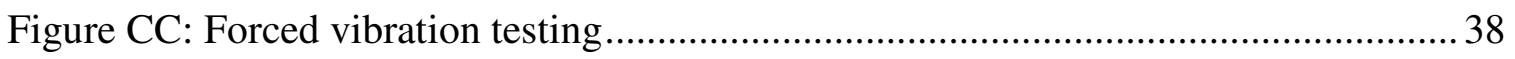

Figure DD: Accelerometer locations converted to analytical degrees of freedom ...........40

Figure EE: Power band method to determine damping .......................................... 45

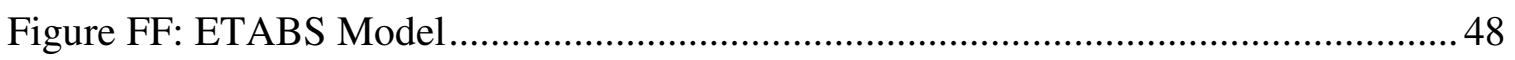

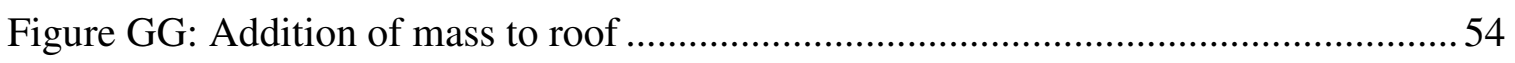

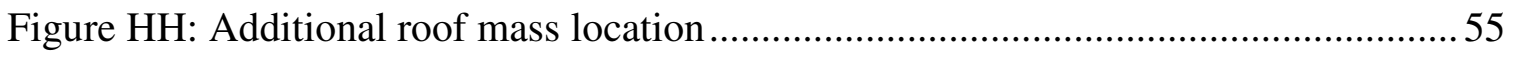

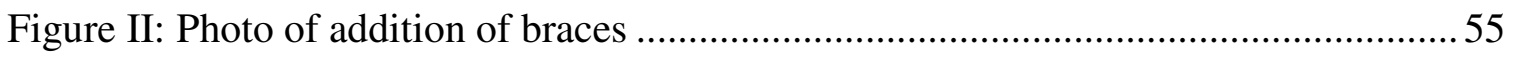

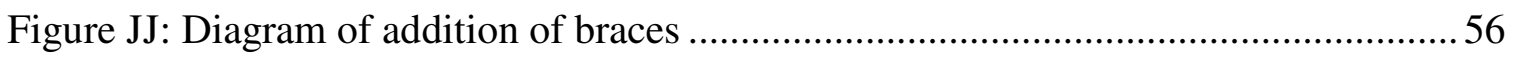




\section{LIST OF NOMENCLATURE}

$f_{a}$

$f_{b}$

$f_{\text {Baseline }}$

$f_{\text {Combo }}$

$f_{n}$

$\zeta$

$M$

$M A C$

$P_{S 1}$

$P_{T 1}$

$P_{\text {Total }}$

$P_{W 1}$

$P_{W 2}$

$P C_{f}$

$P D_{1}$

$\mathrm{PD}_{2}$

$q_{i}$

$R_{d}$

$R_{d \max }$

$u_{i}$
Smaller frequency of applied load $(\mathrm{Hz})$

Larger frequency of applied load (Hz)

Baseline model frequency $(\mathrm{Hz})$

Frequency of the combination of models $(\mathrm{Hz})$

Natural frequency of structure $(\mathrm{Hz})$

Damping ratio of structure (dimensionless)

Mass matrix $\left(\mathrm{lb} \cdot \mathrm{s}^{2} /\right.$ in and $\left.\mathrm{lb} \cdot \mathrm{in} \cdot \mathrm{s}^{2}\right)$

Modal assurance criterion (dimensionless)

Points for first strong mode (points)

Points for first torsional mode (points)

Total points for a model (points)

Points for first weak mode (points)

Points for second weak mode (points)

Percent change of the frequency $(\%)$

Percent difference between model $1 \&$ baseline $(\%)$

Percent difference between model $2 \&$ baseline (\%)

Accelerometer recorded data per Figure DD (in/s $\mathrm{s}^{2}$ )

Deformation response factor (dimensionless)

Maximum value of $R_{d}$ (dimensionless)

Modal response of $i^{\text {th }}$ degree of freedom (in/s $\left.\mathrm{s}^{2}\right)$ 
$\phi_{A} \quad$ First mode shape vector (in $/ \mathrm{s}^{2}$ and $\mathrm{rad} / \mathrm{s}^{2}$ )

$\phi_{B} \quad$ Second mode shape vector $\left(\mathrm{in} / \mathrm{s}^{2}\right.$ and $\left.\mathrm{rad} / \mathrm{s}^{2}\right)$

$\phi_{i} \quad$ Recorded $\mathrm{i}^{\text {th }}$ modal vector (in $/ \mathrm{s}^{2}$ and $\mathrm{rad} / \mathrm{s}^{2}$ )

$\phi_{\text {in }} \quad$ Orthogonalized $\mathrm{i}^{\text {th }}$ modal vector (in $/ \mathrm{s}^{2}$ and $\mathrm{rad} / \mathrm{s}^{2}$ )

$\omega \quad$ Frequency of applied load $(\mathrm{rad} / \mathrm{s})$

$\omega_{a} \quad$ Smaller frequency of applied load ( $\left.\mathrm{rad} / \mathrm{s}\right)$

$\omega_{b} \quad$ Larger frequency of applied load ( $\left.\mathrm{rad} / \mathrm{s}\right)$

$\omega_{n} \quad$ Natural frequency of structure $(\mathrm{rad} / \mathrm{s})$ 


\subsection{INTRODUCTION}

This project examined the feasibility of using a combination of physical testing methods and computer modeling techniques to identify physical alterations made to a steel frame.

\subsection{Purpose}

The primary purpose of this project was to develop both laboratory testing and analytical methods to identify structural changes to a steel frame. Additionally, this project was designed to lay the groundwork for future research in the field by developing testing methods and computer modeling techniques that could be applied to similar structures.

\subsection{Scope}

The scope of this project consisted of three major components. The first component of the project involved the development of a laboratory testing method able to experimentally determine various structural properties of the frame. The second component was involved using these experimentally-determined structural properties to create an accurate analytical model of the existing physical structure. The third component involved making two distinct physical changes to the frame and then developing analytical methods by which these changes could be identified. 


\subsection{LITERATURE REVIEW AND THEORETICAL DEVELOPMENT}

The following sections describe the development of the equations and some of the methods used in this the analysis of this project.

\subsection{Deformation Response Factor}

When a structure is harmonically loaded such that the loading frequency nears the natural frequency of the structure, the deformation of the structure is amplified through a deformation response factor, $R_{d} . R_{d}$ is a function of both the ratio of the frequencies as well as the damping ratio of the structure, as seen below in Equation 1.

$$
R_{d}=\frac{1}{\sqrt{\left[1-\left(\omega / \omega_{n}\right)^{2}\right]^{2}+\left[2 \zeta\left(\omega / \omega_{n}\right)\right]^{2}}}
$$

where $R_{d}=$ deformation response factor (dimensionless),

$\omega=$ frequency of applied load $(\mathrm{rad} / \mathrm{s})$,

$\omega_{\mathrm{n}}=$ natural frequency of structure $(\mathrm{rad} / \mathrm{s})$, and

$\zeta=$ damping ratio of structure (dimensionless).

The results of Equation 1 are more clearly depicted using a graph, as shown in

Figure A, below. The graph plots the deformation response factor with respect to the ratio of the frequencies. Each separate curve represents various values of the damping ratio. 


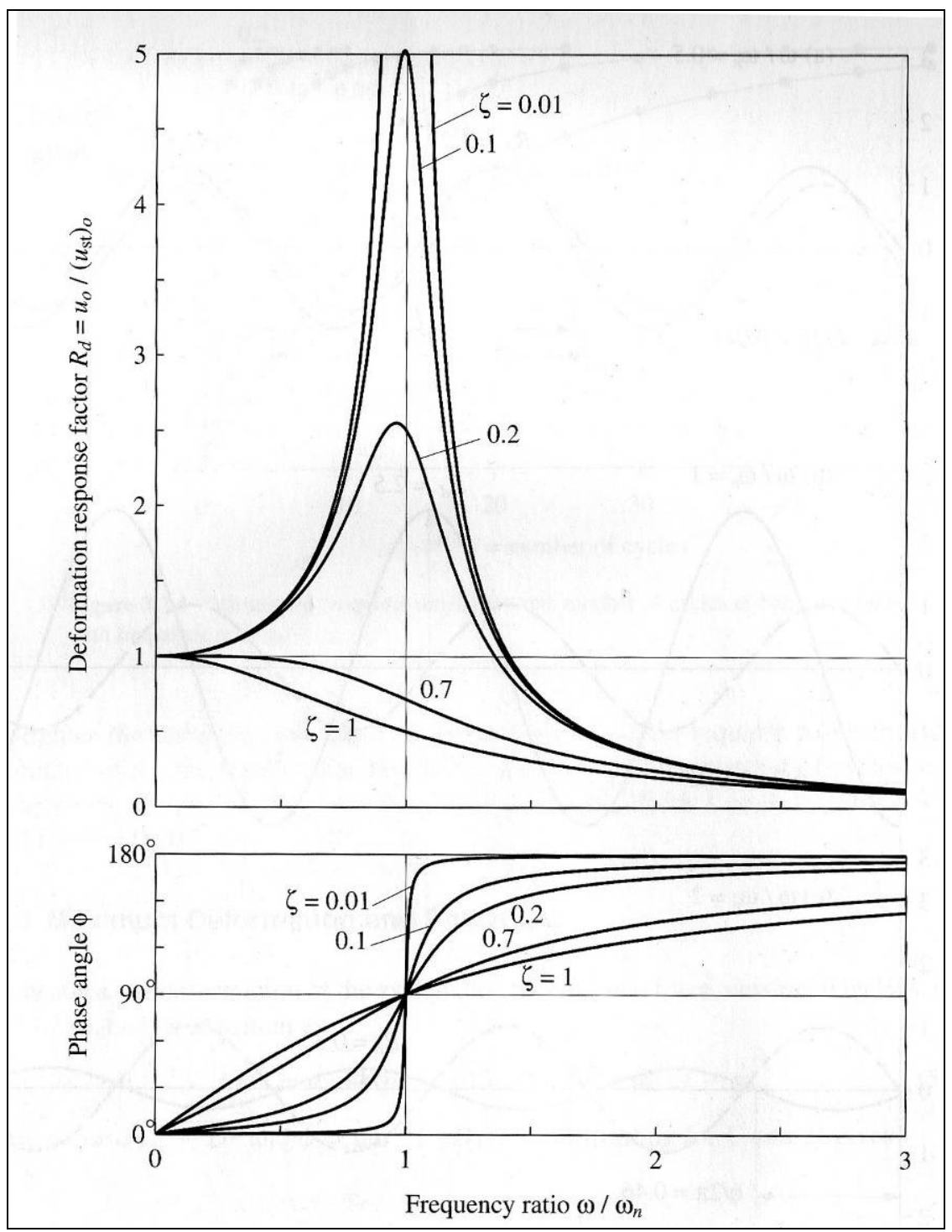

Figure A: $\mathbf{R}_{\mathbf{d}}$ of various damping ratios

Source: Chopra (2007)

The maximum value of $R_{d}, R_{d \max }$, is determined by taking the derivative of Equation 1 with respect to the frequency ratio, resulting in Equation 2, below.

$$
R_{d \max }=\frac{1}{2 \zeta \sqrt{1-\zeta^{2}}}
$$

where $R_{d \max }=$ maximum value of $R_{d}$ (dimensionless) and $\zeta=$ damping ratio of structure (dimensionless). 


\subsection{Half-Power Bandwidth}

As long as the damping ratio is known, Equation 1 and Figure A can provide useful information with regard to predicting the response of a given structure to sinusoidal loading. However, if the damping ratio is not known, but the curve relating $R_{d}$ to the frequency ratio is known, the damping ratio can be determined using the halfpower bandwidth property of the curve, defined by Figure B, below.

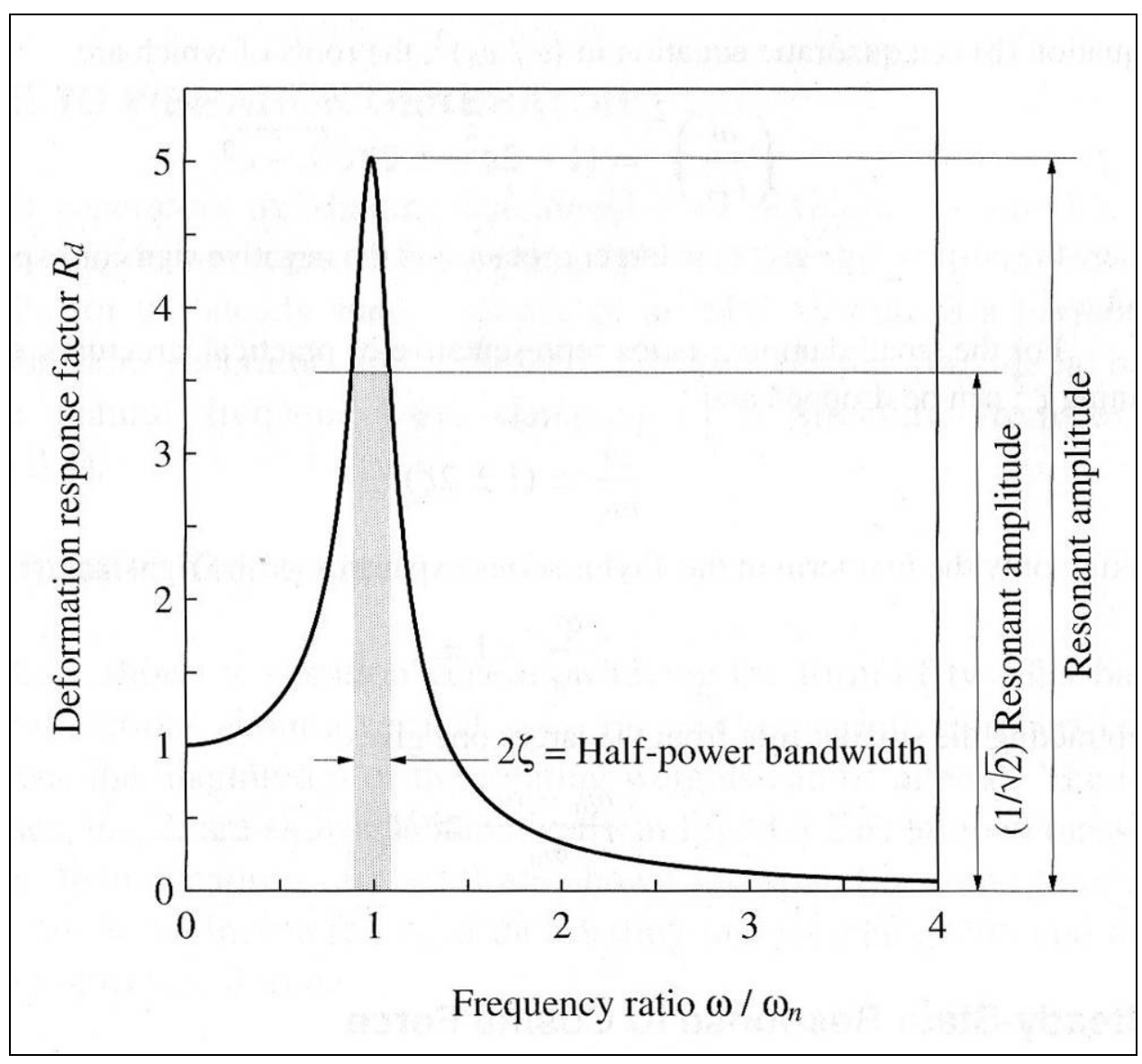

Figure B: Half-power bandwidth

Source: Chopra (2007)

If $\left(\omega_{\mathrm{a}} / \omega_{\mathrm{n}}\right)$ and $\left(\omega_{\mathrm{b}} / \omega_{\mathrm{n}}\right)$ are the frequency ratios that correspond to the points on the curve in which the values are equal to $R_{d}$ divided by the square root of 2 , the result is Equation 3, below. 


$$
\frac{1}{\sqrt{\left[1-\left(\omega / \omega_{n}\right)^{2}\right]^{2}+\left[2 \zeta\left(\omega / \omega_{n}\right)\right]^{2}}}=\frac{1}{\sqrt{2}} \frac{1}{2 \zeta \sqrt{1-\zeta^{2}}}
$$

Eq. 3

where $\omega=$ frequency of applied load $(\mathrm{rad} / \mathrm{s})$,

$\omega_{n}=$ natural frequency of structure $(\mathrm{rad} / \mathrm{s})$, and

$\zeta=$ damping ratio of structure (dimensionless).

Taking Equation 3 and solving for $\omega / \omega_{\mathrm{n}}$ results in Equation 4, below.

$$
\omega / \omega_{n}=\sqrt{1-2 \zeta^{2} \pm 2 \zeta \sqrt{1-\zeta^{2}}}
$$

where $\omega=$ frequency of applied load $(\mathrm{rad} / \mathrm{s})$,

$\omega_{n}=$ natural frequency of structure $(\mathrm{rad} / \mathrm{s})$, and

$\zeta=$ damping ratio of structure (dimensionless).

For the very small values of damping that exist in physical structures, the $\zeta^{2}$ terms are assumed to be equal to zero. Using the first term of the subsequent Taylor series expansion results in Equation 5, below.

$$
\omega / \omega_{n}=1 \pm \zeta
$$

where $\omega=$ frequency of applied load $(\mathrm{rad} / \mathrm{s})$,

$\omega_{n}=$ natural frequency of structure $(\mathrm{rad} / \mathrm{s})$, and

$\zeta=$ damping ratio of structure (dimensionless).

Assigning $\left(\omega_{\mathrm{b}} / \omega_{\mathrm{n}}\right)$ to be the larger root and $\left(\omega_{\mathrm{a}} / \omega_{\mathrm{n}}\right)$ be the smaller root, then subtracting $\left(\omega_{\mathrm{a}} / \omega_{\mathrm{n}}\right)$ from $\left(\omega_{\mathrm{b}} / \omega_{\mathrm{n}}\right)$, results in Equation 6 , below. 


$$
\frac{\omega_{b}-\omega_{a}}{\omega_{n}}=2 \zeta
$$

where $\omega_{a}=$ smaller frequency of applied load $(\mathrm{rad} / \mathrm{s})$,

$\omega_{b}=$ larger frequency of applied load $(\mathrm{rad} / \mathrm{s})$,

$\omega_{n}=$ natural frequency of structure $(\mathrm{rad} / \mathrm{s})$, and

$\zeta=$ damping ratio of structure (dimensionless).

Isolating $\zeta$ and utilizing the relationship between $\omega$ and $f$, the equation in which the damping ratio is determined is displayed as Equation 7, below.

$$
\zeta=\frac{f_{b}-f_{a}}{2 f_{n}}
$$

$$
\text { where } \begin{aligned}
f_{a} & =\text { smaller frequency of applied load }(\mathrm{Hz}), \\
f_{b} & =\text { larger frequency of applied load }(\mathrm{Hz}), \\
f_{n} & =\text { natural frequency of structure }(\mathrm{Hz}), \text { and } \\
\zeta & =\text { damping ratio of structure (dimensionless). }
\end{aligned}
$$

\subsection{Modal Assurance Criterion}

The modal assurance criterion, MAC, compares how well two modal vectors correlate with one another. Randall J. Allemang examines the development, uses, and misuses of the MAC, in his article, "The Modal Assurance Criterion - Twenty Years of Use and Abuse." The MAC is a scalar, and values closest to 1 indicate the highest levels of correlation (Allemang 2003). The MAC is determined by Equation 8, below. 


$$
\operatorname{MAC}\left(\phi_{A}, \phi_{B}\right)=\frac{\left\{\phi_{A}^{T} \cdot \phi_{B}\right\}^{2}}{\left\{\phi_{A}^{T} \cdot \phi_{A}\right\} \cdot\left\{\phi_{B}^{T} \cdot \phi_{B}\right\}}
$$

Eq. 8

where $M A C=$ modal assurance criterion (dimensionless), $\phi_{A}=$ first mode shape vector $\left(\mathrm{in} / \mathrm{s}^{2}\right.$ and $\left.\mathrm{rad} / \mathrm{s}^{2}\right)$, and $\phi_{B}=$ second mode shape vector (in $/ \mathrm{s}^{2}$ and $\left.\mathrm{rad} / \mathrm{s}^{2}\right)$.

Among the many uses listed for the MAC, those that apply to this project include validation of experimental modal models, correlation with analytical modal models, and modal vector error analysis (Allemang 2003). The MAC was utilized in this project during the development of accurate computer modeling, specifically to determine which modeling techniques resulted in the most accurate modal representation of the physical structure.

Allemang makes it a point to address the issue of orthogonality. The MAC cannot be used to check if modes are orthogonal. In this project, the values recorded from experimental testing produced modal vectors that were not orthogonal, so a different method had to be used to properly manipulate them into orthogonal modal vectors.

\subsection{Mode Sweeping}

Mode sweeping is the process by which the effects of more prominent modes are removed from the less prominent modes. Mode sweeping essentially insures that the modes are orthogonal to one another. It should also be noted that in this experiment, the first weak mode was the most prominent and was assumed to be pure, exhibiting negligible effects from the other modes. The purity of the first mode means that the recorded modal vector is identical to the orthogonalized vector. 
The data recorded in a laboratory setting regarding each mode shape generally contained a mixture of other mode shapes. The prominence of these other mode shapes was relative to the $R_{d}$ value of each modal frequency. Unless two modes had very similar frequencies, the relative effects of the lower order modes were much smaller than those of higher order modes. The lowest $\mathrm{R}_{\mathrm{d}}$ value for a higher mode was 1 , whereas the lowest $\mathrm{R}_{\mathrm{d}}$ value for a lower mode approached zero.

Equations 9, 10, and 11, below, were used to sweep the higher order modal effects from the second, third, and fourth recorded modal data.

$$
\begin{gathered}
\phi_{2 n}=\phi_{2}-\frac{\phi_{1}^{T} M \phi_{2}}{\phi_{1}^{T} M \phi_{1}} \phi_{1} \\
\phi_{3 n}=\phi_{3}-\frac{\phi_{1}^{T} M \phi_{3}}{\phi_{1}^{T} M \phi_{1}} \phi_{1}-\frac{\phi_{2 n}^{T} M \phi_{3}}{\phi_{2 n}^{T} M \phi_{2 n}} \phi_{2 n} \\
\phi_{4 n}=\phi_{4}-\frac{\phi_{1}^{T} M \phi_{4}}{\phi_{1}^{T} M \phi_{1}} \phi_{1}-\frac{\phi_{2 n}^{T} M \phi_{4}}{\phi_{2 n}^{T} M \phi_{2 n}} \phi_{2 n}-\frac{\phi_{3 n}^{T} M \phi_{4}}{\phi_{3 n}^{T} M \phi_{3 n}} \phi_{3 n}
\end{gathered}
$$

where $\phi_{1}=$ recorded first modal vector $\left(\mathrm{in} / \mathrm{s}^{2}\right.$ and $\left.\mathrm{rad} / \mathrm{s}^{2}\right)$,

$\phi_{2}=$ recorded second modal vector (in $/ \mathrm{s}^{2}$ and $\mathrm{rad} / \mathrm{s}^{2}$ ),

$\phi_{3}=$ recorded third modal vector (in/ $/ \mathrm{s}^{2}$ and $\left.\mathrm{rad} / \mathrm{s}^{2}\right)$,

$\phi_{4}=$ recorded fourth modal vector $\left(\mathrm{in} / \mathrm{s}^{2}\right.$ and $\left.\mathrm{rad} / \mathrm{s}^{2}\right)$,

$\phi_{2 n}=$ orthogonalized second modal vector (in $/ \mathrm{s}^{2}$ and $\mathrm{rad} / \mathrm{s}^{2}$ ),

$\phi_{3 n}=$ orthogonalized third modal vector $\left(\mathrm{in} / \mathrm{s}^{2}\right.$ and $\mathrm{rad} / \mathrm{s}^{2}$ ),

$\phi_{4 n}=$ orthogonalized fourth modal vector (in/ $/ \mathrm{s}^{2}$ and $\mathrm{rad} / \mathrm{s}^{2}$ ), and

$M=$ mass matrix $\left(\mathrm{lb} \cdot \mathrm{s}^{2} /\right.$ in and $\left.\mathrm{lb} \cdot \mathrm{in} \cdot \mathrm{s}^{2}\right)$. 
The reason behind orthogonalizing the modal vectors is that analytical and computer models produce orthogonal modal vectors. In order to utilize the MAC correctly in comparing any two modal vectors, they must not be influenced by the other mode shapes of the structure. 


\subsection{LABORATORY SETUP}

The project centered on a two-story steel frame located in the High Bay Lab of the Engineering West building on the Cal Poly campus. The simplistic nature of the structure - its relatively small size and its symmetry - made it an ideal system to execute both ambient and forced vibration tests. Figure C, below, is a photo of the frame.

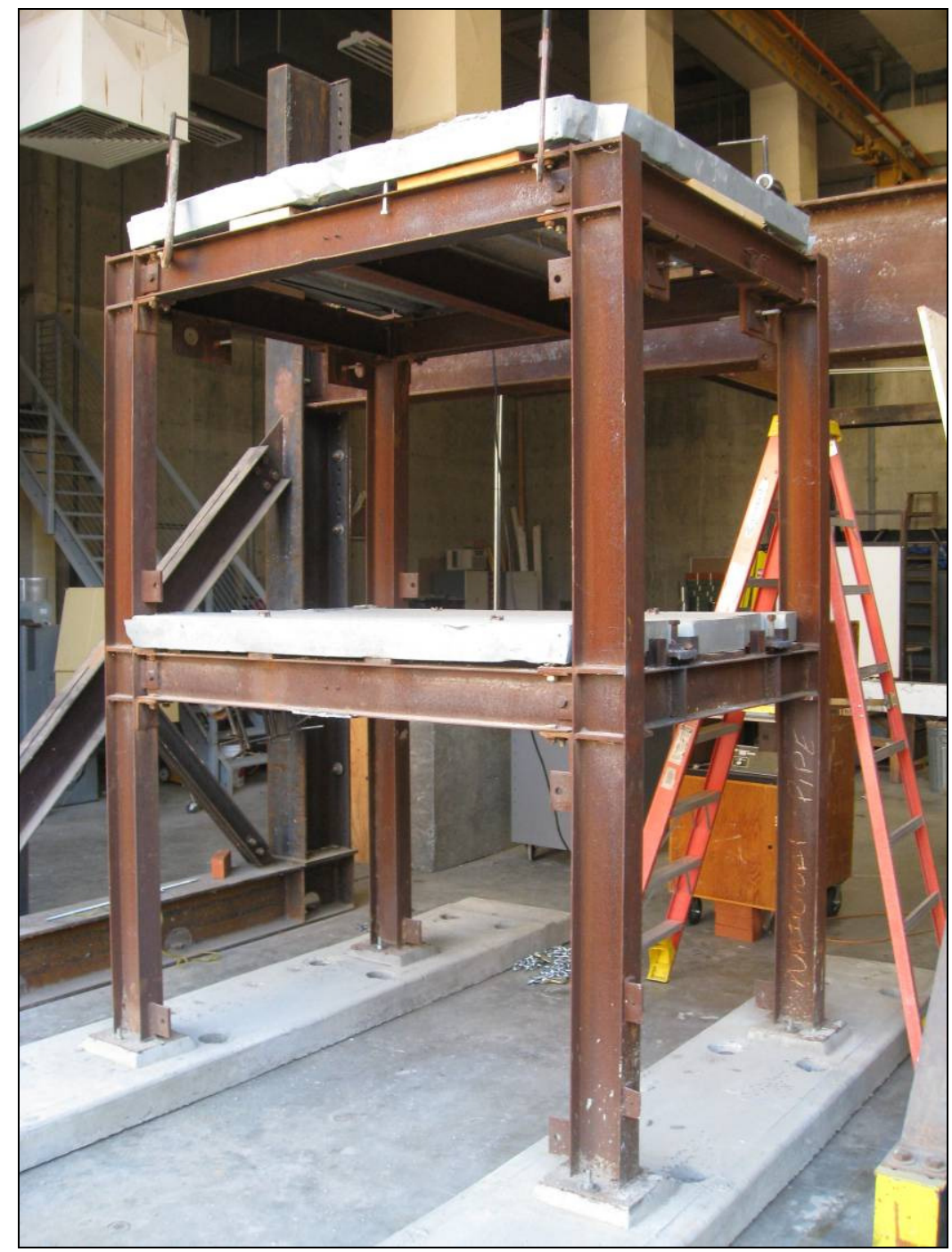

Figure C: Steel frame located in High Bay Lab

Source: Author photo 


\subsection{Frame Properties}

The frame occupied a footprint of just over 6 ' by $4.5^{\prime}$ and was just over 8 ' tall. All of the beams and columns of the frame were determined to be W6x12 (American Institute of Steel Construction 2006). Each story supported a 1.75" concrete slab over 2.25" of fluted metal deck, weighing just over 1000 pounds each. The diagrams in Figure D, below, provide the exact dimensions of the steel frame.

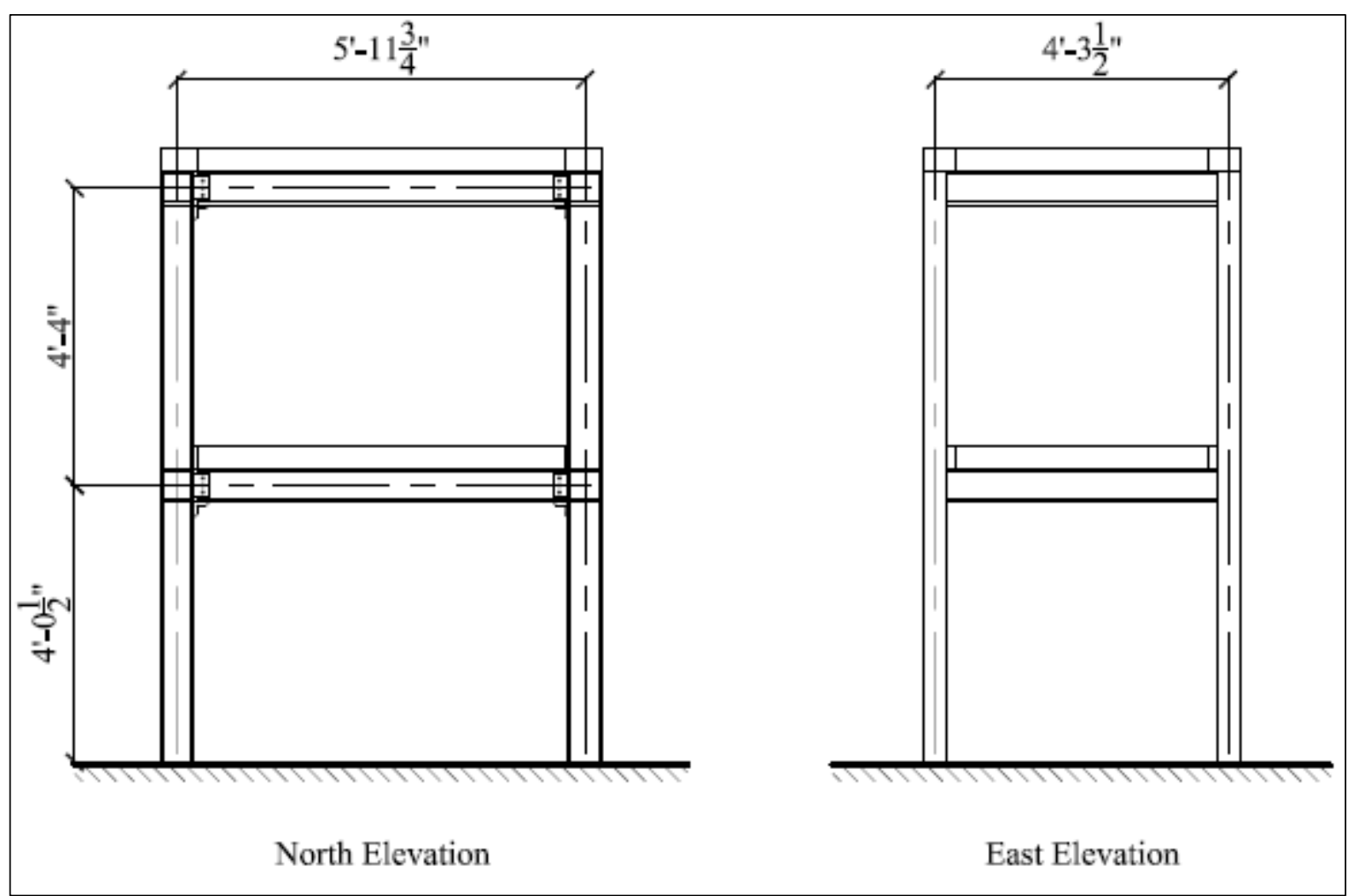

Figure D: Frame Dimensions

Source: Author diagram

\subsubsection{Slabs}

The 1040 pound floor slab did not have a mechanical connection to the beams below; instead, it rested on the beams and was secured from lateral movement by the 
surrounding columns. Figure E, below, is a photograph showing the concrete over the fluted metal deck of the floor slab.

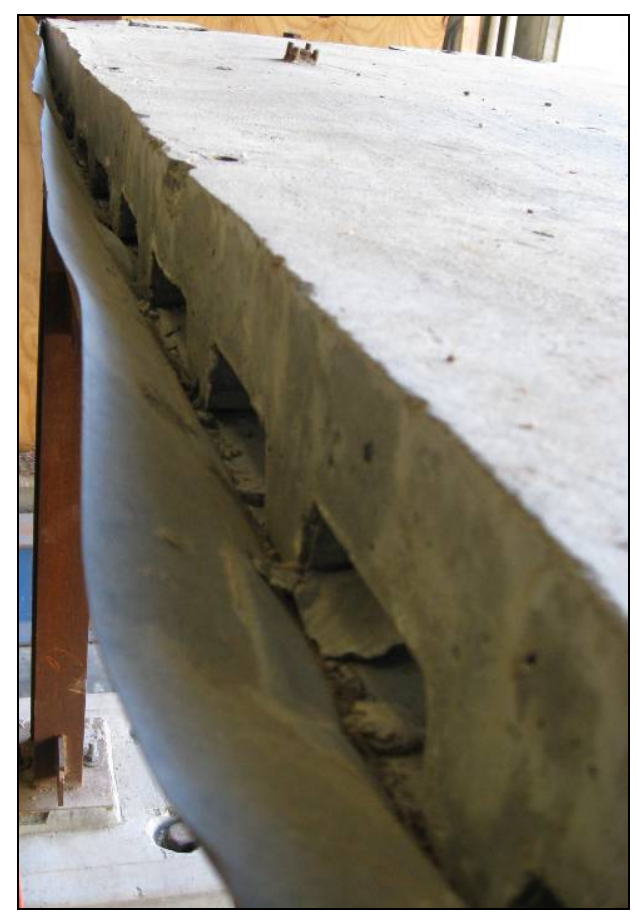

\section{Figure E: Concrete over fluted metal deck}

Source: Author photo

The roof slab was the 1030 pound slab that rested on the top level of beams on the frame. The major difference between the roof slab and floor slab was that the roof slab had to be secured such that it was not able to move laterally. The floor slab was surrounded by columns, preventing its movement, but the columns did not extend above the top level of beams. The method used to secure the slab to the roof involved the use of a C-clamp near each corner of the roof, as seen in Figure F, below. 


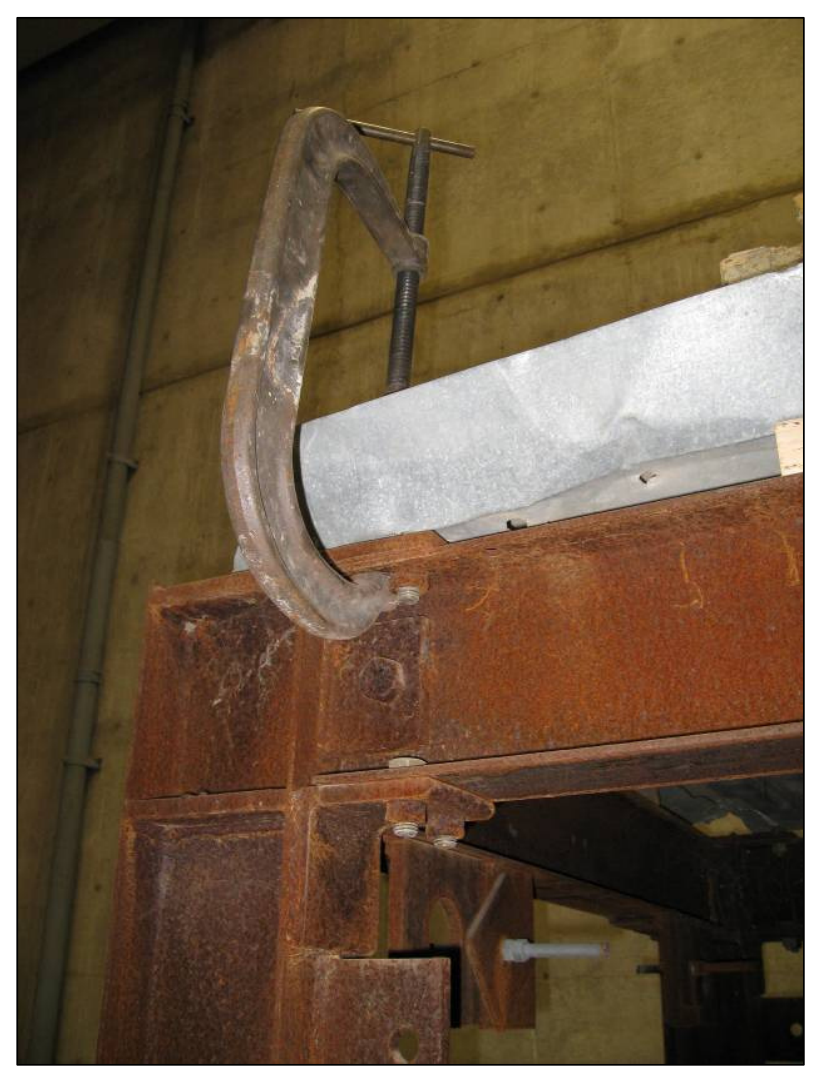

Figure F: Connection of roof slab to steel Source: Author photo

\subsubsection{Connection of Beams to Columns}

The frame resisted applied lateral forces through moment-resisting connections between all of the beams and columns. Although the connections were different in the two principal directions, they essentially provided the same type of connection.

The beams running along the longer dimension of the frame aligned with the strong axis of the columns. Each of these beams was bolted to a steel angle on its bottom and a flat plate on its top. Both of these items were then fully welded to the column. Additionally, stiffener plates aligned with the horizontal members of each of these items, helping to reduce the amount of rotation experienced by the beam relative to the column. Lastly, a vertical shear plate was bolted to the beam and welded to the column. The 
combination of these plates, welds, and bolts provided moment-resisting connections in the "strong axis" orientation of the structure. Figure G, below, is a photo of the typical strong axis beam-to-column connection.

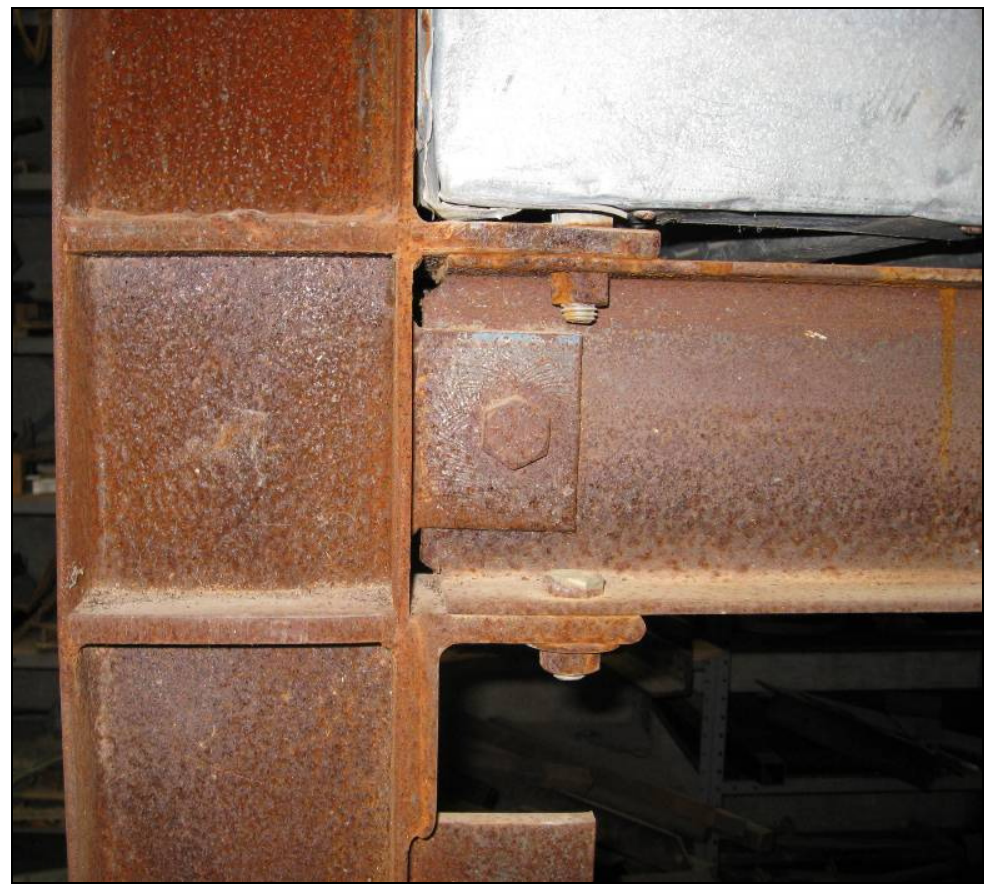

Figure G: Typical long beam-to-column connection

Source: Author photo

The beams installed in the shorter direction aligned with the weak axis of the column, so the typical connection was different than that of the beams in the strong axis. This connection involved the welding of horizontal plates to both the top and bottom of the beam near the column. The entire built up section was then welded to the column web and flanges wherever possible. This provided a moment-resisting connection in the north/south direction. Figure H, below, is a photo showing the typical "weak axis" orientation beam-to-column connection. 


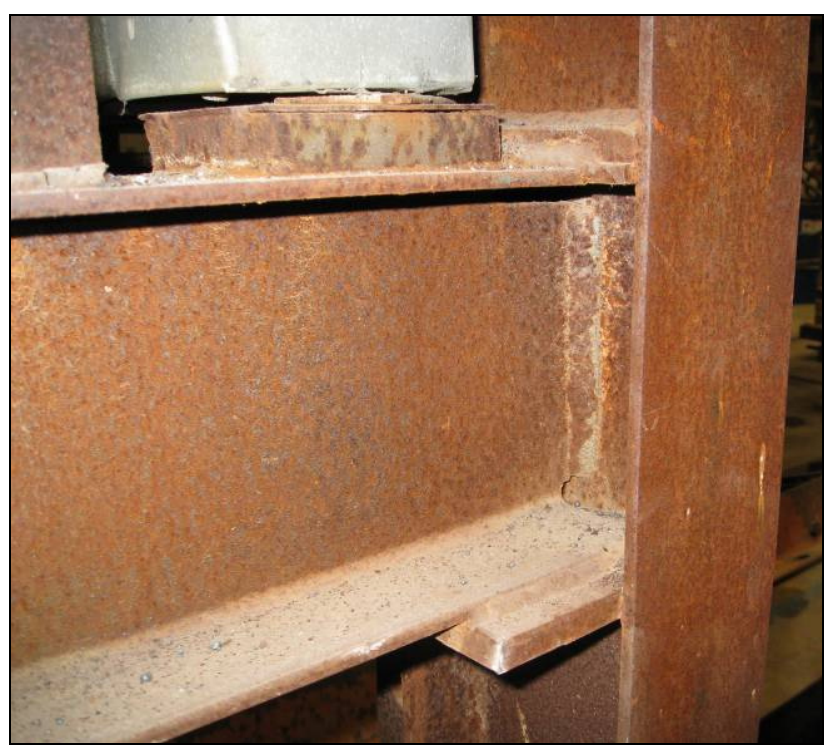

Figure H: Typical short beam-to-column connection

Source: Author photo

\subsection{Testing Equipment}

The frame underwent both ambient vibration testing and forced vibration testing using laboratory equipment that included an accelerometer, a linear long-stroke shaker, arbitrary function generator, and computer software to manipulate the results.

\subsubsection{Accelerometer}

The accelerometer used in this project was an ICP Accelerometer, Model 393B04. It was capable of measuring a large range of accelerations, anywhere between $3 \cdot 10^{-6} \mathrm{~g}$ and $5 \mathrm{~g}$. This wide range of values was very important because of the large difference between the magnitudes of the accelerations recorded during different tests. The accelerometer is pictured in Figure I, below. 


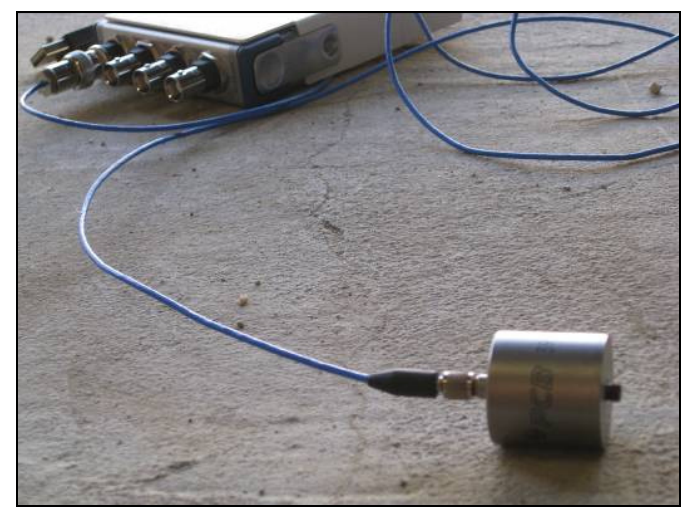

Figure I: Accelerometer

Source: Author photo

When the accelerometer was active, it generated voltages that corresponded with particular frequencies. Recording 2,000 times per second, these voltages were converted into accelerations in the recording process utilizing the accelerometer's unique sensitivity value. This sensitivity value was a direct conversion of voltage to acceleration and was determined for each accelerometer during the calibration by the manufacturer.

\subsubsection{Linear Long-Stroke Shaker}

The linear long-stroke shaker was a 100 pound machine that oscillated at various input frequencies and amplitudes. At its maximum amplitude, it was capable of producing 30 pounds of lateral force as it oscillated back and forth. The shaker, pictured in Figure $\mathrm{J}$, below, attached to the slabs using a friction pad on its underside, preventing it from slipping out of place and producing inconsistent results. 


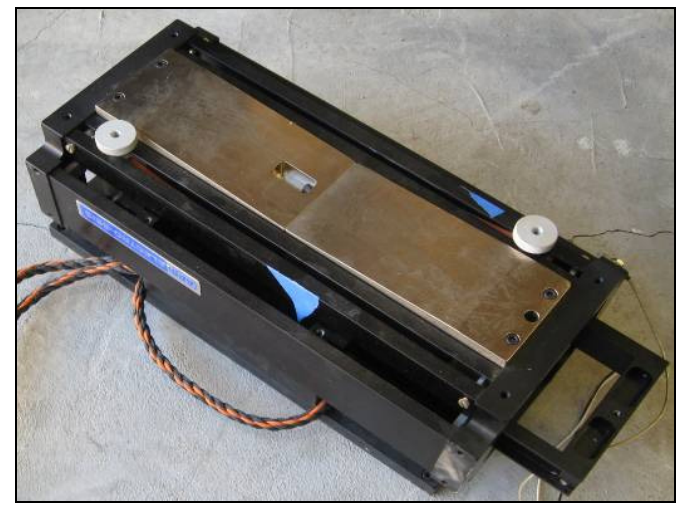

Figure J: Linear long-stroke shaker

Source: Author photo

\subsubsection{Arbitrary Function Generator}

The arbitrary function generator was the device that determined the motion of the linear shaker. For all of the testing in these experiments, the functions generated were sine waves. The two principal variables that could be adjusted within the sine function were the frequency and amplitude of the waves. The amplitude was generally set at its maximum, an input value of 1 volt that equated to the 30 pounds of lateral force mentioned above. Figure K, below, is a photo of the interface of the arbitrary function generator.

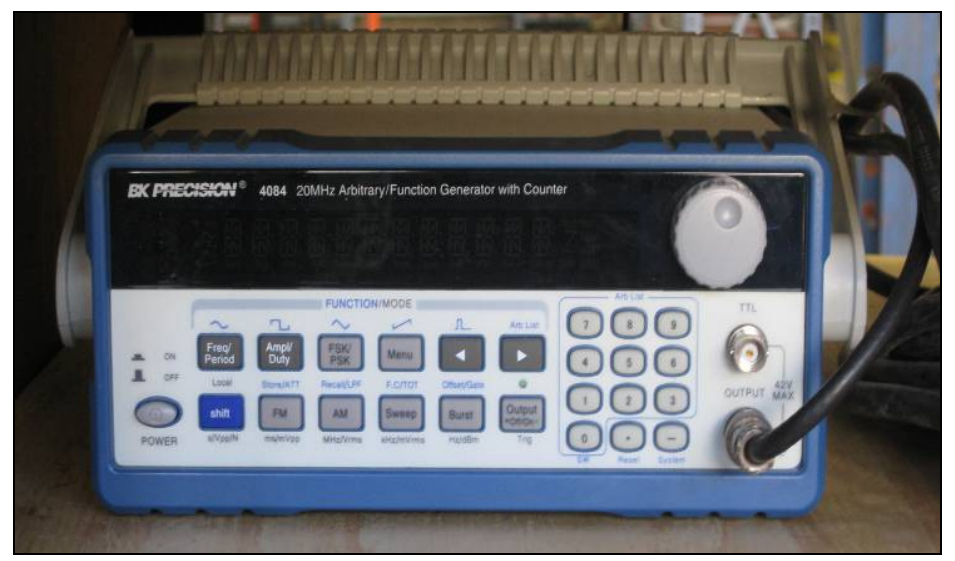

Figure K: Arbitrary function generator

Source: Author photo 


\subsubsection{Labview Signal Express}

The Labview Signal Express computer program was what turned the raw accelerometer recordings into much more user-friendly data. This as the where the inputs for both the sensitivity value of the accelerometer and the number of recordings had to be specified before a collection of data could be generated. Labview Signal Express directly output the peak value of the acceleration and graphically depicted the acceleration response of each frequency. The program was also able to export each data point from the graph into a spreadsheet when necessary.

\subsection{Initial Attachment of Frame to Ground}

The original design of the attachment of the frame to the ground involved bolting the column base plates to two large, above-grade, raft foundations, and these foundations were then bolted to the strong floor in the lab.

\subsubsection{Column Base Plates}

Each of the four columns of the frame was welded to a $1 / 2$ " steel base plate, the exact dimensions of which are shown in Figure L, below. 


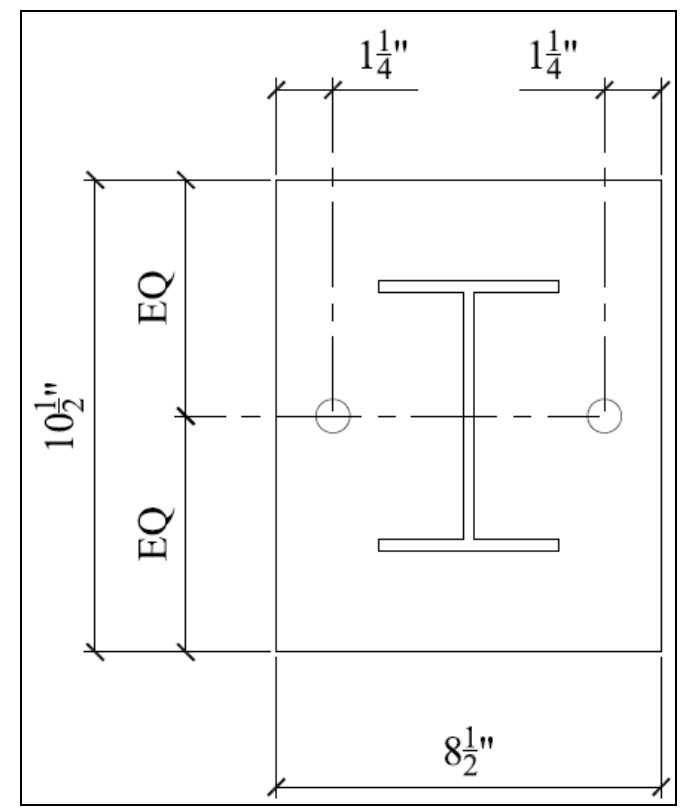

Figure L: Base plate detail

Source: Author diagram

Each plate had a 3/4" diameter hole centered on each side of the column, and the holes matched up with $5 / 8$ " diameter anchor bolts embedded into the raft foundation. A washer and nut were then securely fastened to each bolt, securing each base plate tightly to the foundation. Figure M, below, is a photograph of the base plate attaching the column to the ground.

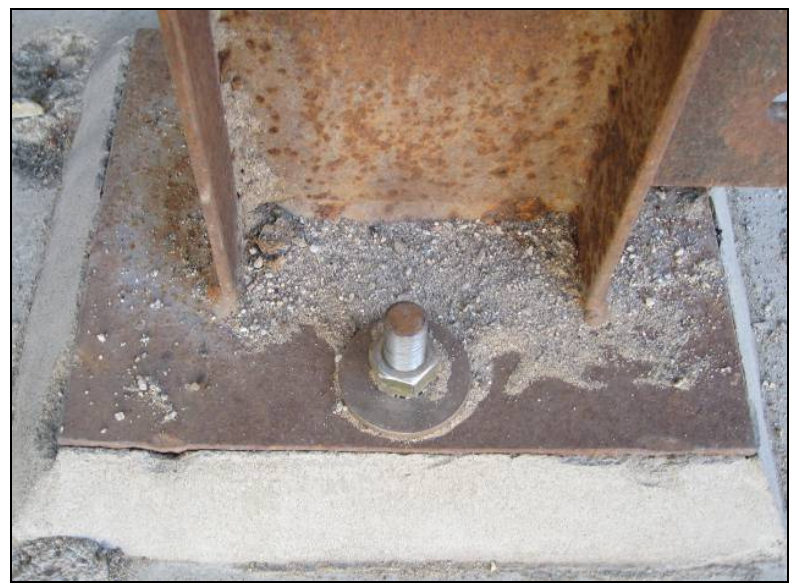

Figure M: Photo of base plate

Source: Author photo 


\subsubsection{Raft Foundations}

Each of the four column base plates was attached to one of the two 5" thick concrete raft foundations. The exact dimensions of the raft foundations are shown in Figure N, below.

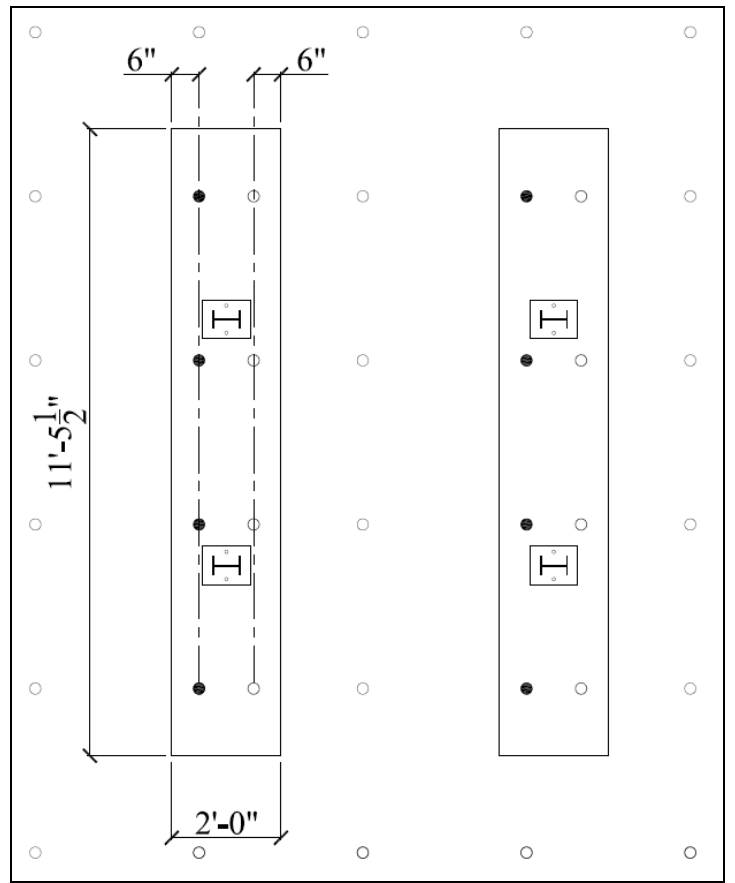

Figure N: Layout of foundation bolts

Source: Author diagram

Figure $\mathrm{N}$ also outlines the layout of the bolts attaching the rafts to the laboratory strong-floor. Each of the eight black-filled circles represents a 1.25" diameter bolt running through a raft foundation into the strong floor. Each raft had one line of four bolts through it, as shown by Figure $\mathrm{N}$ as well as the photo in Figure O, below. 


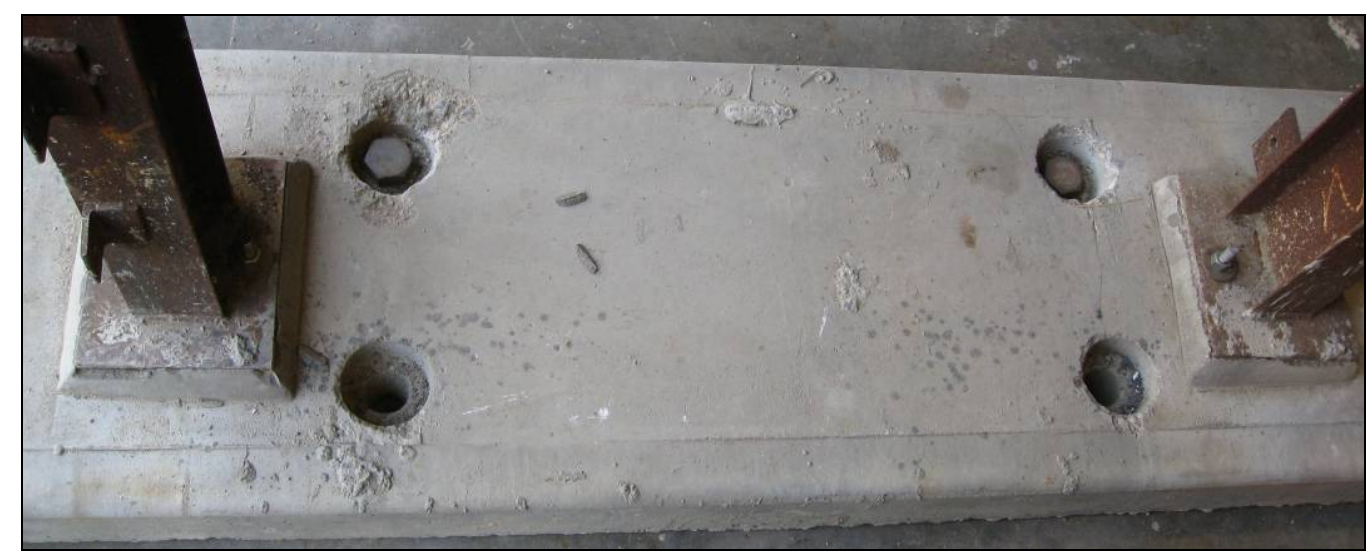

Figure O: Bolts attaching raft to strong-floor

Source: Author photo

\subsection{Revised Attachment of Frame to Ground}

The initial attachment of the frame to the ground was not sufficiently secure enough for the magnitude of forces that would soon be applied to the structure. When initial testing began, inconsistencies in the data began to appear, and the method of attaching the frame to the ground had to be revised.

\subsubsection{Problems Detecting Natural Frequencies}

The problem with the initial laboratory setup was that the detected natural frequencies varied with the amplitude of the shaker. Figure P, below, shows the acceleration at various frequencies caused by 1.0 volts of amplitude in the shaker. Figure $\mathrm{Q}$, further below, shows the accelerations caused by 0.1 volts. 


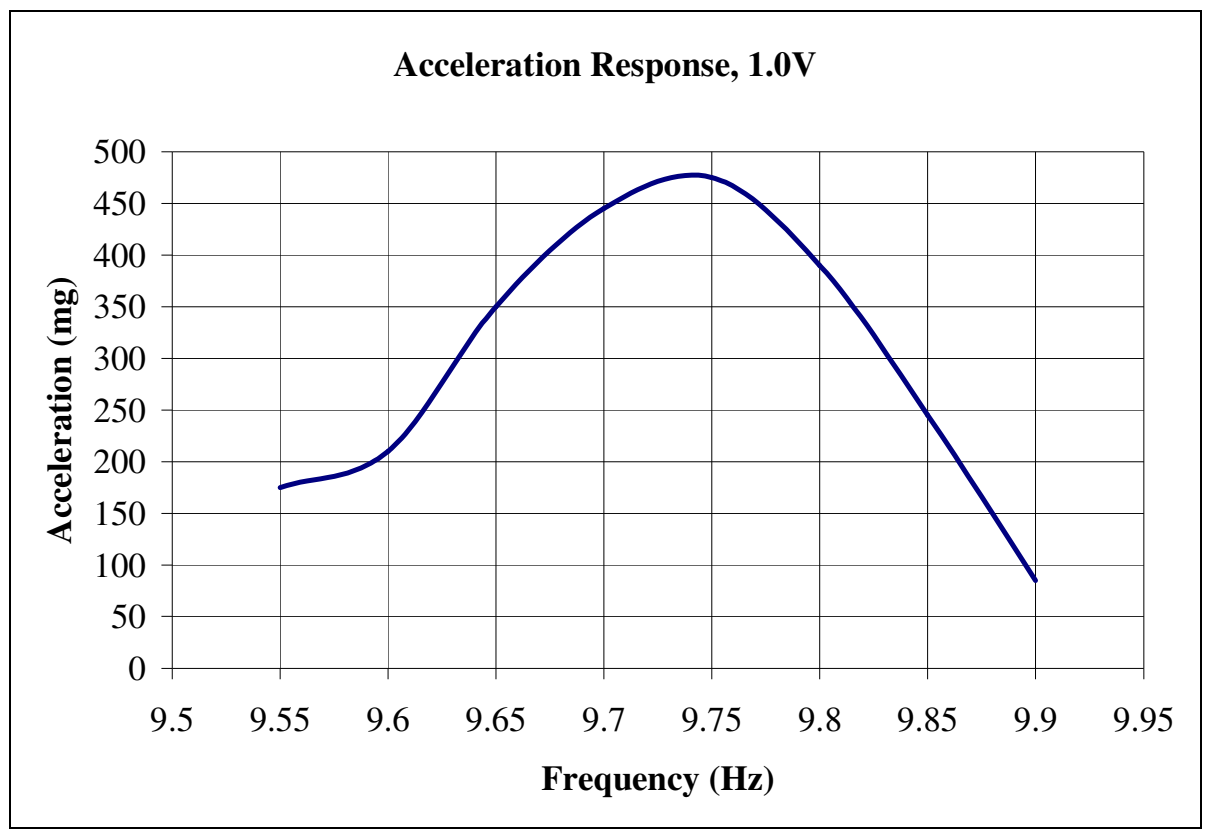

Figure P: Initial attachment strong axis acceleration response, 1.0V Source: Author diagram

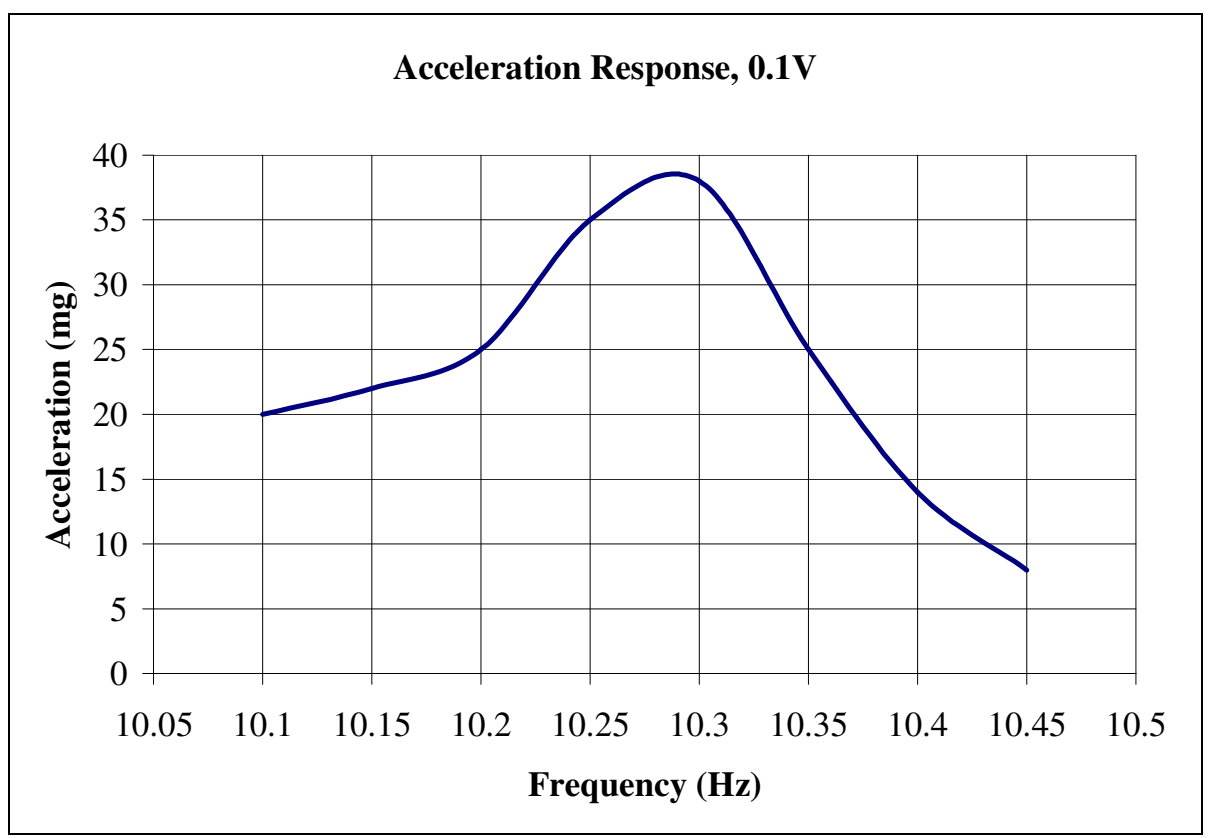

Figure Q: Initial attachment strong axis acceleration response, $0.1 \mathrm{~V}$ Source: Author diagram

The $6 \%$ difference between the detected natural frequencies demonstrated that the response of the structure was not a linear function of the amplitude of the shaker. Because 
the scope of this project did not include the analysis of a nonlinear response, the problem needed to be rectified before usable data could be collected.

\subsubsection{Identifying and Fixing the Problem}

Closer investigations of the initial laboratory setup revealed that the problem revolved around the raft foundations rocking back and forth when a large lateral force was applied to the structure. As seen in Figure R, below, the single line of bolts attaching to foundation to the strong floor could not resist the uplift forces caused by large amplitude shaking of the structure.

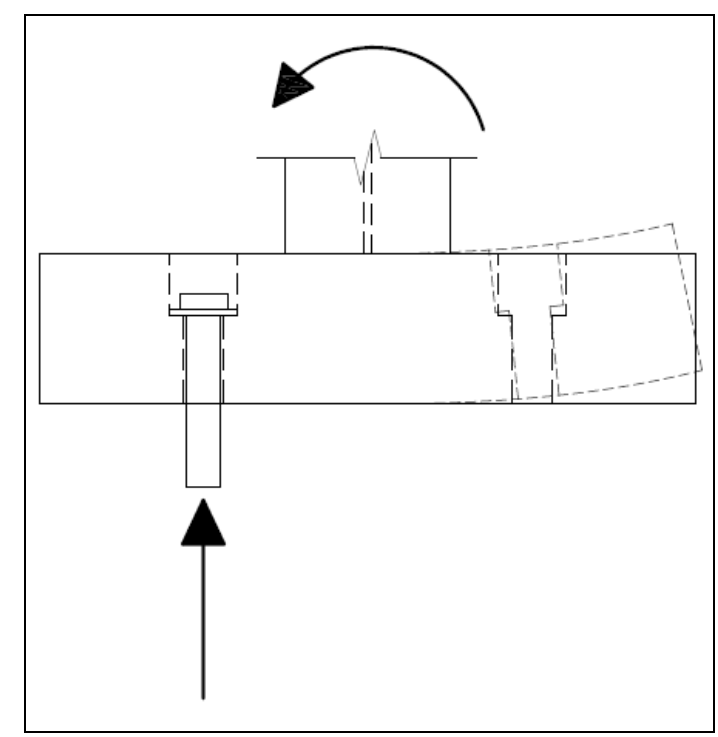

\section{Figure R: Single line of bolts results in uplift}

Source: Author diagram

The most logical and practical solution to eliminating uplift in the raft foundations was to simply remove them from the frame attachment assembly. The original practicality of the raft foundations centered on the fact that they facilitated the attachment of the frame to the strong-floor. However, nothing required that the frame be attached to 
the strong-floor; it could be attached anywhere, as long as the surface was level and provided linear data output.

The frame was moved off of the strong-floor to the back of the High Bay Lab. Research of the structural drawings of the lab showed that the slab in the back of the lab was 6" thick with \#4 rebar spaced 16" center to center. Using a rebar detection tool, the location of all rebar in the slab was mapped.

At this point, the decision was also made to increase the number of bolts in each base plate from two to four, and to increase the bolt diameter from $5 / 8$ " to $3 / 4$ ". Figure $S$, below, shows the location of the new bolts in the base plate. The black-filled circles represent the new bolts, whereas the empty circles represent the original - and now unused - holes in the base plate. The new holes were also drilled with a larger construction tolerance than the original holes, using a 1 " hole (1/8" tolerance) instead of a 3/4" hole (1/16" tolerance).

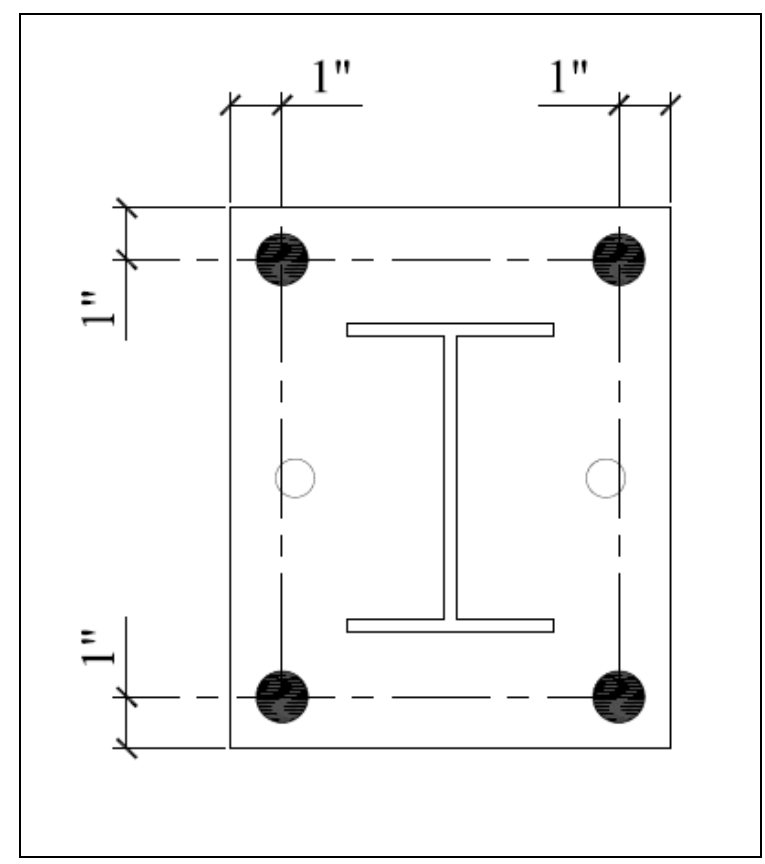

Figure S: Improved base plate detail 


\section{Source: Author diagram}

Knowing the location of the rebar in the slab, the frame was placed over the slab such that none of the base plates was directly above any of the rebar. This allowed for the placement of Hilti LDI expansion anchors, pictured in Figure T, below. The anchors were installed into the existing slab per the manufacturer's instructions.

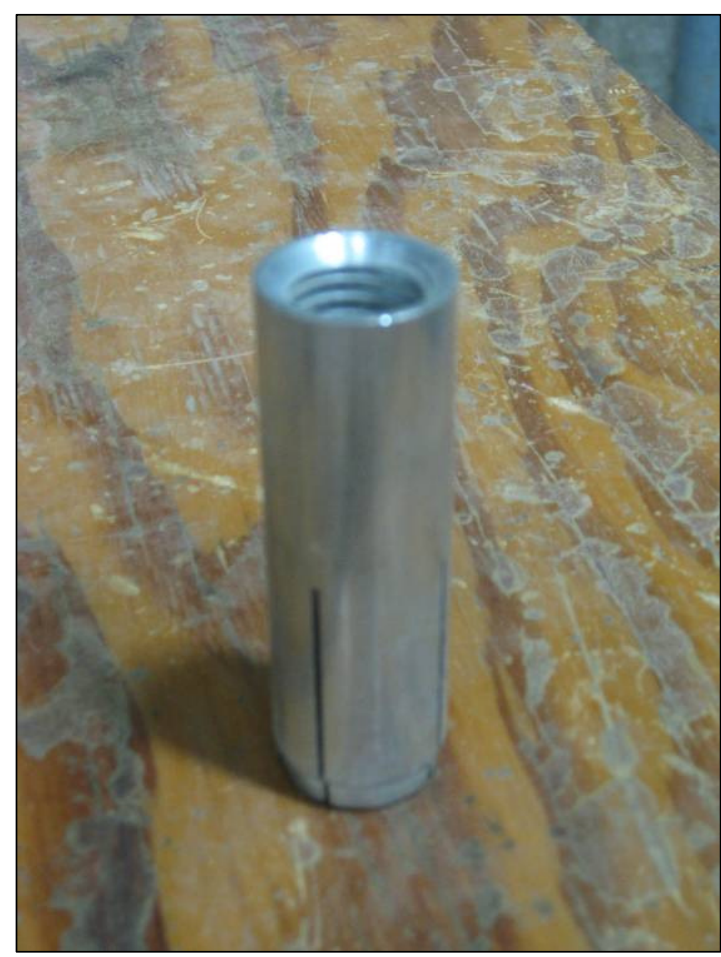

\section{Figure T: Hilti LDI expansion anchor}

Source: Author photo

An anchor was installed at each of the newly drilled base plate hole locations, and a 3/4" diameter threaded rod was placed through each hole and into the anchors. A washer and nut were used to complete the assembly of the mechanical attachment of the frame to the slab. Figure U, below, shows the final connection of the bolts, washers, and nuts into the expansion anchors, securely attaching the frame to the slab. 


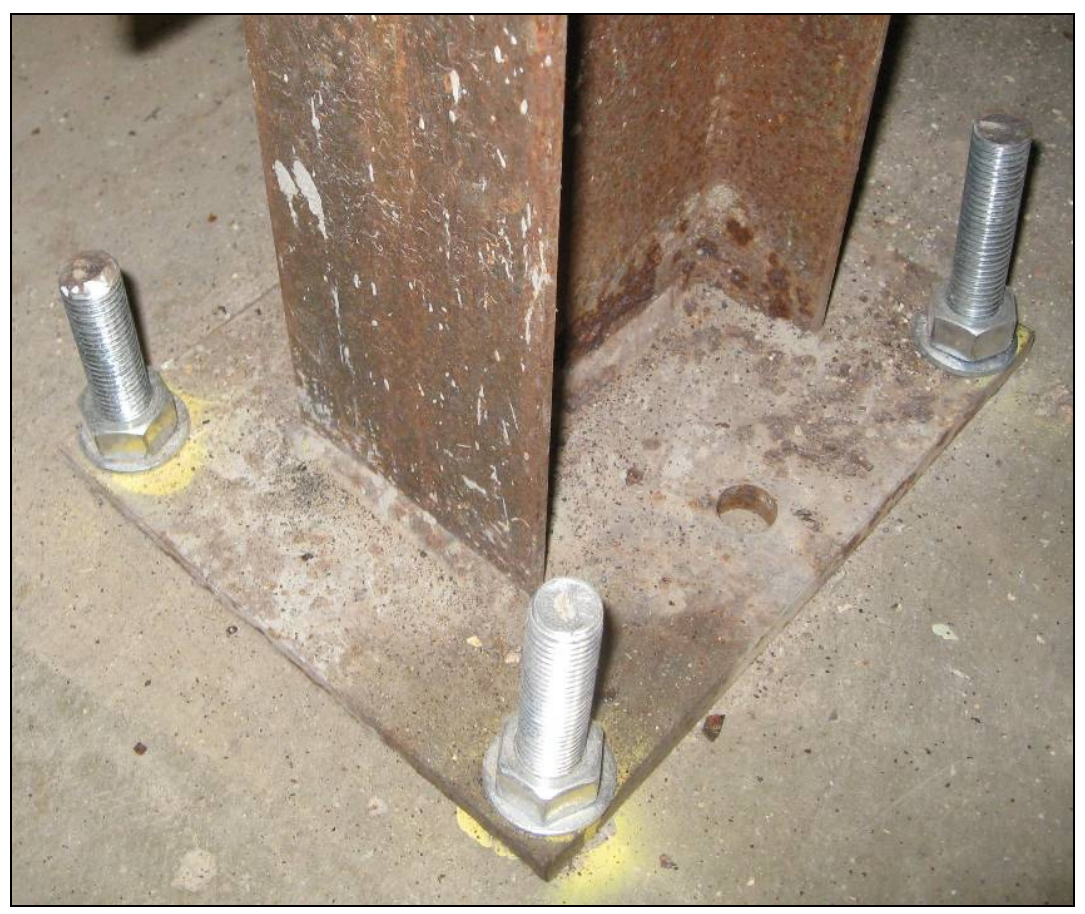

Figure U: Final connection of frame to ground

Source: Author photo

The same tests that determined the original nonlinear connection were then executed on the new frame assembly. The graphs below illustrate the acceleration response of the frame with regard to the same two amplitudes tested previously. Figure $\mathrm{V}$ shows the response to 1.0 volts of amplitude, whereas Figure $\mathrm{W}$ illustrates the response to 0.1 volts of amplitude. 


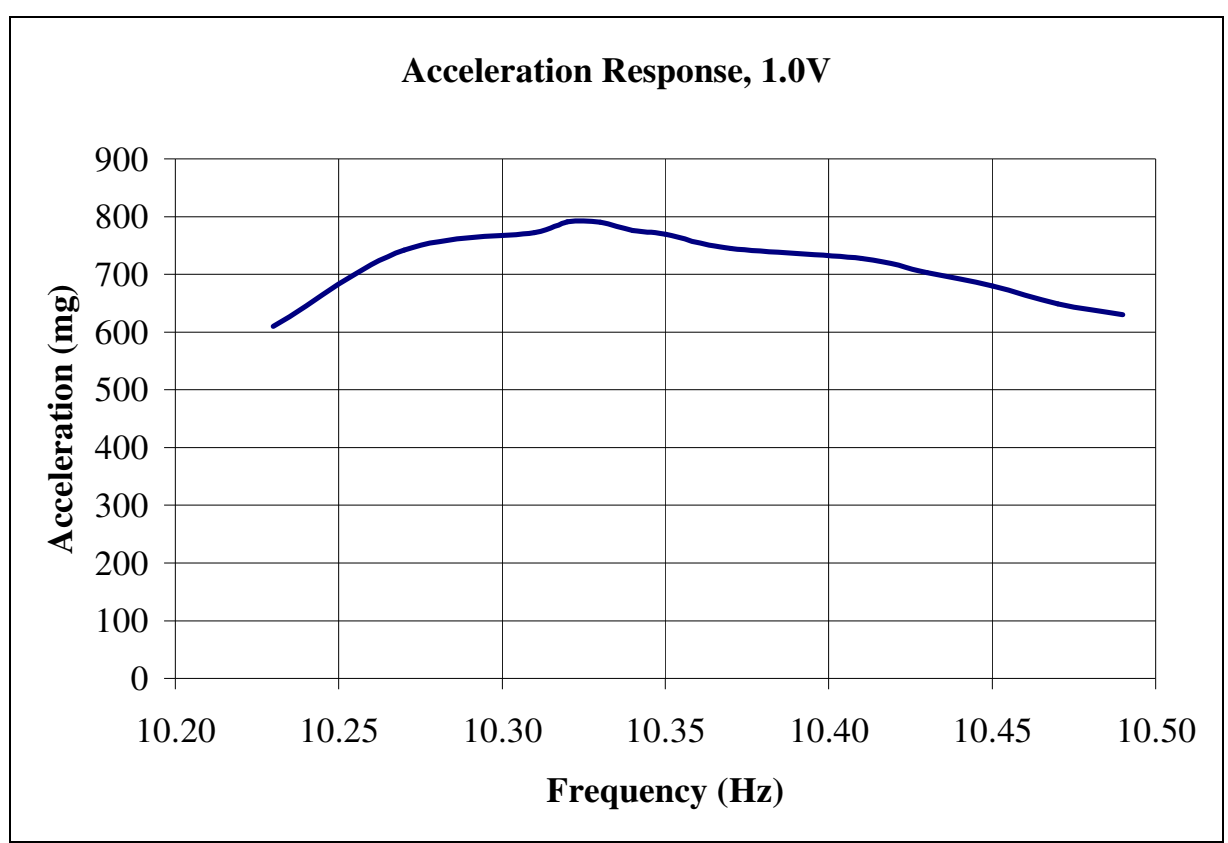

Figure V: Revised attachment strong axis acceleration response, 1.0V Source: Author diagram

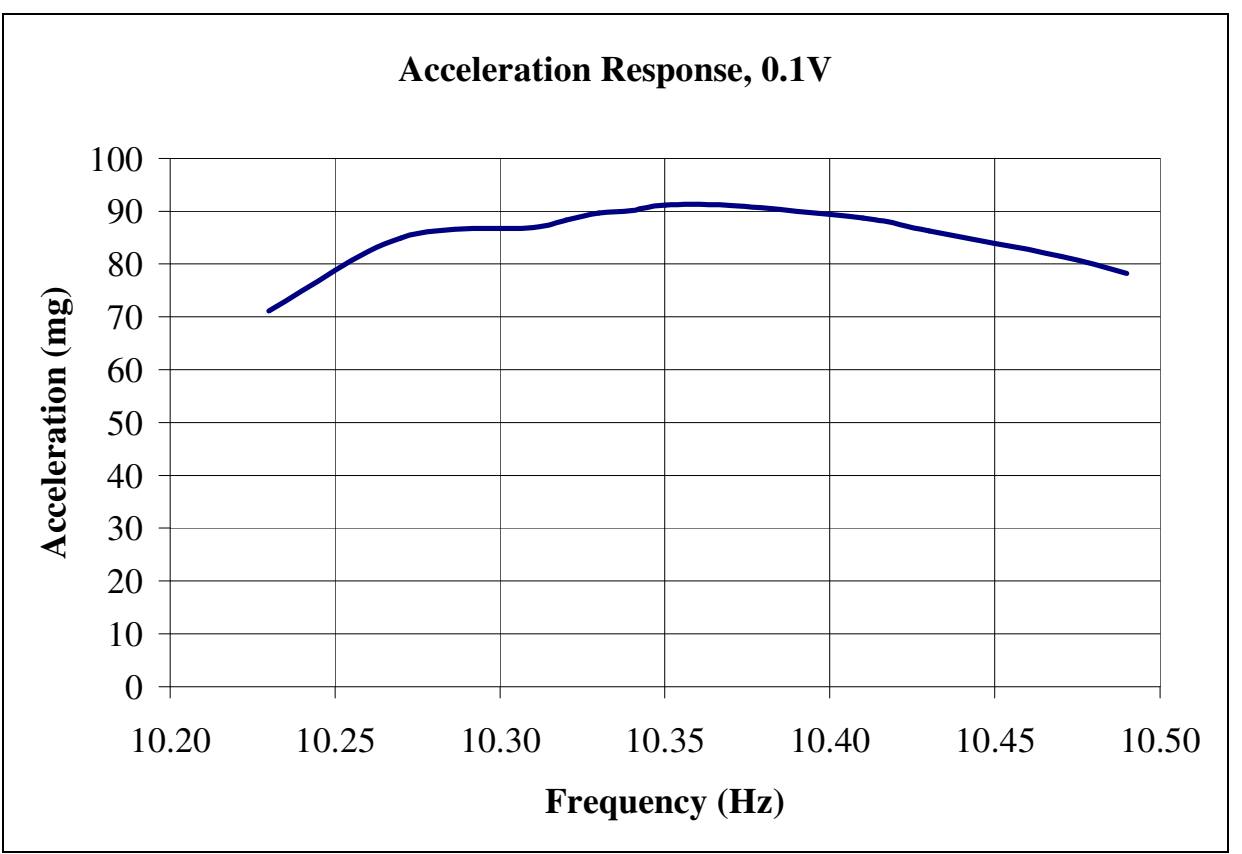

Figure W: Revised attachment strong axis acceleration response, 0.1V Source: Author diagram 
The graphs show that the detected natural frequency was fairly consistent between the two different amplitudes. The higher voltage produced a natural frequency of 10.32 $\mathrm{Hz}$, whereas the lower voltage produced a natural frequency of $10.35 \mathrm{~Hz}$, an acceptable difference of $0.3 \%$.

The frequencies also more closely corresponded to the values produced by the lower amplitude shaking of the initial attachment. The original lower amplitude shaking did not produce a high enough force to cause significant rocking, and the fact that these values resembled the lower amplitude value showed that the issue of rocking had been successfully mitigated. 


\subsection{BASELINE TESTING AND MODELING}

After establishing that the frame had been installed such that reasonable data could be extracted, theoretical values were predicted regarding the natural frequencies and mode shapes of the structure. The frame then was then subject to a series of tests, and the data collected from these tests was compared to the theoretical values for verification of accuracy. The physical properties of the steel frame, as well as the verified results of the tests, were modeled using ETABS, and the ETABS model was adjusted until it best matched the frequencies and mode shapes recorded from the physical structure.

\subsection{Range of Acceptable Values}

The predictions for the frequencies and mode shapes of the frame were created using combinations of different assumptions. The varying assumptions were created to establish upper and lower bounds for potential frequencies of the frame.

The first of the assumptions to be varied was the rigidity of the connection of the columns to the ground. The upper bound assumed that the connection was perfectly fixed, allowing no rotation to occur at the base. The lower bound assumed that the connection was perfectly pinned, unable to resist any rotation at the base.

The second of the assumptions to be varied was the rigidity of the beams. The upper bound assumption was that the beams were perfectly rigid, whereas the lower bound assumed that the flexibility of the beams was dependent on their section properties. 
Analyzing the four possible combinations of assumptions produced a range of results in which the data from physical frame would lie. Figure X, below, graphically depicts each of the four assumptions.

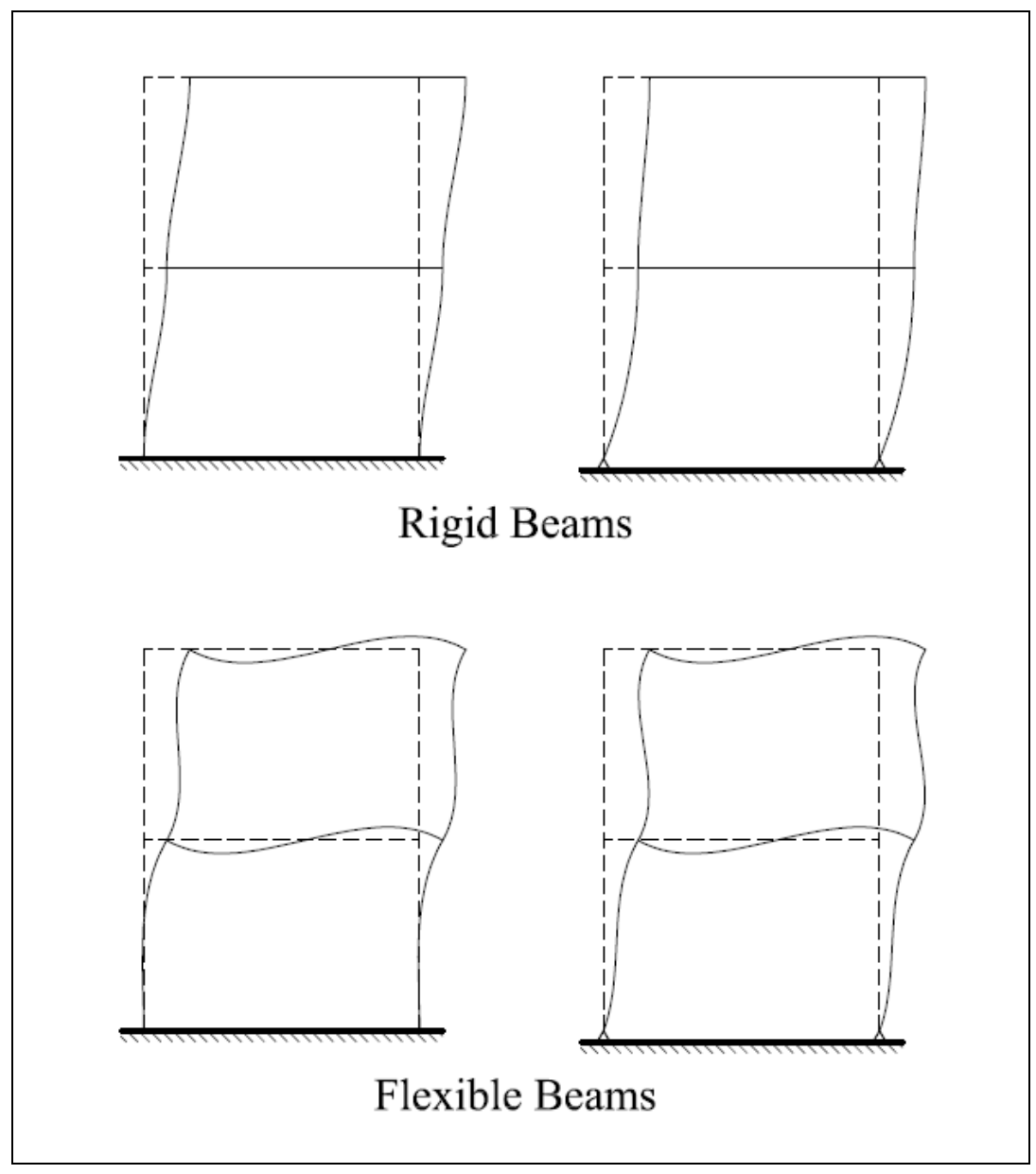

Figure X: Four analytical models

Source: Author diagram

Each of these four models was analyzed, and the frequency of each mode shape was predicted for each combination of fixed and pinned base connections as well as rigid and flexible beam connections. Table A, below, summarizes the natural frequencies for each mode shape. 
Table A: Analytically predicted modal frequencies

\begin{tabular}{|c|r|r|r|r|}
\hline \multirow{2}{*}{ Mode } & \multicolumn{4}{|c|}{ Analytical Model Frequency (Hz) } \\
\cline { 2 - 5 } & $\begin{array}{c}\text { Rigid Beams, } \\
\text { Fixed Base }\end{array}$ & $\begin{array}{c}\text { Rigid Beams, } \\
\text { Pinned Base }\end{array}$ & $\begin{array}{c}\text { Flexible Beams, } \\
\text { Fixed Base }\end{array}$ & $\begin{array}{c}\text { Flexible Beams, } \\
\text { Pinned Base }\end{array}$ \\
\hline $1^{\text {st }}$ Weak & 9.35 & 5.12 & 6.27 & 3.52 \\
\hline $2^{\text {nd }}$ Weak & 23.78 & 21.71 & 15.95 & 13.97 \\
\hline $1^{\text {st }}$ Strong & 25.42 & 13.92 & 12.03 & 7.12 \\
\hline $2^{\text {nd }}$ Strong & 64.65 & 59.03 & 38.67 & 31.12 \\
\hline $1^{\text {st }}$ Torsion & 29.43 & 16.12 & - & - \\
\hline $2^{\text {nd }}$ Torsion & 74.84 & 68.33 & - & \\
\hline
\end{tabular}

Table A predicts the natural frequencies of the mode shapes based on each combination of assumptions. However, predicting the natural torsional frequencies of a structure with flexible beams was not something that could be reasonably accomplished using hand-calculation methods. These values were omitted from the table, and only the theoretical upper bounds for the torsional modal frequencies were able to be determined.

The mode shapes mentioned in Table A corresponded to an assumption of six degrees of freedom for the frame. The degrees of freedom included three at each floor: two translational and one rotational. The translational degrees were orthogonal to one another, each in line with a major axis of the frame. The rotational degree was located at the center of mass of each slab. The number accompanying each mode label corresponded to its order of appearance. The first modes involved a larger response at the roof level, whereas the second modes involve a larger response at the floor level. Figure Y, below, graphically depicts all of the mode shapes based on these six degrees of freedom. 


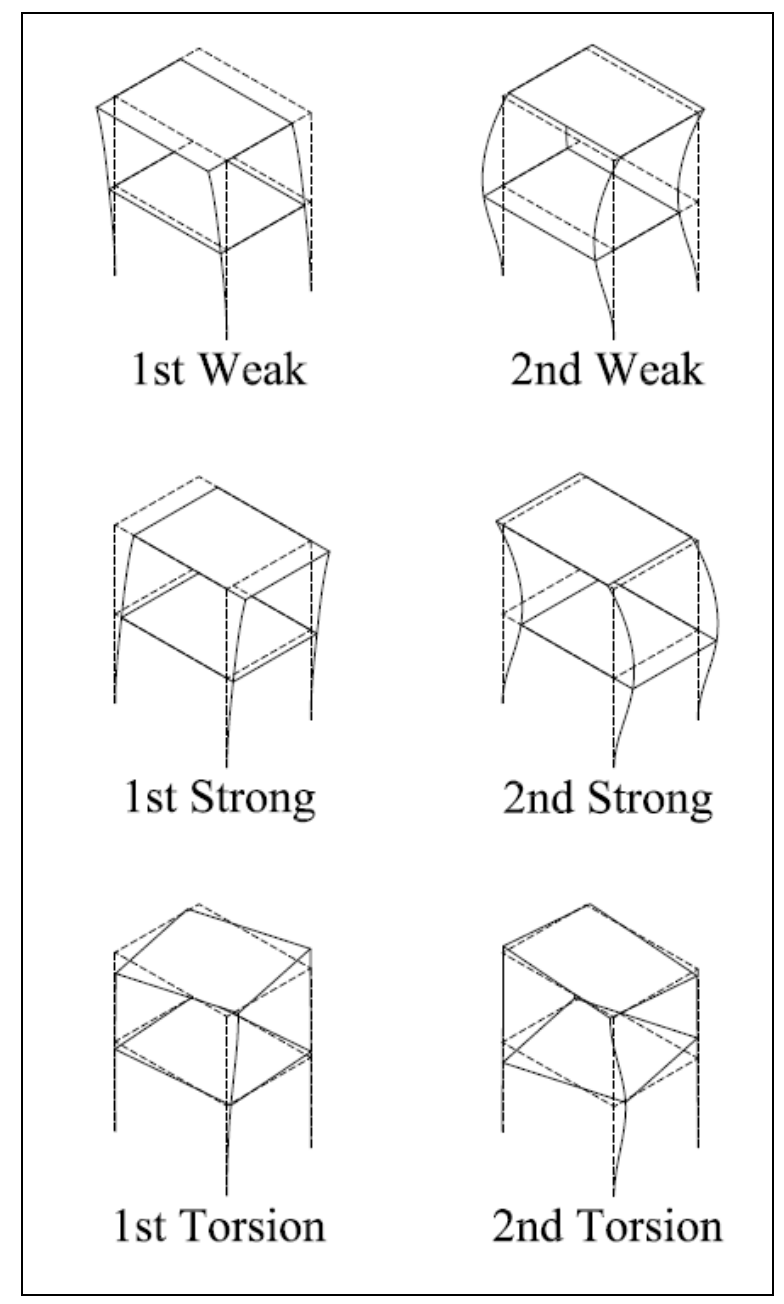

Figure Y: Mode shapes

Source: Author diagram

\subsection{Ambient Vibration Testing}

The structure was subject to ambient vibrations caused by its surroundings. These vibrations were caused by wind, mechanical units, noise, and other environmental factors, generally producing accelerations on the order of $10^{-6} \mathrm{~g}$. Fortunately, the accelerometer used in this project was able to measure these miniscule magnitudes, and an ambient vibration test could be executed. 
Ambient vibration testing (AVT) involved just the accelerometer and the Signal Express software. After properly inputting the unique sensitivity number corresponding to the accelerometer, the accelerometer was placed at various points on the frame and attached using adhesive tape. While in each location, the Signal Express software was set to collect data at 30 second intervals. At each interval a graph was created similar to Figure Z, below.

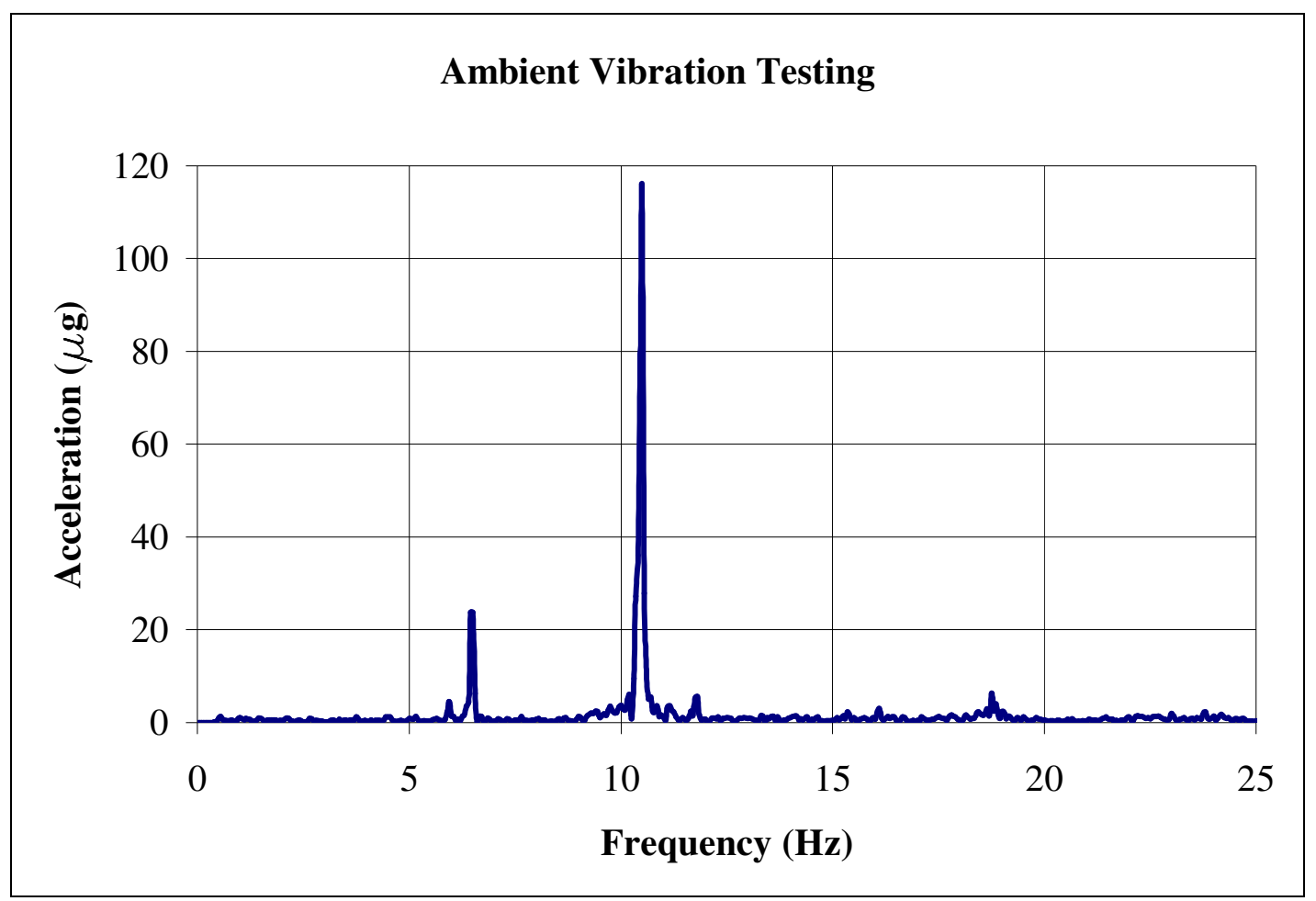

Figure Z: Response to AVT

Source: Author diagram

The graph above represents the ambient vibration response of the accelerometer placed on the roof parallel to the strong axis of the structure. Peaks of varying magnitudes were observed between $6 \mathrm{~Hz}$ and $19 \mathrm{~Hz}$. These peaks represented potential natural frequencies in the structure. For instance, the peak at approximately $10.5 \mathrm{~Hz}$ was the largest magnitude peak for the accelerometer in this location. Because of this particular 
orientation of the accelerometer, this peak was predicted to correspond to the natural frequency of a mode shape in the strong axis. The smaller peaks may correspond to other frequencies in the structure, but moving the accelerometer was necessary to determine their potential relevance.

The principal idea of the test was that if an accelerometer orientation corresponded to the highest magnitude acceleration of a given frequency, the frequency was a potential natural frequency with regard to that orientation. The $115 \mu \mathrm{g}$ peak at 10.5 $\mathrm{Hz}$ in figure $\mathrm{Z}$, above, was the largest value recorded for that particular frequency, and it was predicted that this peak corresponded to a mode shape in the strong axis direction.

The accelerometer was moved to different locations on the roof and oriented in different directions. Each time the accelerometer was moved, AVT was run again, and the peaks were recorded. If the maximum acceleration for a frequency was recorded when the accelerometer was oriented parallel to the weak axis, it was assumed to be a potential natural frequency of that direction. The same was true of the strong axis orientation. However, if a maximum magnitude occurred while the accelerometer was placed at an angle, the frequency was assumed to be potentially associated with a torsional mode. It should be noted that varying the locations of the accelerometer served only to verify that the maximum magnitudes consistently corresponded to the same orientations. Table B, below, summarizes the potential natural frequencies with respect to the orientation of the accelerometer that recorded the largest magnitude of acceleration. 


\section{Table B: Potential natural frequencies determined by AVT}

\begin{tabular}{|r|r|}
\hline Orientation & Frequency $(\mathrm{Hz})$ \\
\hline Weak & 6.50 \\
\hline Strong & 10.50 \\
\hline Torsion & 11.15 \\
\hline Torsion & 11.80 \\
\hline Weak & 18.75 \\
\hline
\end{tabular}

The values in the table should be understood to have corresponded only to potential natural frequencies. The values in the table mostly corresponded very well within the range of predicted values for the frequencies, outlined in Table A, page 31. However, it was clear that only one of the peak values corresponded to a torsional natural frequency. The peak value that did not correspond to a natural frequency could be attributed to other ambient frequencies, such as mechanical equipment in the building.

AVT worked well for preliminarily identifying potential natural frequencies and the mode shapes to which they correspond, but a more precise method was necessary to accurately pinpoint the exact values of the natural frequencies. The low order of magnitude for the recorded accelerations was not large enough to accurately distinguish actual natural frequencies of the structure from other ambient vibrations occurring at steady frequencies.

\subsection{Forced Vibration Testing}

Forced vibration testing (FVT) utilized all of the laboratory equipment outlined in Section 3.1. The first step in the FVT was to determine the natural frequencies of the structure, generally using AVT peaks as a starting point. The second step in the FVT was to map the mode shape of a given frequency. 


\subsubsection{Determination of Natural Frequencies}

For the determinations of the natural frequencies, the shaker was placed on the roof slab or floor slab and oriented such that it could excite any translational or torsional mode shapes. Placing the shaker on the roof slab was more helpful in detecting the first order modes, whereas placing it on the floor slab was more helpful in detecting the second order modes. The accelerometer was placed very similarly on the roof slab or floor slab, also angled to record any translational or rotational excitement in the structure. Figure AA, below, details the location of both the shaker and the accelerometer on the slab.

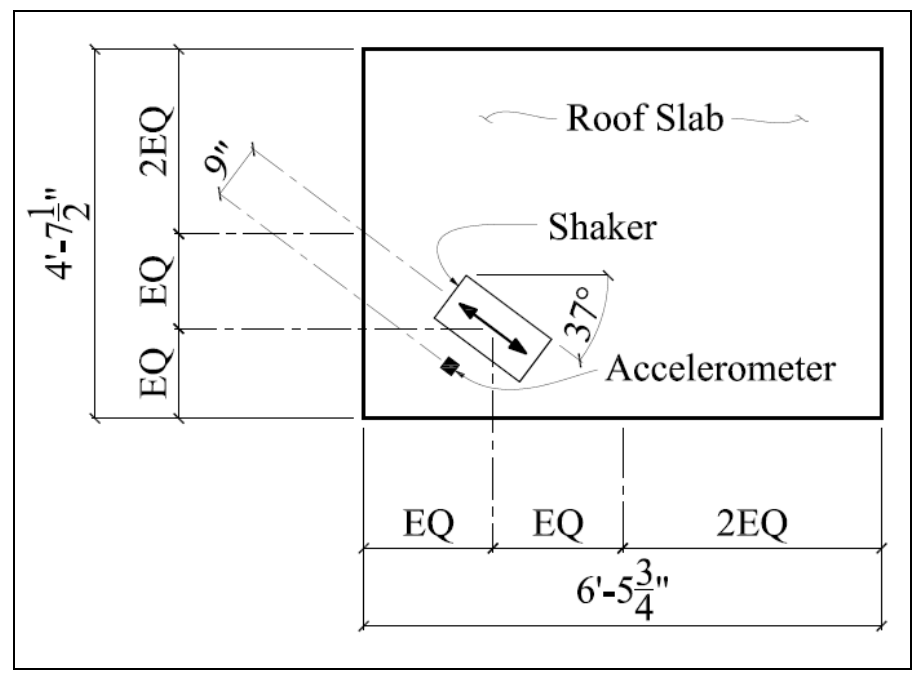

Figure AA: Location of shaker and accelerometer

Source: Author diagram

Once the shaker and accelerometer were placed on the slab, the arbitrary function generator was set to a sine function with a frequency corresponding to a peak in the AVT graphs. After the structure reached a steady state response to the sinusoidal loading of the shaker, accelerations were recorded at 20 second intervals. The only acceleration that was recorded was the acceleration that corresponded to the frequency input by the arbitrary 
function generator. At least three values were recorded and averaged for each input frequency before the frequency was then changed. Figure BB, below, is an example of the accelerometer response to the FVT.

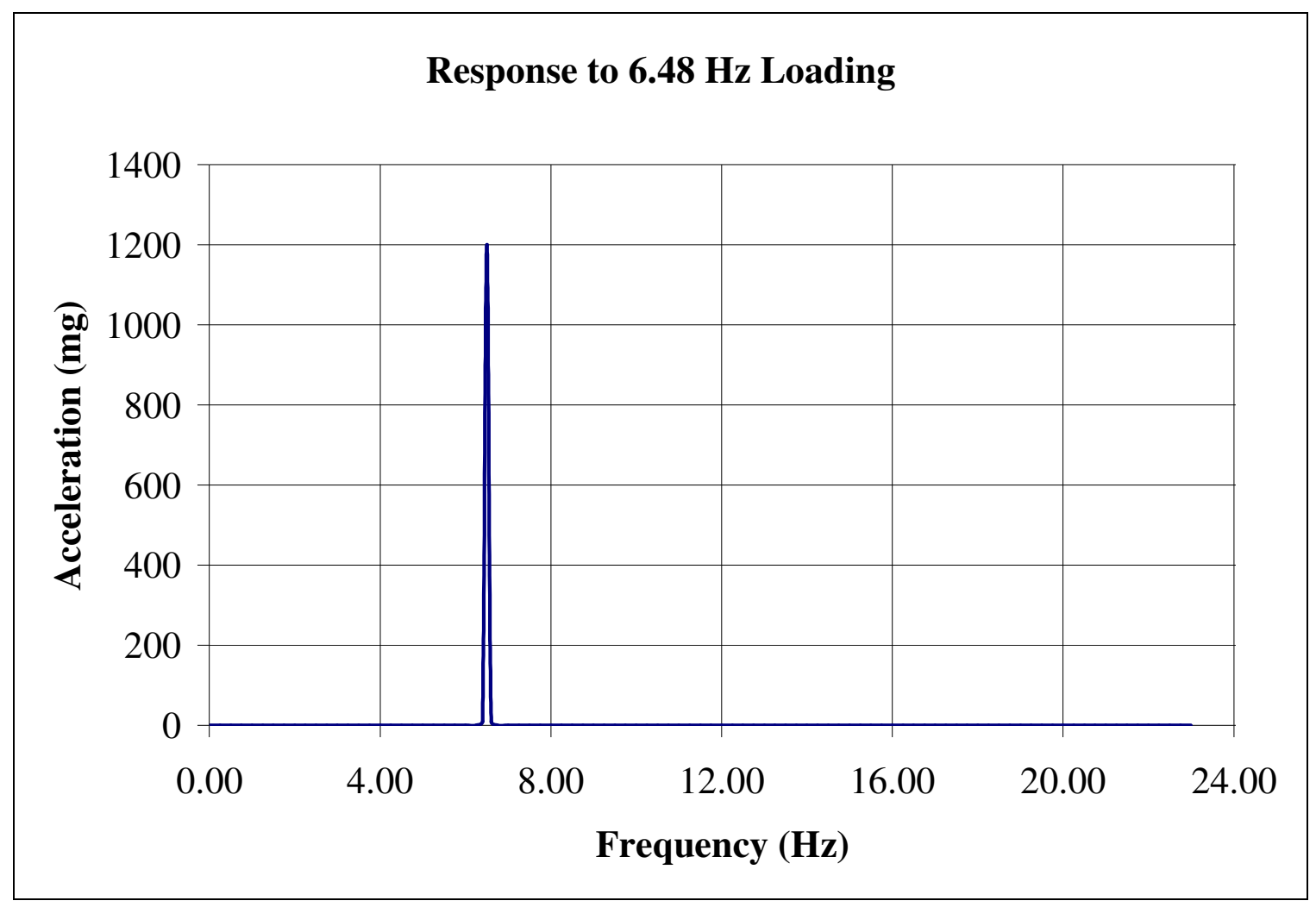

Figure BB: Accelerations of each frequency from $6.48 \mathrm{~Hz}$ loading Source: Author diagram

The graph shows the acceleration response of the structure when the function generator causes the linear shaker to shake with a steady state frequency of $6.48 \mathrm{~Hz}$. The accelerometer was still recording the acceleration of the structure at each frequency, but the magnitude of the acceleration caused by the shaking frequency was much higher than the magnitude of the acceleration of the other frequencies. The other frequencies were essentially producing accelerations on the same order of magnitude as the ambient vibration test. 
The process was then repeated at different frequencies near the previous value until the maximum acceleration was found. A graph was then created to plot the acceleration at each applied frequency, and the peak value on this graph corresponded to a natural frequency of the structure. Figure CC, below, illustrates the values of acceleration detected by FVT at frequencies between $6.35 \mathrm{~Hz}$ and $6.55 \mathrm{~Hz}$.

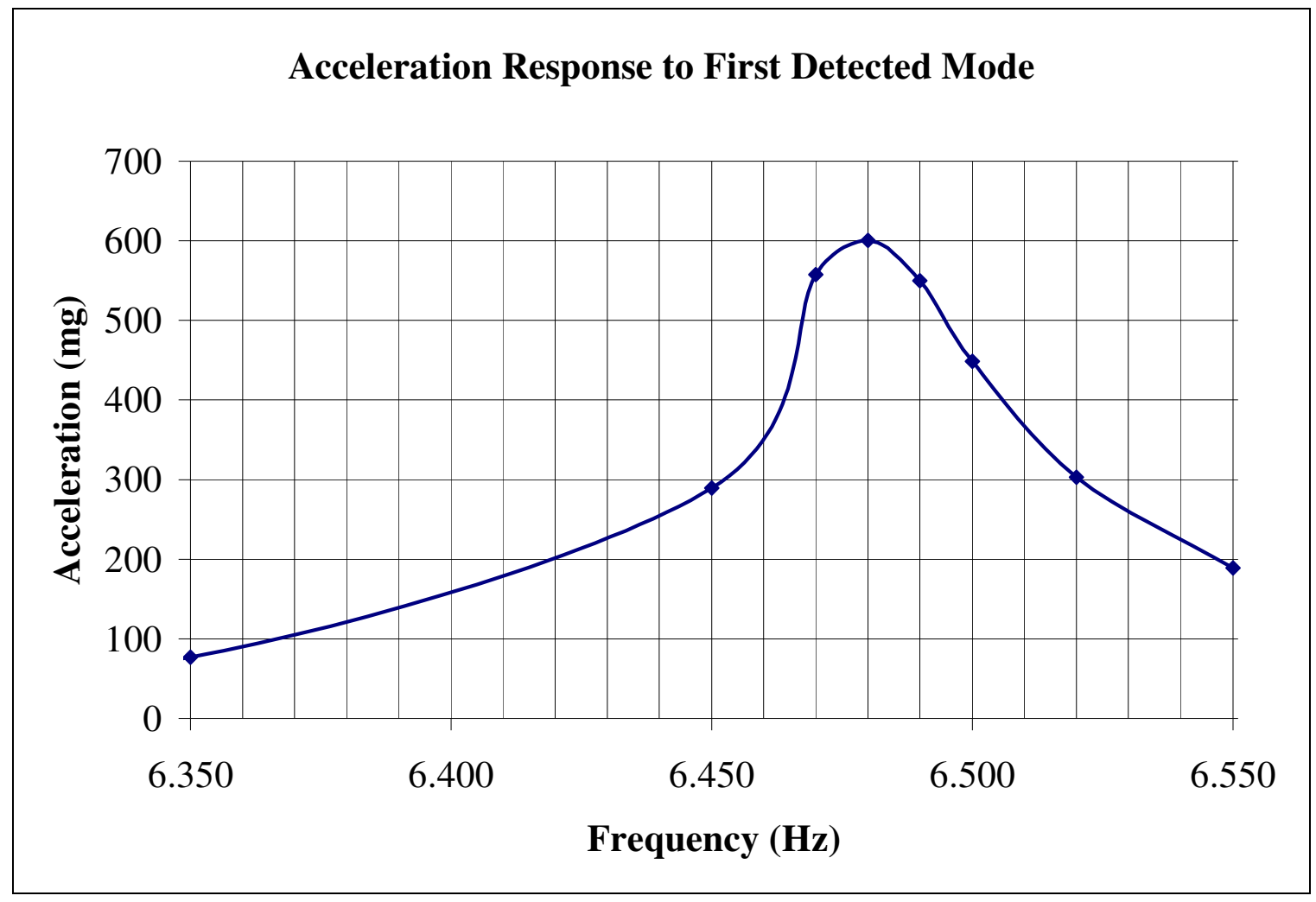

Figure CC: Forced vibration testing

Source: Author diagram

The graph above shows that the maximum acceleration response of the structure occurred at $6.48 \mathrm{~Hz}$. This was considered to be the natural frequency of one of the mode shapes of the structure. Further testing was required to determine the mode shape with which this frequency corresponds, and that is discussed in Section 4.3.2. 
The process for determining the natural frequencies of the structure was then repeated near the other peak values found in the ambient vibration testing. If FVT was not able to detect a definite peak near an AVT peak, the frequency corresponding to the peak was discarded. Table $\mathrm{C}$, below, summarizes the natural frequencies of the structure found by FVT, as well as the comparable values determined by AVT.

\section{Table C: Natural frequencies determined by FVT}

\begin{tabular}{|r|r|}
\hline AVT Frequency $(\mathrm{Hz})$ & FVT Frequency $(\mathrm{Hz})$ \\
\hline 6.50 & 6.48 \\
\hline 10.50 & 10.32 \\
\hline 11.15 & - \\
\hline 11.80 & 11.50 \\
\hline 18.75 & 18.90 \\
\hline
\end{tabular}

FVT was able to detect four natural frequencies in the structure, compared to the five potential natural frequencies detected by AVT. As predicted earlier, only one of the predicted natural frequencies corresponding to a torsional mode shape actually existed, rather than the two detected by AVT. This fact highlights the reason that FVT was more reliable for detecting natural frequencies than AVT. All of the natural frequency data collected from the FVT fell into the range of predicted values outlined Table A, page 31. However, it was impossible to determine with absolute certainty that each frequency actually existed within a predicted range without knowing the mode shapes that corresponded to each natural frequency.

It should be noted that the methods for performing forced vibration testing outlined in this section were not perfect. Theoretically, the structure had six degrees of freedom that could be excited by FVT, but only four natural frequencies were 
successfully determined. This had to do with the fact that the fifth and sixth mode shapes were at very high frequencies, and no apparent peaks could be found using AVT. Without an estimate from AVT, the FVT process was executed at $0.5 \mathrm{~Hz}$ intervals from $19 \mathrm{~Hz}$ to $35 \mathrm{~Hz}$, but no notable increases in acceleration response were observed.

\subsubsection{Determination of Mode Shapes}

The mode shapes were mapped for each frequency by placing the accelerometer at six specific locations on the structure, shown in Figure DD below. After recording the data, the recorded numbers were manipulated in order to be compared to analytical and computer data.

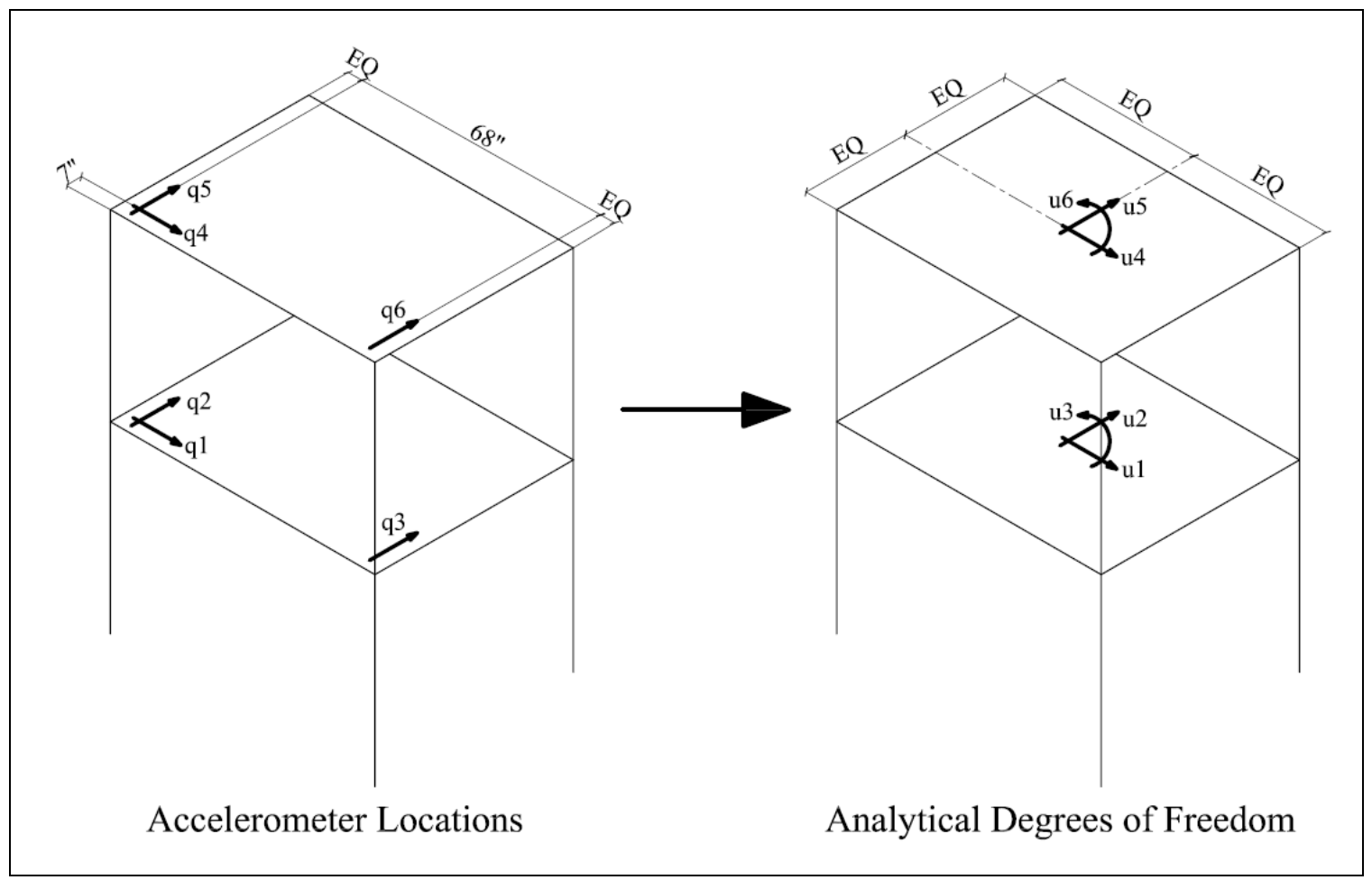

Figure DD: Accelerometer locations converted to analytical degrees of freedom Source: Author diagram 
The arbitrary function generator was set to the lowest natural frequency detected by FVT, and the accelerometer was placed at each of the locations. The accelerations were recorded at intervals of 20 seconds, and at least three were recorded and averaged in each location. The values recorded by the accelerometer were averaged and tabulated in Table D, below.

\section{Table D: Recorded mode shape values for $6.48 \mathrm{~Hz}$}

\begin{tabular}{|r|r|r|r|r|r|}
\hline $\mathrm{q}_{1}(\mathrm{mg})$ & $\mathrm{q}_{2}(\mathrm{mg})$ & \multicolumn{1}{c|}{$\mathrm{q}_{3}(\mathrm{mg})$} & $\mathrm{q}_{4}(\mathrm{mg})$ & $\mathrm{q}_{5}(\mathrm{mg})$ & $\mathrm{q}_{6}(\mathrm{mg})$ \\
\hline 29.3 & 263.0 & 287.3 & 58.5 & 392.0 & 420.8 \\
\hline
\end{tabular}

An important note about the values in the table is the fact that they are all positive. One of the limitations of the lab setup was that it used only one accelerometer. The software provided a magnitude of acceleration at a given location, but it wasn't possible to compare relative accelerations without using multiple accelerometers at the same time. For instance, the accelerations corresponding to $11.50 \mathrm{~Hz}$ generated a mode shape that moves more diagonally than torsionally. However, visual inspection clearly indicated that the structure was moving torsionally. The visual inspection of the structure was used in determining whether to add or subtract the values in determining $\mathrm{u}_{2}, \mathrm{u}_{3}, \mathrm{u}_{5}$, and $\mathrm{u}_{6}$.

The recorded data was then manipulated from its original form into a more standard form for a six degree of freedom structure where each degree of freedom was collinear with the center of mass. The conversion from the raw accelerometer data to the analytical degrees of freedom was based on Eqations 12-18, below. 


$$
\begin{gathered}
u_{1}=q_{1} \\
u_{2}=\frac{q_{2} \pm q_{3}}{2} \\
u_{3}=\frac{\left(q_{3} \mp q_{2}\right) \times 386.4}{68} \\
u_{4}=q_{4} \\
u_{6}=\frac{\left(q_{6} \mp q_{6}\right.}{2} \\
\phi=\left[\begin{array}{l}
\left.q_{5}\right) \times 386.4 \\
68 \\
u_{4} \\
u_{5} \\
u_{6}
\end{array}\right] \\
u_{2} \\
u_{1}
\end{gathered}
$$

Eq. 18

Where $u_{1}=$ modal response of first degree of freedom $\left(\mathrm{in} / \mathrm{s}^{2}\right)$,

$u_{2}=$ modal response of second degree of freedom $\left(\mathrm{in} / \mathrm{s}^{2}\right)$, $u_{3}=$ modal response of third degree of freedom $\left(\mathrm{rad} / \mathrm{s}^{2}\right)$, $u_{4}=$ modal response of fourth degree of freedom $\left(\mathrm{in} / \mathrm{s}^{2}\right)$, $u_{5}=$ modal response of fifth degree of freedom $\left(\mathrm{in} / \mathrm{s}^{2}\right)$, $u_{6}=$ modal response of sixth degree of freedom $\left(\mathrm{rad} / \mathrm{s}^{2}\right)$, $q_{1}=$ accelerometer recorded data per Figure DD $\left(\mathrm{in} / \mathrm{s}^{2}\right)$, $q_{2}=$ accelerometer recorded data per Figure DD (in/ $\left./ \mathrm{s}^{2}\right)$, $q_{3}=$ accelerometer recorded data per Figure DD $\left(\mathrm{in} / \mathrm{s}^{2}\right)$, $q_{4}=$ accelerometer recorded data per Figure DD (in/s $\left.{ }^{2}\right)$, $q_{5}=$ accelerometer recorded data per Figure DD $\left(\mathrm{in} / \mathrm{s}^{2}\right)$, $q_{6}=$ accelerometer recorded data per Figure DD (in $\left./ \mathrm{s}^{2}\right)$, and $\phi=$ modal vector (in $/ \mathrm{s}^{2}$ and $\mathrm{rad} / \mathrm{s}^{2}$ ). 
The mode shape was then normalized by dividing each component by the maximum value in the mode shape vector for this frequency. The function generator was then set to the next detected natural frequency, and the process was repeated until each frequency had response values at each analytical degree of freedom. It should also be noted that the process of mode sweeping, outlined in Section 2.4, was applied to the second, third, and fourth modes. This was done in order to produce final values that could be used in a comparison with analytical and computer values.

The final results of the mode sweeping were also used to determine which generalized mode shape, from Figure $\mathrm{Y}$ on page 32, corresponded to which frequency. Table E, below, summarizes theses results.

\section{Table E: Matching mode shapes to natural frequencies}

\begin{tabular}{|r|r|r|}
\hline Frequency $(\mathrm{Hz})$ & Mode Shape & $\begin{array}{c}\text { Predicted Frequency } \\
\text { Range }(\mathrm{Hz})\end{array}$ \\
\hline 6.48 & 1st Weak & $3.52-9.35$ \\
\hline 10.32 & 1st Strong & $7.12-25.42$ \\
\hline 11.50 & 1st Torsion & $<29.43$ \\
\hline 18.90 & 2nd Weak & $13.97-23.78$ \\
\hline
\end{tabular}

These results were also compared to the predictions based on AVT. AVT correctly predicted the general mode shape for each frequency. Thus, AVT was able to be used as a preliminary test not only for natural frequencies, but for mode shapes as well. And similarly to its detection of natural frequencies, AVT was only able to produce a good starting point; FVT was necessary to precisely define the mode shapes beyond generalizations based on which orientation produced the largest accelerations.

The frequencies for the mode shapes identified in Table E, above, all existed well within the ranges of predicted frequency values outlined in Table A, page 31. Knowing 
the mode shape that corresponds to each frequency allowed for the placement of each natural frequency into its specific range of predicted values.

\subsection{Analysis of Mode Shapes}

The acceleration responses directly recorded by the accelerometer at a given natural frequency were primarily the responses caused by that particular natural frequency of the structure. However, each mode shape was actually a weighted sum of all the mode shapes. The amount of influence each mode shape had on each other mode shape was determined by the proximity of its frequency to the frequency of the mode shape in question, the damping ratio of the structure, and the position of the linear shaker.

\subsubsection{Determination of Damping Ratio}

The damping ratio of each mode shape was determined using the half-power bandwidth method discussed in Section 2.2. Figure EE, below, shows the first detected mode. It also includes a horizontal line drawn according to the parameters of the halfpower bandwidth method. 


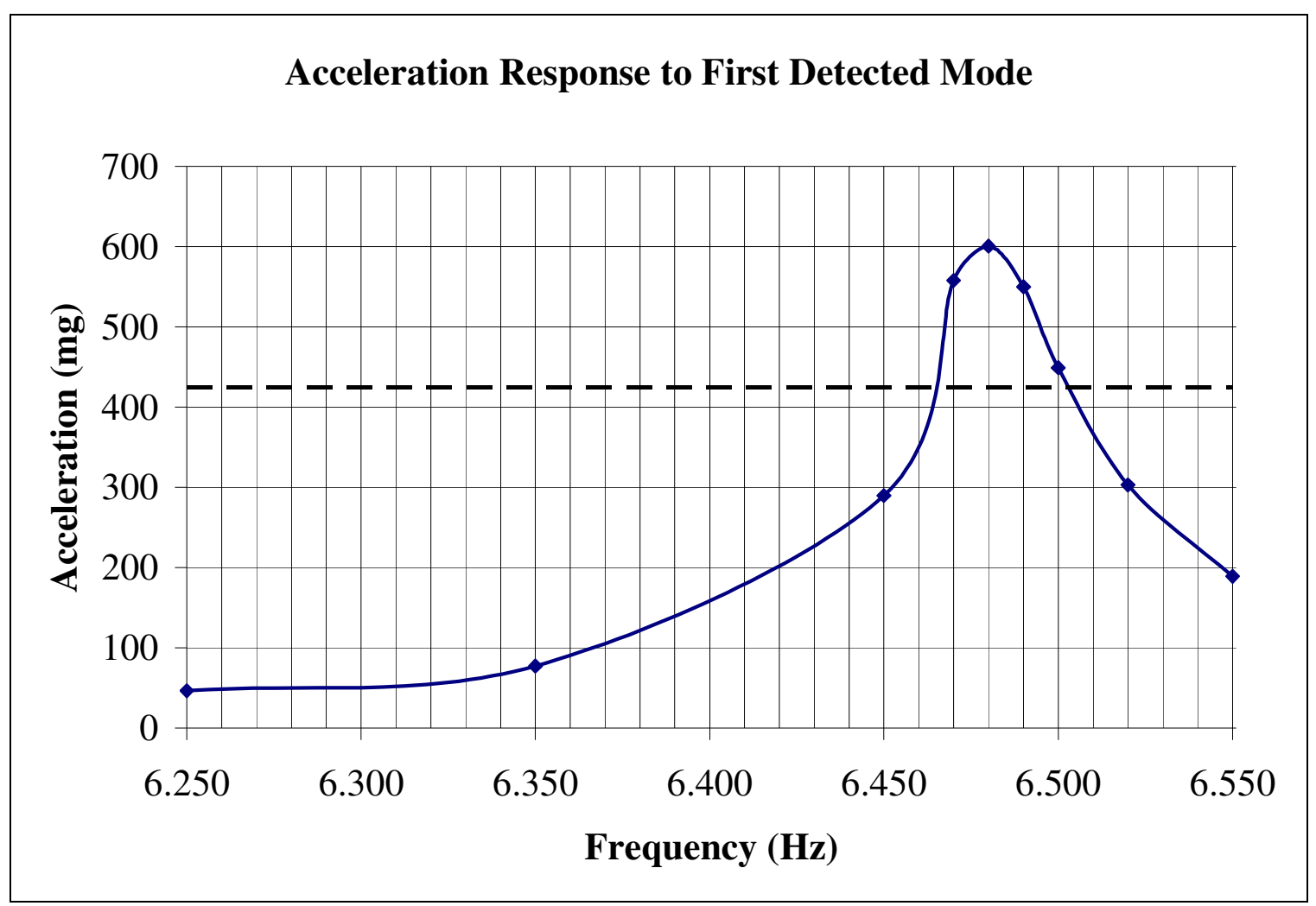

Figure EE: Power band method to determine damping

Source: Author diagram

The horizontal line intersects the graph at approximately $6.465 \mathrm{~Hz}$ and $6.502 \mathrm{~Hz}$.

Using these values in Equation 7, the damping ratio was determined to be approximately $0.29 \%$. Although this value is quite low, it is not completely unreasonable for a nearly bare steel structure. The damping ratio was then determined for each other mode shape as well, and the results are summarized in Table F, below.

Table F: Damping ratio of each mode shape

\begin{tabular}{|c|c|c|}
\hline $\begin{array}{l}\text { Frequency } \\
(\mathrm{Hz})\end{array}$ & Mode Shape & $\begin{array}{l}\text { Damping } \\
\text { Ratio }\end{array}$ \\
\hline 6.48 & 1st Weak & 0.0029 \\
\hline 10.32 & 1st Strong & 0.0165 \\
\hline 11.50 & 1st Torsion & 0.0183 \\
\hline 18.90 & 2nd Weak & 0.0119 \\
\hline
\end{tabular}


All damping ratios listed are very low, but very little exists within the structure with the ability to damp out the energy. It should also be noted that the very low value of damping in the first weak mode contributed well to the assumption that the mode was pure. As shown in the graph in Figure A, page 3, lower damping ratios corresponded to higher deformation response factors. A high value of $\mathrm{R}_{\mathrm{d}}$ corresponded to a mode shape that was negligibly influenced by higher frequency mode shapes.

\subsection{Computer Modeling}

The data recorded proved to be within the range of predicted results, but didn't exactly mimic either end of the spectrum of assumptions. The connection to the ground appeared to be neither perfectly fixed nor perfectly pinned, and the beams appeared to be neither perfectly rigid nor perfectly flexible. Instead, the data appeared to be somewhere in the middle. Attempting to analyze this particular situation with hand calculations proved to be quite cumbersome, so a computer model was developed to represent the structure.

The combination of the geometry of the frame, its natural frequencies, and its mode shapes provided most of the information necessary to successfully establish an accurate computer representation of the existing physical structure. The model was created in ETABS, and it required many adjustments before it adequately matched the recorded data.

\subsubsection{Basic Modeling Techniques}

The steel skeleton was modeled using centerline dimensions as provided in Figure $\mathrm{D}$, page 11 . The beams and columns were all modeled using the predefined program 
properties of a W6x12 section, including the mass. The beams were modeled such that their flexibility was not affected by the slabs. Rigid offsets were utilized at connections of beams to columns, assuring that the lengths of the beams were modeled accurately. All minor additions to the steel, such as small plates for potential brace or wall attachments, were not explicitly modeled and their contribution to the mass and stiffness of the model was considered negligible.

The concrete slabs were modeled by defining a new 3-1/8" thick slab shell element to take into account slab stiffness in every dimension. The slabs were placed at each level at the same nodes as the beams. Each was then divided into a mesh of 320 (a grid of 16x20) finite elements in order to better model the distribution of mass in the slabs. If a slab wasn't divided into a series of finite elements, the computer would incorrectly distribute the weight when analyzing the structure torsionally. Dividing the slab into a series of smaller elements forced the computer to distribute the mass of the slab such that it much more closely matched the actual existing structure. Each slab was manually assigned its measured mass rather than using the predefined mass in the program, and each was assigned to be a semi-rigid diaphragm. The semi-rigid diaphragm allowed the computer analysis to utilize the properties of the slabs in determining the stiffness of each slab. Figure FF, below, is a screen capture of the ETABS model. 


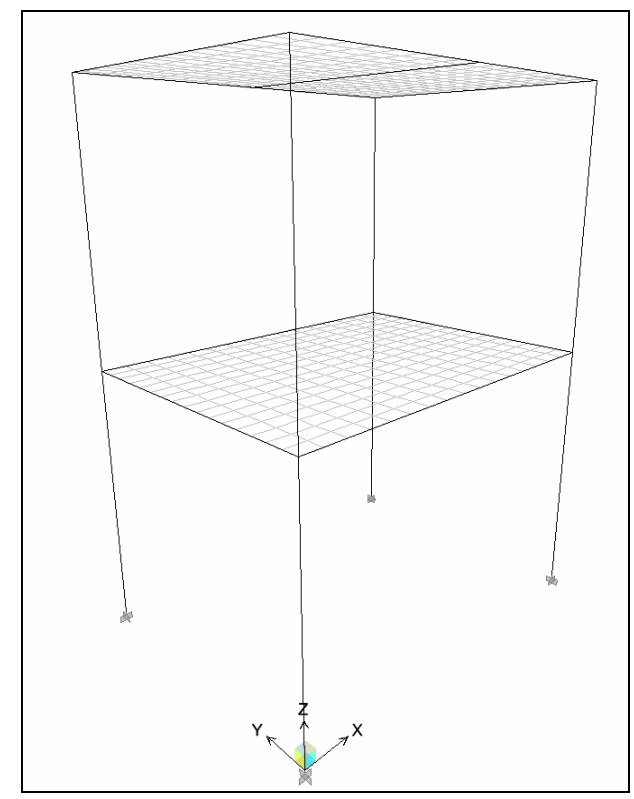

Figure FF: ETABS Model

Source: Author diagram

\subsubsection{Advanced Modeling Techniques}

Basic modeling techniques were able to produce a model that started to resemble the physical specimen. However, the frequencies and mode shapes of the computer model were not quite close enough to the actual values that were recorded from testing the frame, and further adjustments needed to be made to the model using more advanced modeling techniques. These techniques dealt explicitly with the flexibility of the connections within the model.

The first connection was that of the boundary conditions of the frame: the columns to the ground. When the connection was modeled as fully rotationally rigid, the natural frequencies of the model were much higher than the physical frame. However, when the connection was modeled with no rotational stiffness, the natural frequencies were much lower than the physical frame. The fact that the experimental values were 
within this range was not at all surprising, as the base plates at each column were very thin and flexible. Even though they were bolted down very tightly, the connection still allowed for small amounts of rotation at the base of the column. Unlike the rocking raft foundations, the flexibility in the base plates was not a nonlinear issue. The linearity of the connection was experimentally verified in Section 3.4.2. Uplift was able to be resisted, but the base plate was not able to fully resist the rotation at the base.

The second connection was that of the beams to the columns. The original assumptions in the model provided a fully rotationally rigid connection from the beam to the rigid offset. However, the possibility of flexibility existed in the connections between the beams and the columns. In the strong axis orientation, the long beams would tend to have high rotations, and the possibility existed that the connection was not adequate enough to resist all of the rotation. Additionally, the connection of the beam to the column was offset, leaving room for this rotation to occur. In the weak axis orientation, the connections of the beams to the weak axis of the column web could have provided a small amount of flexibility, causing a connection that was not perfectly rigid. Because these connections had the possibility of being only mostly rigid, they were modeled with increased flexibility.

The flexibility of each connection was modeled by releasing the moment resistance of the element and replacing it with a rotational spring. The resistance value of each spring was identical at each similar condition in the model. A value of zero represented a perfectly fixed connection, whereas a value of infinity represented a perfectly fixed connection. The beam to column connection was supposed to provide a fixed connection, but some flexibility definitely existed in the connection. Conversely, 
the column to ground connection appeared to be more flexible because of the lack of stiffness in the base plates. Thus, the stiffness values for the connections of the columns to the ground were lower than those for the connections of the beams to the columns. The springs were repeatedly adjusted until the frame adequately matched the physical frame.

\subsubsection{Determination of the Adequacy of Computer Model}

The two primary goals were to match the natural frequencies and the mode shapes of the computer model to the physical structure. Multiple computer models were created based on the techniques described in previous sections. One model was created with the primary goal of matching the natural frequencies of the model to those of the structure; matching the mode shapes was a secondary goal. A second model was created to match the mode shapes of the model to those of the structure; matching the natural frequencies was a secondary goal. The reason behind the development of multiple models was to narrow down a range of connection stiffness values that could be used for the model.

The natural frequencies and mode shapes of each model were recorded and compared to the physical structure. The natural frequencies were compared using a percent difference between the model and the structure, while the mode shapes were compared by using the MAC values discussed in Section 2.3. Table G, below, summarizes the percent differences between the natural frequencies of each model and the physical structure. Table H, further below, summarizes the MAC values of each model with respect to the physical structure. 
Table G: Percent difference of natural frequencies

\begin{tabular}{|l|r|r|r|r|}
\hline \multicolumn{1}{|c|}{ Model } & $\begin{array}{c}\text { 1st Weak } \\
\text { (\% Diff.) }\end{array}$ & $\begin{array}{c}\text { 1st Strong } \\
\text { (\% Diff.) }\end{array}$ & $\begin{array}{c}\text { 1st Torsion } \\
\text { (\% Diff.) }\end{array}$ & $\begin{array}{c}\text { 2nd Weak } \\
\text { (\% Diff.) }\end{array}$ \\
\hline Match Nat. Freq. & 0.00 & 0.19 & 1.39 & 0.58 \\
\hline Match Mode Shapes & 0.00 & 5.25 & 20.96 & 22.65 \\
\hline
\end{tabular}

\section{Table H: MAC with respect to physical structure}

\begin{tabular}{|l|c|c|c|c|}
\hline \multicolumn{1}{|c|}{ Model } & $\begin{array}{c}\text { 1st Weak } \\
\text { (MAC) }\end{array}$ & $\begin{array}{c}\text { 1st Strong } \\
\text { (MAC) }\end{array}$ & $\begin{array}{c}\text { 1st Torsion } \\
\text { (MAC) }\end{array}$ & $\begin{array}{c}\text { 2nd Weak } \\
\text { (MAC) }\end{array}$ \\
\hline Match Nat. Freq. & 0.9891 & 0.9702 & 0.5762 & 0.5699 \\
\hline Match Mode Shapes & 0.9892 & 0.9657 & 0.6433 & 0.5261 \\
\hline
\end{tabular}

Although the original intention of developing two models was to determine a range of likely rotational stiffness values, it quickly became clear that the model developed with the primary goal of matching natural frequencies should be used. This model was chosen because the natural frequencies very closely matched those of the physical structure, and its mode shapes matched those of the physical structure with nearly the same accuracy as the second model. Additionally, the first model was developed well within the parameters discussed in Section 4.5.2, whereas the second model began to push the limits of what could be considered an accurate representation of the flexibility of the connections within the physical structure.

The fact that the MAC values for each model were very similar also demonstrates that adjusting the stiffness of the connections did not change the possible mode shapes significantly. In fact, development ceased on the development of the mode-shapematching model when unrealistic input values became necessary to generate comparable mode shapes. For instance, the rotational stiffness of the roof level beams was considered perfectly rigid while the rotational stiffness of the floor level beams was considered 
perfectly pinned. Although the roof and floor conditions weren't necessarily identical, they did bear a significant similarity to one another, and the disparity between the two values was too high to be considered an accurate representation of the physical structure.

Using very different rotational stiffness values throughout the structure generated two models with very similar mode shapes and very different natural frequencies. Only one model could be developed that mimicked the four natural frequencies of the physical structure, but at least two models were found that mimicked its mode shapes.

The model created with the primary intention of natural frequencies was chosen as the final baseline model to be used for computer analysis. It was chosen for two important reasons: its development utilized realistic rotational stiffness values and natural frequencies were much more difficult to match with the physical structure than the mode shapes. Table I, below, summarizes the values of the spring rotational stiffness applied at each beam-to-column connection and the column-to-ground connection.

\section{Table I: Spring rotational stiffnesses in ETABS model}

\begin{tabular}{|l|r|r|}
\hline Location & Weak $(\mathrm{k} \mathrm{in} / \mathrm{rad})$ & Strong $(\mathrm{k} \mathrm{in} / \mathrm{rad})$ \\
\hline Roof & 9500 & Infinite \\
\hline Floor & 9500 & Infinite \\
\hline Ground & 800 & 3150 \\
\hline
\end{tabular}

Each value in the table above applied to four input points on the computer model. The roof location corresponded to the two beam-to-column connections of the two beams in each of the two principal directions of roof of the structure. The same designation was used for the floor location. The ground location applied to the four column-to-ground connections in each of the two principal directions of the structure. A value of infinite 
represents a rigid connection. The model created based on these spring values produced natural frequencies summarized in Table $\mathrm{J}$, below.

Table J: Natural frequencies of physical structure and computer model

\begin{tabular}{|l|c|c|c|r|r|r|}
\hline \multicolumn{1}{|c|}{ Model } & $\begin{array}{c}\mathrm{f}_{1 \text { st weak }} \\
(\mathrm{Hz})\end{array}$ & $\begin{array}{c}\mathrm{f}_{2 \text { nd weak }} \\
(\mathrm{Hz})\end{array}$ & $\begin{array}{c}\mathrm{f}_{1 \text { st strong }} \\
(\mathrm{Hz})\end{array}$ & $\begin{array}{c}\mathrm{f}_{\text {2nd strong }} \\
(\mathrm{Hz})\end{array}$ & $\begin{array}{c}\mathrm{f}_{1 \text { st torsion }} \\
(\mathrm{Hz})\end{array}$ & $\begin{array}{c}\mathrm{f}_{\text {2nd torsion }} \\
(\mathrm{Hz})\end{array}$ \\
\hline Physical & 6.48 & 18.90 & 10.32 & - & 11.50 & - \\
\hline Computer & 6.48 & 19.01 & 10.34 & 44.64 & 11.66 & 43.29 \\
\hline
\end{tabular}

The computer model not only matched the natural frequencies of the physical structure well, but all six of the natural frequencies were in the range of acceptable values. The second strong modal frequency was bounded from $31.12 \mathrm{~Hz}$ to $64.65 \mathrm{~Hz}$, and the second torsional frequency needed to be less than $74.84 \mathrm{~Hz}$. 


\subsection{PHYSICAL CHANGES TO THE BASE FRAME}

The frame underwent two physical modifications. In its altered states, the frame was then subjected to the same testing as before. Additionally, masses and braces were added to the baseline computer model in varying magnitudes and locations, creating a large number of variations with which the physical structure could be compared. Methods were developed to determine which computer model or models best matched the actual changes to the structure.

\subsection{Additions}

The first change to the structure involved the addition of a 600 pound wall framing sample, placed eccentrically to the center of mass of the roof. Figure GG, below, is a photograph of the wall sample addition. Figure $\mathrm{HH}$, further below, is a plan-view diagram detailing the exact location of the sample on the roof of the structure.

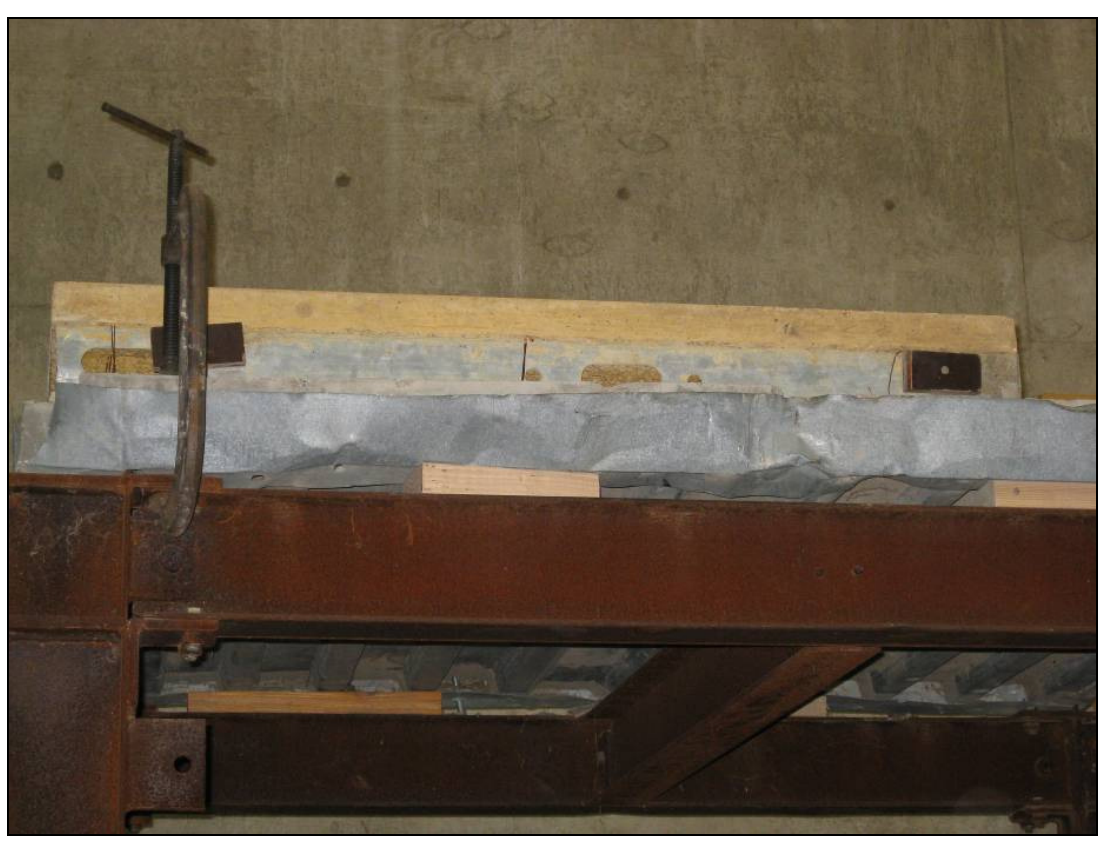

Figure GG: Addition of mass to roof

Source: Author diagram 


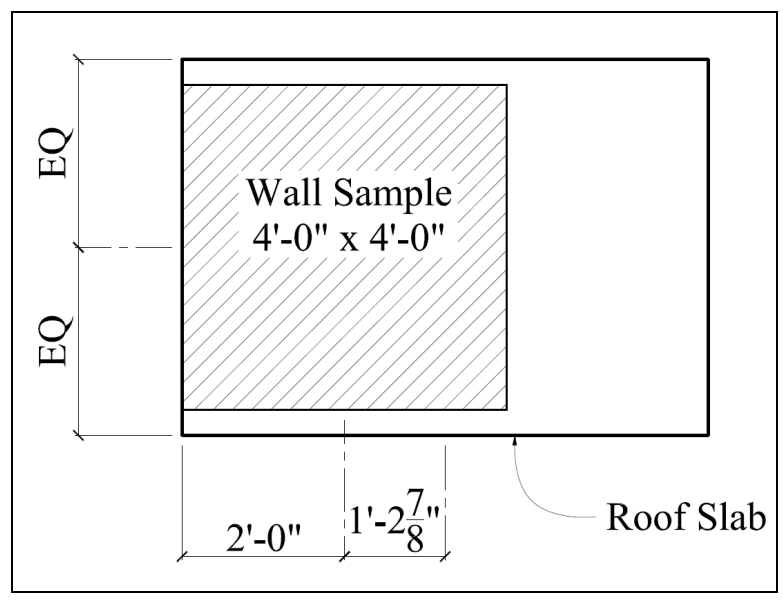

Figure HH: Additional roof mass location

Source: Author diagram

The second change to the structure was the addition of two diagonal braces in the form of \#4 rebar while leaving the additional mass on the roof. A photo of the brace addition is shown in Figure II, below.

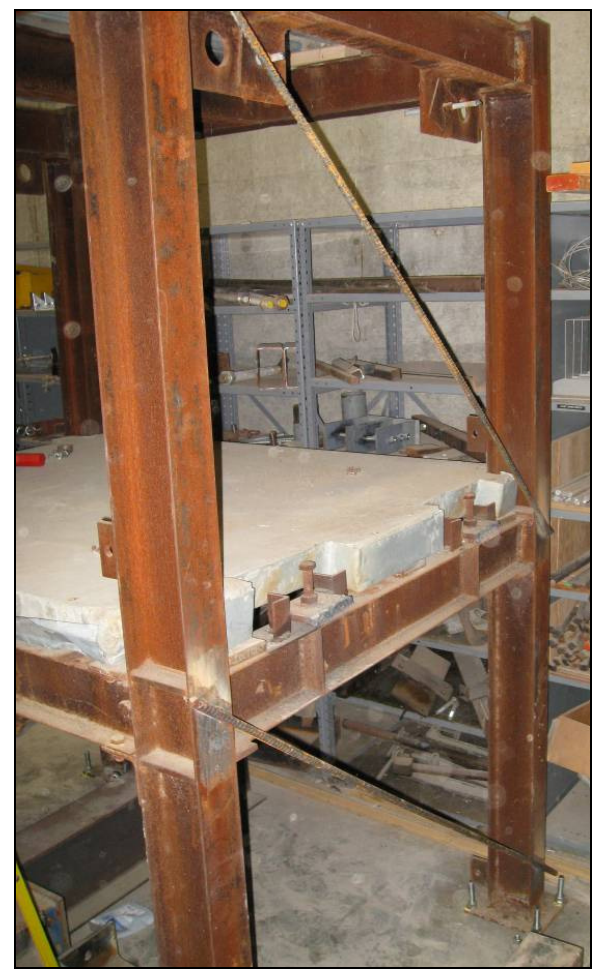

Figure II: Photo of addition of braces

Source: Author diagram 
The $1 / 2$ " diameter braces were welded to the column such that they ran through the centerlines of both the beams and columns. The braces were added to only one side of the frame, parallel to the weak axis, such that they caused a change in stiffness in both torsional and translational modal response. However, the braces provided only a very minor change to the strong axis translational mode shape because they did virtually nothing to resist any movement in that direction. Figure JJ, below, shows a diagram of the addition of the wall sample to and the braces to the side.

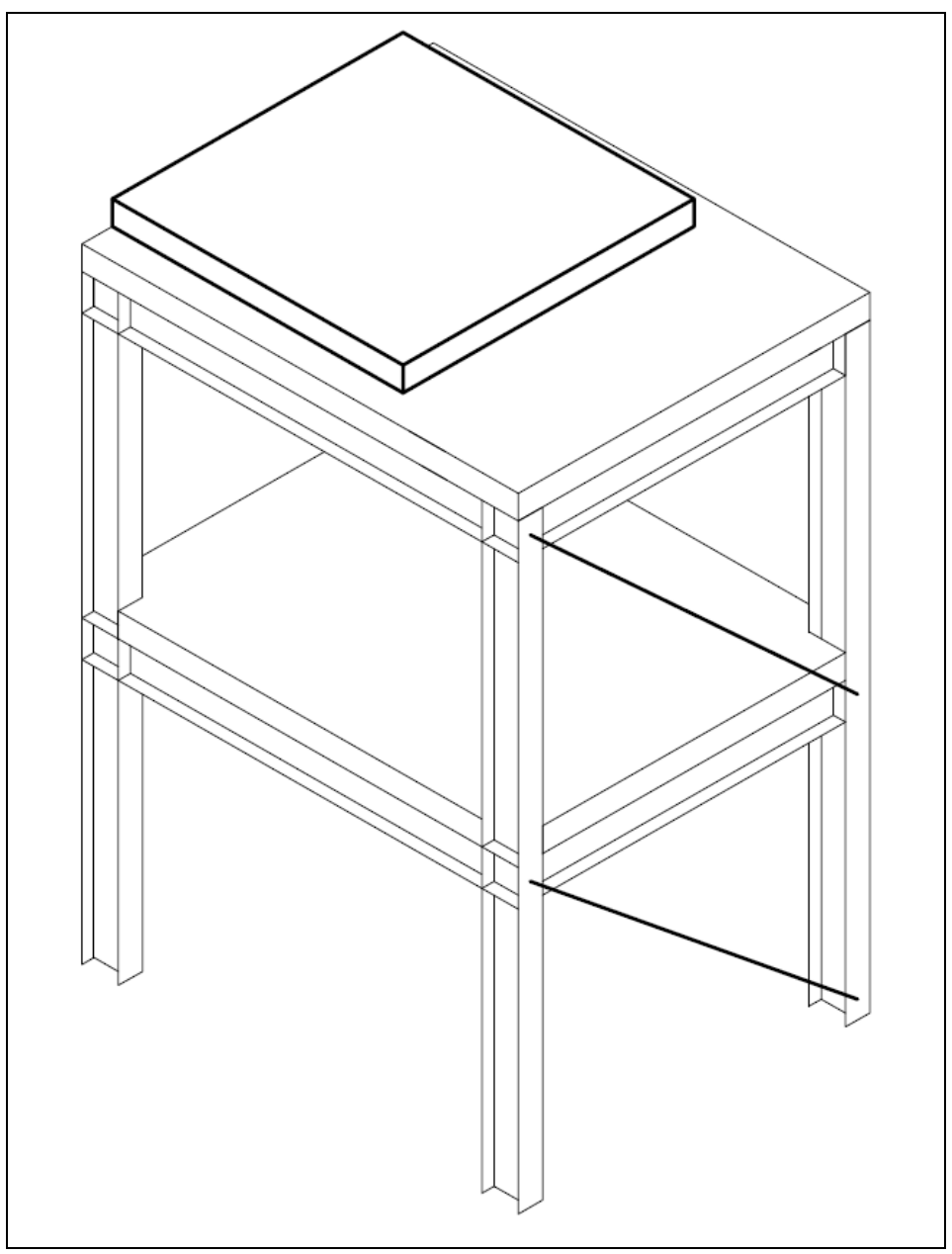

Figure JJ: Diagram of addition of braces

Source: Author diagram 


\subsection{Testing the Changes}

Each alteration was tested following the same procedure for forced vibration testing outlined in Section 4.3. The first alteration, the single change, involved only the additional mass added to the roof. The second alteration, the double change, involved both the additional mass on the roof and the braces added to the side of the structure. FVT provided the natural frequencies, as well as the mode shapes and damping ratios, of the physically altered structures. Because of the nonsymmetrical nature of the changes, the translational mode shapes began to appear more torsional, but not to the point that they couldn't be compared to the original modes shapes of the frame. The natural frequencies of both the baseline structure and the altered structures are summarized in Table K, below.

Table K: Natural frequencies of the altered physical structure

\begin{tabular}{|l|r|r|r|r|}
\hline \multicolumn{1}{|c|}{ Frame } & \multicolumn{1}{c|}{$\begin{array}{c}\mathrm{f}_{1 \text { st weak }} \\
(\mathrm{Hz})\end{array}$} & $\begin{array}{c}\mathrm{f}_{1 \text { st strong }} \\
(\mathrm{Hz})\end{array}$ & $\begin{array}{c}\mathrm{f}_{1 \text { st torsion }} \\
(\mathrm{Hz})\end{array}$ & $\begin{array}{c}\mathrm{f}_{\text {2nd weak }} \\
(\mathrm{Hz})\end{array}$ \\
\hline Baseline & 6.48 & 10.32 & 11.50 & 18.90 \\
\hline Add. Mass & 5.55 & 8.91 & 10.75 & 18.46 \\
\hline Add. Mass and Braces & 6.57 & 8.82 & 14.91 & 20.59 \\
\hline
\end{tabular}

The addition of the mass performed as expected, reducing the natural frequencies of all of the mode shapes of the frame. Because mass is inversely proportional to frequency, this trend was not surprising. Adding the braces to the structure also performed as expected, increasing all of the frequencies because stiffness is directly proportional to frequency. 


\subsection{Establishing Possible Computer Model Solutions}

In order to identify the changes in the physical structure, the baseline computer model had to have a set of changed models for which to compare. Each change to the baseline model only included single additive properties, such as the addition of mass or the addition of braces.

Mass was added in varying amounts and in varying locations throughout the structure. It was added to either a corner quadrant of a slab, a side half of a slab in which the additional mass spanned the shorter dimension, or an entire slab. This mass was added to either the floor slab or the roof slab. Lastly, mass was added to the entirety of both slabs. In each model, the amount of additional mass was represented by a multiplier. The multiplier was applied to the distributed mass of the slab at the part of the slab represented by the model name. Tables L, M, and N, below, summarize the results of adding mass to different parts of the roof slab, floor slab, and both slabs, respectively.

Diagonal braces were added to one side of the computer model, spanning the short dimension. A brace was added either connecting the roof level to the floor level, the floor level to the ground level, or both. The braces were of diameters varying from 1/8" to $1 "$. Table $\mathrm{O}$, further below, summarizes the results of adding varying bracing members to the structure. 
Table L: Change in natural frequency due to addition of roof mass

\begin{tabular}{|l|r|r|r|r|}
\hline \multicolumn{1}{|c|}{ Model Name } & $\mathrm{f}_{1 \text { st weak }}(\mathrm{Hz})$ & $\mathrm{f}_{\text {2nd weak }}(\mathrm{Hz})$ & $\mathrm{f}_{1 \text { st strong }}(\mathrm{Hz})$ & $\mathrm{f}_{1 \text { st torsion }}(\mathrm{Hz})$ \\
\hline 1.25 Corner Roof Mass & 6.37 & 18.90 & 10.18 & 11.55 \\
\hline 1.5 Corner Roof Mass & 6.27 & 18.80 & 10.03 & 11.44 \\
\hline 1.75 Corner Roof Mass & 6.18 & 18.69 & 9.88 & 11.36 \\
\hline 2 Corner Roof Mass & 6.09 & 18.62 & 9.73 & 11.29 \\
\hline 3 Corner Roof Mass & 5.75 & 18.35 & 9.18 & 11.04 \\
\hline 4 Corner Roof Mass & 5.45 & 18.15 & 8.70 & 10.86 \\
\hline 1.25 Side Roof Mass & 6.27 & 18.80 & 10.04 & 11.43 \\
\hline 1.5 Side Roof Mass & 6.09 & 18.62 & 9.77 & 11.24 \\
\hline 1.75 Side Roof Mass & 5.91 & 18.48 & 9.51 & 11.05 \\
\hline 2 Side Roof Mass & 5.75 & 18.35 & 9.27 & 10.89 \\
\hline 2.5 Side Roof Mass & 5.45 & 18.15 & 8.83 & 10.62 \\
\hline 3 Side Roof Mass & 5.19 & 17.99 & 8.46 & 10.37 \\
\hline 1.25 Total Roof Mass & 6.10 & 18.59 & 9.77 & 11.19 \\
\hline 1.5 Total Roof Mass & 5.93 & 18.45 & 9.51 & 10.99 \\
\hline 1.75 Total Roof Mass & 5.77 & 18.32 & 9.27 & 10.81 \\
\hline 2 Total Roof Mass & 5.25 & 17.86 & 8.46 & 10.07 \\
\hline
\end{tabular}

Table M: Change in natural frequency due to addition of floor mass

\begin{tabular}{|l|r|r|r|r|}
\hline \multicolumn{1}{|c|}{ Model Name } & $\mathrm{f}_{1 \text { st weak }}(\mathrm{Hz})$ & $\mathrm{f}_{\text {2nd weak }}(\mathrm{Hz})$ & $\mathrm{f}_{1 \text { st strong }}(\mathrm{Hz})$ & $\mathrm{f}_{1 \text { st torsion }}(\mathrm{Hz})$ \\
\hline 1.25 Corner Floor Mass & 6.44 & 18.73 & 10.27 & 11.60 \\
\hline 1.5 Corner Floor Mass & 6.39 & 18.48 & 10.19 & 11.55 \\
\hline 1.75 Corner Floor Mass & 6.35 & 18.25 & 10.12 & 11.51 \\
\hline 2 Corner Floor Mass & 6.31 & 18.02 & 10.05 & 11.45 \\
\hline 1.25 Side Floor Mass & 6.39 & 18.48 & 10.19 & 11.55 \\
\hline 1.5 Side Floor Mass & 6.31 & 18.02 & 10.06 & 11.44 \\
\hline 1.75 Side Floor Mass & 6.23 & 17.61 & 9.92 & 11.34 \\
\hline 2 Side Floor Mass & 6.15 & 17.27 & 9.79 & 11.24 \\
\hline 1.25 Total Floor Mass & 6.32 & 18.02 & 10.06 & 11.43 \\
\hline 1.5 Total Floor Mass & 6.16 & 17.21 & 9.79 & 11.22 \\
\hline 1.75 Total Floor Mass & 6.01 & 16.58 & 9.54 & 11.01 \\
\hline 2 Total Floor Mass & 5.87 & 16.10 & 9.31 & 10.82 \\
\hline
\end{tabular}


Table N: Change in natural frequency due to addition of mass to roof and floor

\begin{tabular}{|l|r|r|r|r|}
\hline \multicolumn{1}{|c|}{ Model Name } & $\mathrm{f}_{1 \text { st weak }}(\mathrm{Hz})$ & $\mathrm{f}_{\text {2nd weak }}(\mathrm{Hz})$ & $\mathrm{f}_{1 \text { st strong }}(\mathrm{Hz})$ & $\mathrm{f}_{1 \text { st torsion }}(\mathrm{Hz})$ \\
\hline 1.25 All Mass & 5.97 & 17.54 & 9.52 & 11.00 \\
\hline 1.5 All Mass & 5.56 & 16.34 & 8.87 & 10.44 \\
\hline 1.75 All Mass & 5.22 & 15.36 & 8.34 & 9.96 \\
\hline 2 All Mass & 4.94 & 14.56 & 7.89 & 9.53 \\
\hline
\end{tabular}

Table O: Changes in natural frequency due to addition of braces

\begin{tabular}{|l|r|r|r|r|}
\hline \multicolumn{1}{|c|}{ Model Name } & $\mathrm{f}_{1 \text { st weak }}(\mathrm{Hz})$ & $\mathrm{f}_{\text {2nd weak }}(\mathrm{Hz})$ & $\mathrm{f}_{1 \text { st strong }}(\mathrm{Hz})$ & $\mathrm{f}_{1 \text { st torsion }}(\mathrm{Hz})$ \\
\hline 0.125 Top Brace & 6.58 & 19.80 & 10.34 & 11.71 \\
\hline 0.250 Top Brace & 6.76 & 21.79 & 10.34 & 11.82 \\
\hline 0.375 Top Brace & 6.91 & 24.10 & 10.34 & 11.89 \\
\hline 0.500 Top Brace & 7.00 & 26.04 & 10.33 & 11.95 \\
\hline 0.625 Top Brace & 7.06 & 27.55 & 10.33 & 11.96 \\
\hline 0.750 Top Brace & 7.09 & 28.57 & 10.33 & 11.98 \\
\hline 0.875 Top Brace & 7.12 & 29.24 & 10.32 & 11.98 \\
\hline 1.000 Top Brace & 7.13 & 29.76 & 10.31 & 11.96 \\
\hline 0.125 Bottom Brace & 6.81 & 19.38 & 10.34 & 11.99 \\
\hline 0.250 Bottom Brace & 7.39 & 20.49 & 10.34 & 12.82 \\
\hline 0.375 Bottom Brace & 7.78 & 22.37 & 10.34 & 13.66 \\
\hline 0.500 Bottom Brace & 8.01 & 24.81 & 10.34 & 14.25 \\
\hline 0.625 Bottom Brace & 8.13 & 27.17 & 10.34 & 14.58 \\
\hline 0.750 Bottom Brace & 8.21 & 29.24 & 10.34 & 14.79 \\
\hline 0.875 Bottom Brace & 8.26 & 30.77 & 10.34 & 14.93 \\
\hline 1.000 Bottom Brace & 8.29 & 31.95 & 10.34 & 15.02 \\
\hline 0.125 Double Brace & 6.91 & 20.08 & 10.34 & 12.08 \\
\hline 0.250 Double Brace & 7.69 & 22.57 & 10.34 & 13.48 \\
\hline 0.375 Double Brace & 8.22 & 25.25 & 10.34 & 15.77 \\
\hline 0.500 Double Brace & 8.49 & 27.32 & 10.33 & 18.59 \\
\hline 0.625 Double Brace & 8.64 & 28.74 & 10.33 & 21.55 \\
\hline 0.750 Double Brace & 8.72 & 29.76 & 10.32 & 24.45 \\
\hline 0.875 Double Brace & 8.77 & 30.77 & 10.32 & 27.03 \\
\hline 1.000 Double Brace & 8.80 & 32.15 & 10.31 & 28.82 \\
\hline
\end{tabular}




\subsection{Identifying Changes to the Steel Frame}

Two methods were developed to best determine which arbitrary computer models best corresponded to the actual alteration. The first method was developed for identifying a single change (roof mass addition) while the second method was developed for a double change (roof mass and brace additions).

\subsubsection{Identifying a Single Change}

The single change to the structure involved the addition of mass, detailed in Figure $\mathrm{HH}$, page 55. The method for identifying a single change to a model involved the percent difference between the frequencies of each computer model and those of the addition of roof mass to the physical structure. The percent differences were assigned points based on their size. Table $\mathrm{P}$, below, summarizes the assigned points for each range of percent differences.

\section{Table P: Points assigned for range of percent difference}

\begin{tabular}{|l|r|}
\hline \multicolumn{1}{|c|}{ Range } & Points \\
\hline $0-1 \%$ & 5 \\
\hline $1-2 \%$ & 2 \\
\hline $2-5 \%$ & 1 \\
\hline $5-10 \%$ & 0 \\
\hline$>10 \%$ & -5 \\
\hline
\end{tabular}

Each mode was then assigned a weight. The three first modes - first weak translational, first strong translational, first torsional - were each assigned a weight of two, while the second weak translational mode was assigned a weight of one. The larger weight assignments were assigned to the higher modes because of their prominence 
within the system. On a frame of this size, second order modes did not have nearly as large of an impact as first order modes due to their lower mass participation factors.

The points for each frequency of a given computer model were multiplied by their weights and summed. Equation 19, below, outlines exactly how the points were summed for each model.

$$
P_{\text {Total }}=2\left(P_{W 1}+P_{S 1}+P_{T 1}\right)+P_{W 2}
$$

Where $P_{\text {Total }}=$ Total points for a model (points),

$P_{W 1}=$ Points for $1^{\text {st }}$ weak mode (points),

$P_{W 2}=$ Points for $2^{\text {nd }}$ weak mode (points),

$P_{S 1}=$ Points for $1^{\text {st }}$ strong mode (points), and

$P_{T l}=$ Points for $1^{\text {st }}$ torsional mode (points).

Every model from Tables L, M, N, and O was analyzed using Equation 19. Table Q, below, summarizes the total points for each model. Only mass or brace locations with at least one positive-point-producing model are recorded in the table. 
Table Q: Total points for each model

\begin{tabular}{|l|c|}
\hline \multicolumn{1}{|c|}{ Model Name } & $\mathrm{P}_{\text {Total }}$ \\
\hline 1.25 Corner Roof Mass & 0 \\
\hline 1.5 Corner Roof Mass & 0 \\
\hline 1.75 Corner Roof Mass & 0 \\
\hline 2 Corner Roof Mass & 7 \\
\hline 3 Corner Roof Mass & 11 \\
\hline 4 Corner Roof Mass & 12 \\
\hline 1.25 Side Roof Mass & 0 \\
\hline 1.5 Side Roof Mass & 7 \\
\hline 1.75 Side Roof Mass & 7 \\
\hline 2 Side Roof Mass & 13 \\
\hline 2.5 Side Roof Mass & 20 \\
\hline 3 Side Roof Mass & 3 \\
\hline 1.25 Total Roof Mass & 7 \\
\hline 1.5 Total Roof Mass & 7 \\
\hline 1.75 Total Roof Mass & 19 \\
\hline 2 Total Roof Mass & 1 \\
\hline 1.25 Total Floor Mass & 0 \\
\hline 1.5 Total Floor Mass & 0 \\
\hline 1.75 Total Floor Mass & 0 \\
\hline 2 Total Floor Mass & 6 \\
\hline 1.25 All Mass & 3 \\
\hline 1.5 All Mass & 0 \\
\hline 1.75 All Mass & 0 \\
\hline 2 All Mass & \\
\hline
\end{tabular}

Once the models had been analyzed using Equation 19, their point totals were reviewed to determine the change in the frame. Identifying the change involved identifying the model or models with the highest point totals. In this case, the highest point total corresponded to the model labeled "2.5 Side Roof Mass." The second highest point total is relatively large as well, and that corresponded to "1.75 Total Roof Mass." 
The "2.5 Side Roof Mass" model represented the addition of a 773 pound mass with a center of mass located 18" from the center of mass of the structure. The " 1.75 Total Roof Mass" model involved the addition of a 773 pound mass with a center of mass perfectly aligned with the center of mass of the structure. The physical change involved a 600 pound mass was added with its center of mass eccentric $14.875 "$ to the center of mass of the structure.

Both models predicted the same amount of additional weight, and both predicted it within $29 \%$ of what it actually was. The primary difference between the models is that the model that recorded a highest point total predicted an eccentric mass, whereas the model that recorded the second highest point total predicted the mass aligned with the center of mass of the structure. Although the process did not determine the exact change that was made to the steel frame, the large field of models that was created represented such a wide variety of potential changes to the structure that this method for identifying a single change in the structure was determined to be satisfactory.

The method predicted the additional mass to be $29 \%$ larger than it actually was. The reason for the overestimate of the additional mass stems from the calibration of the baseline model. An alteration of the baseline model was created to mimic the actual addition of mass to the physical structure. This altered model predicted the natural frequencies of the structure to be an average of $1.96 \%$ higher than the values that were recorded in the lab. The method essentially compensates for the error by increasing its prediction for the additional mass of the structure. It should also be noted that although it overestimated the weight of the additional mass by $29 \%$, it only overestimated the total weight of the altered structure by $4.8 \%$. 
The overestimation of the frequencies in the model mimicking the actual addition of mass is likely due to some inaccuracies in the baseline model. Firstly, the slabs were modeled at a lower height than they actually exist on the physical structure. In the model, the center of mass of each slab was vertically aligned with the top of the beams on which it was supported. In the physical structure, the center of mass of each slab is approximately 3" above the top of the beams at each level. Furthermore, the 600 pound additional mass was actually added on top of the roof slab; its center of mass is another 4" above the center of mass of the roof slab below it. Modeling the masses at their actual increased heights, rather than aligned with the top of the beams, would lower the natural frequencies of the model. Secondly, the possibility exists that the stiffness of the connections between the beams and columns was overestimated, a result of the spring values and rigid offset lengths that were assumed for the structure. Reducing either the spring value of the connection or the length of the rigid offset would slightly increase the flexibility in the system, thus lowering the natural frequencies of the structure and increasing the accuracy of the model.

\subsubsection{Identifying Two Changes}

The two changes applied to the structure involved the addition of both mass and braces, detailed in Figure JJ, page 56. Identifying two changes to a frame using only a collection of singly changed models was a more involved task than simply detecting a single change. This method also involved using the percent differences between each singly changed model and the baseline model and determining a method of combining them to effectively predict the two changes to the structure. 
Any two of the computer models were hypothesized to be the two changes that actually occurred. For the first frequency, each magnitude of each percent difference was square rooted, while their sign was kept in front of the square root. These square roots were then added together, and the magnitude is then squared, again keeping the sign outside of the calculation. This process is outlined in Equation 20, below. It should be noted that the equation can be expanded to accommodate any number of models by continuing to add or subtract the square root of the magnitude percent changes of the models within the parentheses in a similar fashion to the first two models.

$$
P C_{f}= \pm\left( \pm \sqrt{\left|P D_{1}\right|} \pm \sqrt{\left|P D_{2}\right|}\right)^{2}
$$

Where $P C_{f}=$ percent change of the frequency $(\%)$,

$P D_{1}=$ percent difference between model $1 \&$ baseline $(\%)$, and $P D_{2}=$ percent difference between model $2 \&$ baseline $(\%)$.

This number represented the percent change of that particular frequency. Multiplying this percent change by the natural frequency of the baseline computer model provided a modal frequency of the combination of changes that could be compared to the frequency of the same mode recorded for the doubly changed physical model. Equation 21 , following, represents this process.

$$
f_{\text {Combo }}=\left(1+P C_{f}\right) \cdot f_{\text {Baseline }}
$$

Where $f_{\text {Combo }}=$ frequency of the combo of models $(\mathrm{Hz})$,

$P C_{f}=$ percent change of the baseline model frequency $(\%)$, and $f_{\text {Baseline }}=$ baseline model frequency $(\mathrm{Hz})$.

Equations 20 and 21 were then applied to the other frequencies, producing a frequency for each of the modes. The differences between the combination of computer 
models and the doubly changed physical structure were calculated to find a percent error. The percent error for each frequency was then assigned points and weights, as outlined in Section 5.4.1, and a total point value was calculated for each combination of models.

Table R, below, summarizes the point values for combinations of two, three, and four changes. 


\section{Table R: Total points for each combination of models}

\begin{tabular}{|l|r|}
\hline \multicolumn{1}{|c|}{ Models in Combination } & $\mathrm{P}_{\text {Total }}$ \\
\hline 2.5 Side Roof Mass, & \\
0.500 Double Brace & 1 \\
\hline 2.0 Side Roof Mass, & -1 \\
0.500 Double Brace & \\
\hline 2.5 Side Roof Mass, & -2 \\
0.625 Double Brace & \\
\hline 1.5 Total Roof Mass, & 0 \\
0.500 Double Brace & \\
\hline 1.75 Total Floor Mass, & -2 \\
1.000 Top Brace & \\
\hline 2 All Mass, & -4 \\
0.250 Bottom Brace & \\
\hline 3 Corner Roof Mass, & \\
1.75 Side Floor Mass, & -4 \\
0.750 Double Brace & \\
\hline 1.75 Corner Floor Mass, & \\
0.500 Top Brace, & -20 \\
0.125 Bottom Brace & \\
\hline 1.25 All Mass, & \\
2 Total Roof Mass, & \\
0.375 Top Brace, & \\
0.875 Bottom Brace & \\
\hline
\end{tabular}

The combination of models that produced the most points included the following two: the model that provided an additional 773 pound roof mass distributed with a center of mass located 18" from the center of the roof as well as the model that provided a half inch diameter steel brace at both the top and bottom floors. The actual change was a 600 pound mass with a center of mass located $14.875^{\prime \prime}$ from the center of the roof as well as the addition of a half inch diameter steel brace at both the top and bottom floors.

This pair of models predicted the weight of the additional roof mass within $29 \%$ of its actual value (again estimating the total structure weight to within 5.7\% accuracy), and they predicted the brace size and location perfectly. The fact that this method was 
able to use this combination of two separate single changes to predict the double change with this accuracy demonstrates that this method was a satisfactory approach to identifying the double change in the structure. 


\subsection{CONCLUSIONS}

The project established laboratory procedures that resulted in the ability to determine the natural frequencies, mode shapes, and damping ratios of a steel frame. The frame was attached to the ground such that the procedures produced results in a linear fashion; the results of the lab testing did not change depending on the intensity of the testing.

Ambient vibration testing was valid as a starting point for determining the natural frequencies and mode shapes of the structure. However, AVT was not able to be used beyond a preliminary estimate. It produced five potential natural frequencies in the structure within a range that only four natural frequencies actually existed. This likely resulted from other machinery in the laboratory vibrating at a consistent frequency, but the extremely small magnitudes of the accelerations made it impossible to differentiate the true natural frequencies from the machinery frequency. Additionally, the mode shapes of the structure could be qualitatively determined using a combination of AVT and analytical predictions, but no quantitative results could be produced to determine the exact mode shapes of the structure. The data collected from ambient vibration testing only served useful as a starting point for forced vibration testing.

Forced vibration testing was able to quantitatively determine the natural frequencies, mode shapes, and damping ratios of the structure. Using the natural frequencies predicted by AVT, FVT was able to determine four natural frequencies of the structure. FVT was then able to determine both the mode shape and the damping ratio 
Appendix 71

that corresponded to each natural frequency. In order to compare the mode shapes to both analytical and computer model output, the recorded mode shape data was converted into a more conventional six degree of freedom structure and then orthogonalized using the process of mode sweeping. The natural frequencies determined by FVT fell in the range of frequencies predicted for each mode shape by theoretical analytical models, further verifying their accuracy. The final results of FVT included four natural frequencies, orthogonalized mode shapes, and damping ratios.

A computer model of the structure was created using ETABS. The model was calibrated to match the results of FVT as well as possible. The model matched each of the natural frequencies of the structure within $1.39 \%$ or better. The mode shapes were matched as well as possible: the first weak and first strong mode shapes corresponded quantitatively well to the FVT results, but the first torsion and second weak mode shapes were only able to be modeled with qualitative accuracy.

Identifying a single change - the addition of a large eccentric mass - to the structure was done using a weighted point system, detailed in Section 5.4.1. This method analyzed the large field of models representing single changes to the baseline model, and it was able to determine that a mass was added eccentrically to the roof. Because the method predicted the weight of the mass within $29 \%$ of its actual value, and it predicted it added eccentrically, the method was determined to be satisfactory for identifying a single change to the structure. 
Identifying the double change - the addition of a large eccentric mass and the addition of a diagonal brace at each level - to the structure involved comparing the percent differences between each singly changed model and the baseline model. The method, detailed in Section 5.4.2, was able to predict a wide variety of information that proved to be accurate. It determined that the mass was added eccentrically to the roof of the structure, and it predicted the weight of the additional mass within $29 \%$. It also determined that braces were added at both the roof and floor levels, and it determined the size of the braces exactly. This collection of correct predictions supports the conclusion that this method was able to satisfactorily identify a double change in the structure. 


\section{REFERENCES}

(Allemang 2003) Allemang, Randall J. "Modal Assurance Criterion - Twenty Years of Use and Abuse." Sound and Vibration. (August 2003) 14-21.

(American Institute of Steel Construction 2006) American Institute of Steel Construction. Steel Construction Manual. Thirteenth Edition. 2006.

(Chopra 2007) Chopra, Anil K. Dynamics of Structures: Theory and Applications to Earthquake Engineering. Third Edition. Upper Saddle River, New Jersey: Pearson Prentice Hall, 2007. 


\section{APPENDIX}

\section{A.1 Accelerometer Specifications}

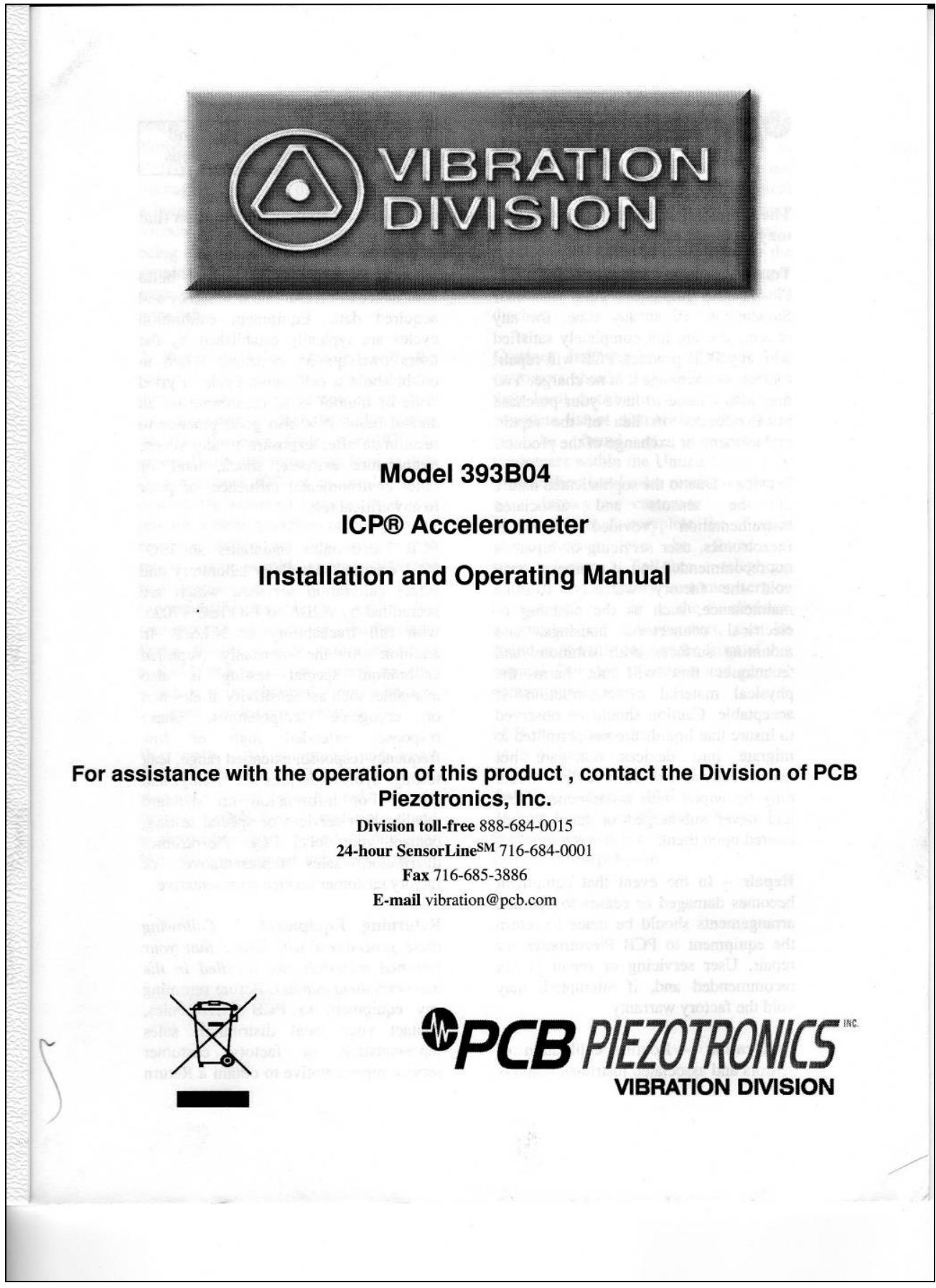

Identification of Physical Changes to a Steel Frame 


\title{
General \\ OPERATING GUIDE
}

for use with

\section{PIEZOELECTRIC ICP ${ }^{\circledR}$ ACCELEROMETERS}

\author{
SPECIFICATION SHEET, INSTALLATION DRAWING \\ AND CALIBRATION INFORMATION ENCLOSED
}

PCB ASSUMES NO RESPONSIBILITY FOR DAMAGE CAUSED TO THIS PRODUCT AS A RESULT OF PROCEDURES THAT ARE INCONSISTENT WITH THIS OPERATING GUIDE.

\subsection{INTRODUCTION}

Congratulations on the purchase of a quality, ICP acceleration sensor. In order to ensure the highest level of performance for this product, it is imperative that you properly familiarize yourself with the correct mounting and installation techniques before attempting to operate this device. If, after reading this manual, you have any additional questions concerning this sensor or its application, feel free to call a factory Application Engineer at 716-684-0001 or your nearest PCB sales representative.

\subsection{ICP $^{\circledast}$ ACCELEROMETERS}

Powered by simple, inexpensive, constant-current signal conditioners, these sensors are easy to operate and interface with signal analysis, data acquisition and recording instruments. The following features further characterize ICP ${ }^{\circledast}$ sensors:

- Fixed voltage sensitivity, regardless of cable type or length.

- Low-impedance output signal, which can be transmitted over long cables in harsh environments with virtually no loss in signal quality.

- Two-wire operation with low cost coaxial cable, twoconductor ribbon wire or twisted-pair cabling.

- Low-noise, voltage-output signal compatible with standard readout, signal analysis, recording, and data acquisition equipment.

- Low cost per-channel - ICP ${ }^{\circledR}$ accelerometers require only an inexpensive, constant-current signal conditioner to operate.

\footnotetext{
ICP is a registered trademark of PCB Group, Inc., which uniquely identifies PCB sensors that incorporate built-in microelectronics.
}

- Intrinsic self-test feature - monitoring the sensor's output bias voltage provides an indication of proper operation, faulty condition, and bad cables.

In the rear of this manual you will find a Specification Sheet, which provides the complete performance characteristics of your particular sensor.

\subsection{OPTIONAL FEATURES}

Many sensors are supplied with standard, optional features. When listed before the model number, the following prefix letters indicate that the sensor is manufactured or supplied with a particular optional feature: "A" option: adhesive mount; "HT" option: extended high temperature range; "J" option: electrically ground isolated; "M" option: metric mounting thread; "Q" option: extended discharge time constant; "T" option: built-in transducer electronic data sheet (TEDS); and "W" option: attached, water-resistant cabling. Other prefix letters, such as "K", "KR", "GK", "GKR", "KL", and "GKL", indicate that the sensor is ordered in kit form, including interconnect cabling and signal conditioner. If you have any questions or concerns regarding optional features, consult the Vibration Division's product catalog or contact a PCB factory representative.

\subsection{INSTALLATION OVERVIEW}

When choosing a mounting method, consider closely both the advantages and disadvantages of each technique. Characteristics like location, ruggedness, amplitude range, accessibility, temperature, and portability are extremely critical. However, the most important and often overlooked consideration is the effect the mounting technique has on the high-frequency performance of the accelerometer.

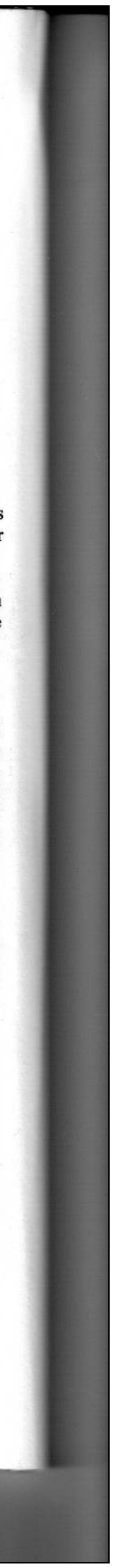


Shown in figure 1 are six possible mounting techniques and their effects on the performance of a typical piezoelectric accelerometer. (Note that not all of the mounting methods may apply to your particular sensor). The mounting configurations and corresponding graph demonstrate how the high-frequency response of the accelerometer may be compromised as mass is added to the system and/or the mounting stiffness is reduced.

NOTE: The low-frequency response is unaffected by the mounting technique. This roll-off behavior is typically fixed by the sensor's built-in electronics. However, when operating AC-coupled signal conditioners with readout devices having an input impedance of less than one megohm, the low frequency range may be affected. If necessary, contact a factory representative for further assistance.

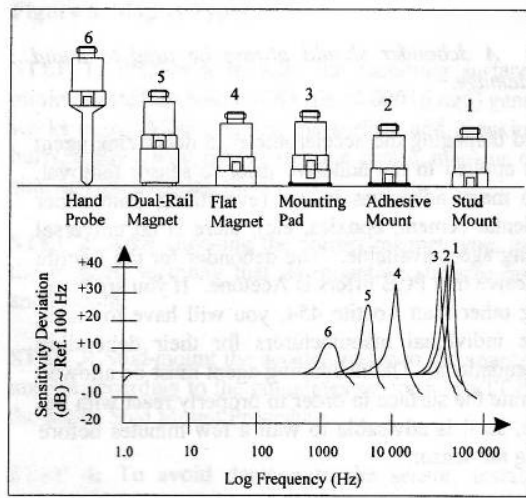

Figure 1. Assorted Mounting Configurations and Their Effects on High Frequency

\subsection{STUD MOUNT}

This mounting technique requires smooth, flat contact surfaces for proper operation and is recommended for permanent and/or secure installations. Stud mounting is also recommended when testing at high frequencies.

NOTE: Do NOT attempt mounting on curved, rough, or uneven surfaces, as the potential for misalignment and limited contact surface may significantly reduce the sensor's upper operating frequency range.

STEP 1: First, prepare a smooth, flat mounting surface, then drill and tap a mounting hole in the center of this are as shown in Figure 2 and in accordance with the enclosed Installation Drawing.

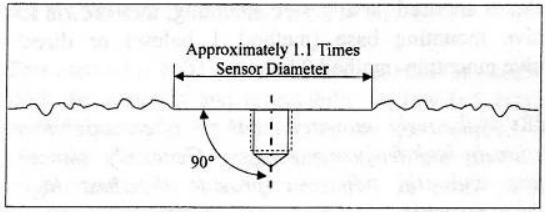

Figure 2. Mounting Surface Preparation

A precision-machined mounting surface with a minimum finish of $63 \mu \mathrm{in}(0.00016 \mathrm{~mm})$ is recommended. (If it is not possible to properly prepare the test structure mounting surface, consider adhesive mounting as a possible alternative). Inspect the area, checking that there are no burrs or other foreign particles interfering with the contact surface.

STEP 2: Wipe clean the mounting surface and spread on a light film of grease, oil, or similar coupling fluid prior to installation.

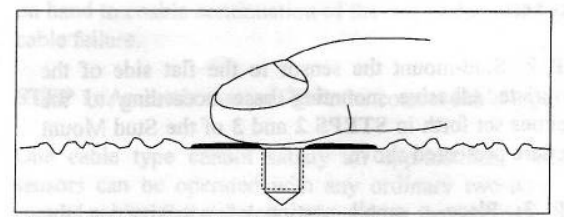

Figure 3. Mounting Surface Lubrication

Adding a coupling fluid improves vibration transmissibility by filling small voids in the mounting surface and increasing the mounting stiffness. For semipermanent mounting, substitute epoxy or another type of adhesive.

STEP 3: Screw the mounting stud into the base of accelerometer and hand-tighten (this step is unnecessary for units having an integral mounting stud). Then, screw the sensor into the tapped hole that was prepared in the test object. Tighten the unit in place by applying, with a torque wrench, the recommended mounting torque, as listed on the enclosed Installation Drawing.

NOTE: It is important to use a torque wrench during this step. Under-torquing the sensor may not adequately couple the device; over-torquing may result in stud failure.

\subsection{ADHESIVE MOUNT}

Adhesive mounting is often used for temporary installation or when the test object surface cannot be adequately prepared for stud mounting. Adhesives like hot glue and wax perform well for temporary installations whereas two-part epoxies and quick-bonding gels (super glue) provide a more permanent installation. Two 
techniques are used for adhesive mounting; they are via an adhesive mounting base (method 1 below) or direct adhesive mounting (method 2 below).

NOTE: Adhesively mounted sensors often exhibit a reduction in high-frequency range. Generally, smooth surfaces and stiff adhesives provide the best high frequency response.

\section{METHOD 1 - Adhesive Mounting Base}

This method involves attaching a base to the test structure, then securing the sensor to the base. This allows for easy removal of the accelerometer. Also, since many bases are manufactured of "hard-coated" aluminum, they provide electrical isolation to eliminate ground loops and reduce electrical interference that may propagate from the surface of the test object.

STEP 1: Prepare a smooth, flat mounting surface. A minimum surface finish of $63 \mu$ in $(0.00016 \mathrm{~mm})$ generally works best.

STEP 2: Stud-mount the sensor to the flat side of the appropriate adhesive mounting base according to the guidelines set forth in STEPS $\mathbf{2}$ and $\mathbf{3}$ of the Stud Mount Procedure presented above.

STEP 3: Place a small portion of adhesive on the underside of the mounting base (the underside is discernable by the concentric grooves which are designed to accept the adhesive). Firmly press down on the assembly to displace any extra adhesive remaining under the base.

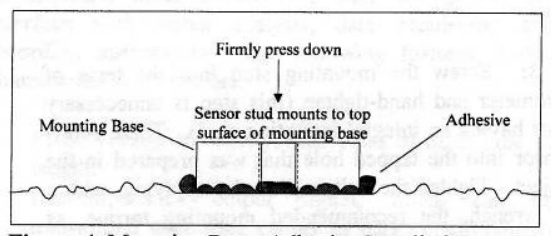

Figure 4. Mounting Base: Adhesive Installation

\section{METHOD 2 - Direct Adhesive Mount}

For restrictions of space or for convenience, most sensors can be adhesive-mounted directly to the test structure (an exception being units having integral mounting studs).

STEP 1: Prepare a smooth, flat mounting surface. A minimum surface finish of $63 \mu$ in $(0.00016 \mathrm{~mm})$ generally works best.

STEP 2: Place a small portion of adhesive on the underside of the sensor. Firmly press down on the top of the assembly to displace any adhesive. Be aware that excessive amounts of adhesive can make sensor removal difficult. Also, adhesive that may invade the tapped mounting hole in the base of the sensor will compromise future ability to stud mount the unit.

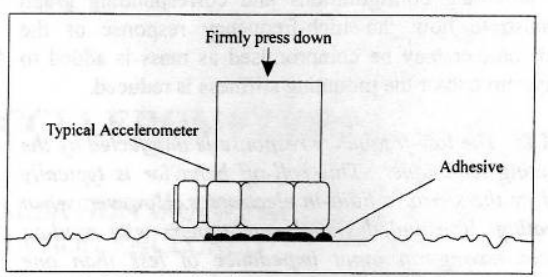

Figure 5. Direct Adhesive Mounting

4.2-1 ADHESIVE MOUNT REMOVAL (other than wax)

NOTE: A debonder should always be used to avoid sensor damage.

To avoid damaging the accelerometer, a debonding agent must be applied to the adhesive prior to sensor removal. With so many adhesives in use (everything from super glues, dental cement, epoxies, etc), there is no universal debonding agent available. The debonder for the Loctite 454 adhesive that PCB offers is Acetone. If you are using anything other than Loctite 454 , you will have to check with the individual manufacturers for their debonding recommendations. The debonding agent must be allowed to penetrate the surface in order to properly react with the adhesive, so it is advisable to wait a few minutes before removing the sensor.

After the debonding agent has set, you can use an ordinary open-end wrench if the accelerometer has a hex base or square base, or the supplied removal tool for teardrop accelerometers. After attaching either, use a gentle shearing (or twisting) motion (by hand only) to remove the sensor from the test structure.

\subsection{MAGNETIC MOUNT}

Magnetic mounting provides a convenient means for making quick, portable measurements and is commonly used for machinery condition monitoring, predictive maintenance, spot checks, and vibration trending applications.

NOTE: The correct magnet choice and an adequately prepared mounting surface are critical for obtaining reliable measurements, especially at high frequencies. Poor installations can cause as much as a 50\% drop in the sensor frequency range.

Not every magnet is suitable for all applications. For example, rare earth magnets are commonly used because 
of their high strength. Flat magnets work well on smooth, flat surfaces, while dual-rail magnets are required for curved surfaces such as motor housings and pipes. In the case of non-magnetic or rough surfaces, it is recommended that the user first weld, epoxy, or otherwise adhere a steel mounting pad to the test surface. This provides a smooth location for mounting and a target to insure that subsequent measurements for trending purposes are taken at the same location.

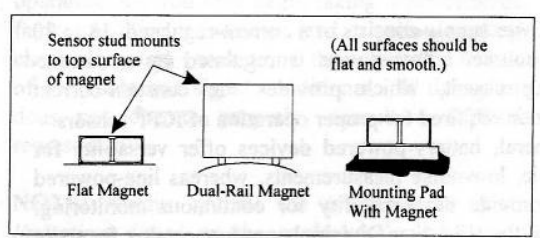

Figure 6. Magnet Types

STEP 1: Prepare a smooth, flat mounting surface. A minimum surface finish of $63 \mu$ in $(0.00016 \mathrm{~mm})$ generally works best. After cleaning the surface and checking for burrs, apply a light film of silicone grease, machine oil, or similar-type coupling fluid.

STEP 2: After choosing the correct magnet type, inspect the magnet, verifying that its mounting surfaces are flat and smooth.

STEP 3: Stud-mount the accelerometer to the appropriate magnet according to the guidelines set forth in STEP 3 of the above Stud Mount Procedure.

STEP 4: To avoid damage to the sensor, install the magnet/sensor assembly to the prepared test surface by gently "rocking" or "sliding" it into place.

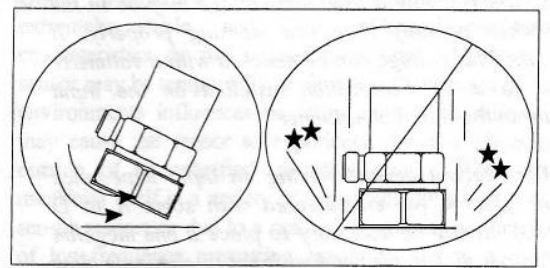

Figure 7. Magnet Mounting

CAUTION: Magnetically mounting of an accelerometer has the potential to generate very high (and very damaging) acceleration $(g)$ levels. To prevent such damage, exercise caution and install the assembly gently by rocking it into place. If shock is expected to be a particular concern, use a sensor with built-in shock protection. For further assistance, contact a factory representative.

\subsection{HANDHELD OR PROBE TIP MOUNT}

This method is NOT recommended for most applications. Both the accuracy and repeatability at low $(<5 \mathrm{~Hz})$ and high frequency $(>1 \mathrm{kHz})$ ranges are questionable. It is generally used only for machinery condition monitoring, when installation space is restricted, or other portable trending applications. The technique, however, can be useful for initially determining locations of greatest vibration to establish a permanent sensor installation point.

\subsection{CABLING}

Care and attention to cable installation and cable condition is essential as the reliability and accuracy of any measurement system is no better than that of its weakest link. Do to the nature of vibration measurements, all sensor cables will ultimately fatigue and fail. Good installation practice will extend the life of a cable, however, it is highly recommended to keep spare cables on hand to enable continuation of the test in the event of a cable failure.

STEP 1: Ascertain that you have the correct cable type.

One cable type cannot satisfy all applications. $\mathrm{ICP}^{\circledR}$ sensors can be operated with any ordinary two-wire or coaxial cable. Special, low-noise cables that are typically recommended for use with high-impedance, charge-output sensors can also be used. For applications requiring conformity to CE, low noise cables are essential. Industrial applications often require shielded, twisted-pair cables to reduce the effects of EMI and RFI that is present near electrical motors and machinery. Teflon-jacketed cabling may be necessary to withstand corrosive environments and higher temperatures. Consult the Vibration Division's product catalog for more information about cables or feel free to contact a factory representative for a specific recommendation on cables that are best suited for your application.

STEP 2: Connect the cable to the accelerometer.

A small amount of thread-locking compound placed on the connector threads prior to attachment helps secure the cable during testing. In wet, oily, or dirty environments, the connection can be sealed with silicone rubber sealant, $\mathrm{O}$-rings, and flexible, heat-shrink tubing.

Coaxial Cables: Make connection by inserting the cable's connector pin into the sensor's mating socket. Then thread the connector into place by turning the cable connector's outer shell onto the accelerometer's electrical connector.

NOTE: Do not spin the accelerometer while holding the cable connector stationary, as this will cause undue 
friction on the center pin of the cable connector and lead to premature fatigue.

Multi-pin connectors: Make connection by inserting the sensor's mating pins onto the cable connector's mating sockets. Then thread the connector into place by turning the cable connector's outer shell onto the accelerometer's electrical connector.

Pigtail Connections: Certain miniature accelerometers and shock sensors are provided with lightweight cables attached to "Pigtail" connections. This type of connection reduces overall weight and incidence of connection intermittency under shock conditions. In the event of a cable or connection failure, the cables may be repaired in the field simply by re-soldering the stripped leads to the exposed pins on the sensor. (Check the Installation Drawing to determine signal and ground pins). In many cases, it is also helpful to protect the solder joint with heat-shrink tubing or epoxy.

NOTE: If you do not have the experience or resources to attach pigtail leads, consult PCB to discuss factory attachment. Damage to internal electronics may be caused by excessive heat during soldering and such failure is not covered by warranty.

STEP 3: Route the cable to the signal conditioner, making certain to relieve stress on the sensor/cable connection. Also, minimize cable motion by securing it with tape, clamps or ties at regular intervals.

Common sense should be used to avoid physical damage and minimize electrical noise. For instance, avoid routing cables near high-voltage wires. Do not route cables along floors or walkways where they may be stepped on or become contaminated. To avoid ground loops, shielded cables should have the shield grounded at one end only, typically at the signal conditioner.

STEP 4: Finally, connect the remaining cable end to the signal conditioner. It is good practice to dissipate any electrical charge that may have accumulated in the cable by shorting the signal pin to the ground pin or shell prior to attachment.

\subsection{POWERING}

All ICP ${ }^{\circledast}$ sensors require constant current excitation for proper operation. For this reason, use only PCB constantcurrent signal conditioners or other approved constantcurrent sources. A typical system schematic is shown in Figure 8.

NOTE: Damage to the built-in electronics resulting from the application of incorrect power, or the use of an unapproved power source, is NOT covered by warranty.

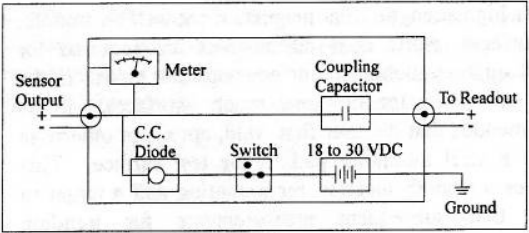

Figure 8. Typical System Schematic

The power supply consists of a current-regulated, 18 to 30 VDC source. This power is regulated by a currentlimiting circuit, which provides the constant-current excitation required for proper operation of $\mathrm{ICP}^{\circledast}$ sensors. In general, battery-powered devices offer versatility for portable, low-noise measurements, whereas line-powered units provide the capability for continuous monitoring. Consult the Vibration Division's product catalog for more information about signal conditioners.

NOTE: Under no circumstances should a voltage be supplied to an ICP ${ }^{\circledast}$ accelerometer without a currentregulating diode or equivalent electrical circuit. This may include ohmmeters, multi-meters and continuity testers.

Meters or LEDs are used on PCB signal conditioners to monitor the bias voltage on the sensor output signal, to check sensor operation, and detect cable faults. Normally, a "yellow" reading indicates an open circuit; "green" indicates normal operation; and "red" indicates either a short or overload condition. Finally, a capacitor at the output stage of the device removes the sensor output bias voltage from the measurement signal. This provides a zero-based, AC-coupled output signal that is compatible with most standard readout devices.

NOTE: Units having a low bias voltage may be in the "red," when actually they are working properly. If suspect, the bias voltage can be checked with a voltmeter attached to a " $T$ " connector installed on the input connector to the signal conditioner.

Note: For readout devices having an input impedance near one gigohm (as encountered with some $A$ to $D$ converters), it may be necessary to place a one megohm resistor in parallel to the readout input to eliminate slow turn-on and signal drift.

Today, many FFT analyzers, data acquisition modules, and data collectors have the proper constant-current excitation built-in for direct use with ICP sensors. Before using this feature, however, check that the supply voltage and constant current are within acceptable limits for use with your particular sensor. (Check enclosed Specification Sheet). Please contact the respective signal

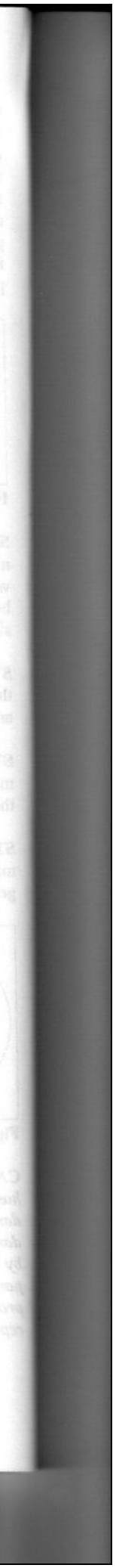


conditioner manufacturer or check the product manual for more information.

\subsection{OPERATING}

After completing the system setup, switch on the signal conditioner and allow 1 to 2 minutes for the system to stabilize. The meter (or LED) on the signal conditioner should be reading "green." This indicates proper operation and you may begin taking measurements. If a faulty condition is indicated (red or yellow reading), first check all system connections, then check the functionality of the cable and signal conditioner. If the system still does not operate properly, consult a PCB factory representative.

NOTE: Always operate the accelerometer within the limitations listed on the enclosed Specification Sheet. Operating the device outside these parameters can cause temporary or permanent damage to the sensor.

\subsection{ACCELEROMETER CALIBRATION}

Accelerometer calibration provides, with a definable degree of accuracy, the necessary link between the physical quantity being measured and the electrical signal generated by the sensor. In addition, other useful information concerning operational limits, physical parameters, electrical characteristics, or environmental influences may also be determined. Without this link, analyzing data becomes a nearly impossible task. Fortunately, most sensor manufacturers provide a calibration record that documents the exact characteristics of each sensor. (The type and amount of data varies depending on the manufacturer, sensor type, contractual regulations, and other special requirements).

Under normal conditions, piezoelectric sensors are extremely stable, and their calibrated performance characteristics do not change over time. However, the sensor may be temporarily or permanently affected by harsh environments influences or other unusual conditions that may cause the sensor to experience dynamic phenomena outside of its specified operating range. This change manifests itself in a variety of ways, including: a shift of the sensor resonance due to a cracked crystal; a temporary loss of low-frequency measuring capability due to a drop in insulation resistance; or total failure of the built-in microelectronic circuit due to a high mechanical shock.

For these reasons, it is recommended that a recalibration cycle be established for each accelerometer. This schedule is unique and is based on a variety of factors, such as: extent of use, environmental conditions, accuracy requirements, trend information obtained from previous calibration records, contractual regulations, frequency of "crosschecking" against other equipment, manufacturer recommendation, and any risk associated with incorrect readings. International standards, such as ISO 10012-1, provide insight and suggest methods for determining recalibration intervals for most measuring equipment. With the above information in mind and under "normal" circumstances, PCB conservatively suggests a 12 - to $24-$ month recalibration cycle for most piezoelectric accelerometers.

NOTE: It is good measurement practice to verify the performance of each accelerometer with a Handheld Shaker or other calibration device before and after each measurement. The PCB Handheld Shaker operates at a fixed frequency and known amplitude $(1.0 \mathrm{~g})$ to provide a quick check of sensor sensitivity.

\subsection{RECALIBRATION SERVICE}

PCB offers recalibration services for our piezoelectric accelerometers, as well as units produced by other manufacturers. Our internal metrology laboratory is certified to ISO 9001, accredited by A2LA to ANSI/IEC 17025 and ANSI/NCSL Z540-1, complies with ISO 10012-1 (and former MIL-STD-45662A), and uses equipment directly traceable to NIST. Our investment in equipment, traceability and conformance to industry standards ensures accurate calibration against relevant specifications, in a timely fashion.

\subsection{BACK-TO-BACK CALIBRATION THEORY}

Many companies choose to purchase the equipment necessary to perform the recalibration procedure in house. While this may result in both a savings of time and money, it has also been attributed to incorrect readings and costly errors. Therefore, in an effort to prevent the common mistakes associated with customer-performed calibration, this document includes a broad overview of the Back-to-Back Calibration technique. This technique provides a quick and easy method for determining the sensitivity of a test accelerometer over a wide frequency range.

Back-to-Back Calibration is perhaps the most common method for determining the sensitivity of piezoelectric accelerometers. This method relies on a simple comparison to a previously calibrated accelerometer, typically referred to as a reference standard.

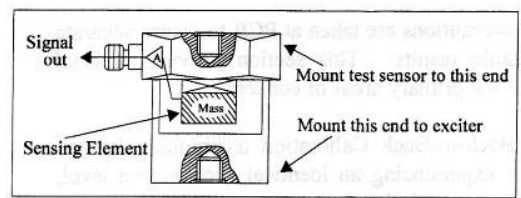

Figure 9. Reference Standard Accelerometer 
These high-accuracy devices, which are directly traceable to a recognized standards laboratory, are designed for stability, as well as configured to accept a test accelerometer. By mounting a test accelerometer to the reference standard and then connecting this combination to a suitable vibration source, it is possible to vibrate both devices and compare the data as shown in Figure 10. (Test set-ups may be automated and vary, depending on the type and number of accelerometers being calibrated).

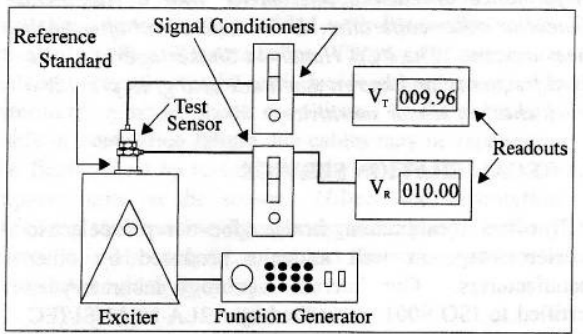

Figure 10. Typical Back-to-Back Calibration System

Because the acceleration is the same on both sensors, the ratio of their outputs $\left(\mathrm{V}_{\mathrm{T}} / \mathrm{V}_{\mathrm{R}}\right)$ must also be the ratio of their sensitivities. With the sensitivity of the reference standard $\left(S_{R}\right)$ known, the exact sensitivity of the test sensor $\left(\mathrm{S}_{\mathrm{T}}\right)$ is easily calculated by using the following equation:

$$
\mathrm{S}_{\mathrm{T}}=\mathrm{S}_{\mathrm{R}}\left(\mathrm{V}_{\mathrm{T}} / \mathrm{V}_{\mathrm{R}}\right)
$$

By varying the frequency of the vibration, the sensor may be calibrated over its entire operating frequency range The typical response of an unfiltered accelerometer is shown in Figure 11.

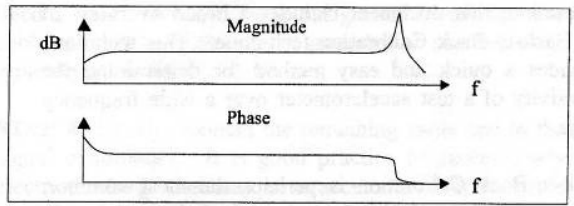

Figure 11. Typical Test Accelerometer Response

\subsection{PCB CALIBRATION PROCEDURE}

Numerous precautions are taken at PCB to insure accurate and repeatable results. This section provides a brief overview of the primary areas of concern.

Since the Back-to-Back Calibration technique relies on each sensor experiencing an identical acceleration level, proper mounting of the test sensor to the reference standard is imperative. Sensors with mounting holes are attached directly to the reference standard with a stud tightened to the recommended mounting torque. A shouldered mounting stud is typically used to prevent the stud from "bottoming out" in the hole. Both mounting surfaces are precision-machined and lapped to provide a smooth, flat interface according to the manufacturer's specification. A thin layer of silicone grease is placed between the mating surfaces to fill any imperfections and increase the mounting stiffness. The cables are stressrelieved by first routing them to the shaker head, then to a nearby stationary location. This reduces cable motion, which is especially important when testing charge output sensors, and helps to prevent extraneous motion or stresses from being imparted into the system. A typical set-up is shown in Figure 12.

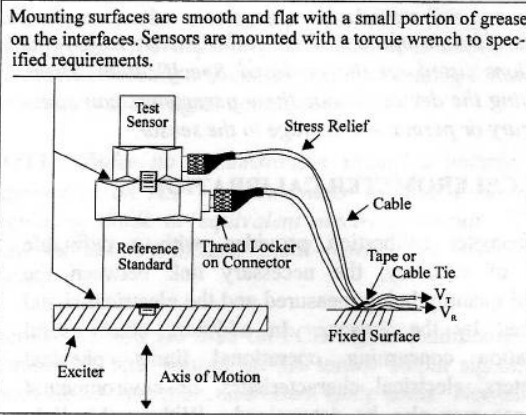

Figure 12. Typical Calibration Set-Up

Adhesively mounted sensors use similar practices. However, in this case, a small portion of quick-bonding gel, or similar temporary adhesive, is used to attach the test sensor to a reference standard designed with a smooth, flat mounting surface.

In addition to mounting, the selection of the proper equipment is critical. Some of the more important considerations include: 1) the reference standard must be specified and previously calibrated over the frequency and/or amplitude range of interest; 2) the shaker should be selected to provide minimal transverse (lateral) motion and minimal distortion; and 3 ) the quality of the meters, signal generator, and other devices should be selected so as to operate within the limits of permissible error.

\subsection{COMMON MISTAKES}

Most calibration errors are caused by simply overlooking some of the fundamental principals of dynamics. This section attempts to address some of the more common concerns.

For stud-mount sensors, always mount the accelerometer directly to the reference standard. Ensure that the mounting surfaces are smooth, flat, and free of any burrs. Always use a 
coupling fluid, such as silicone grease, in the mounting interface to maintain a high mounting stiffness. Mount the sensor according to the manufacturer's recommended mounting torque. DO NOT use any intermediate mounting adaptors, as the mounted resonant frequency may be reduced, and thereby compromise the high-frequency performance. If necessary, use adaptor studs.

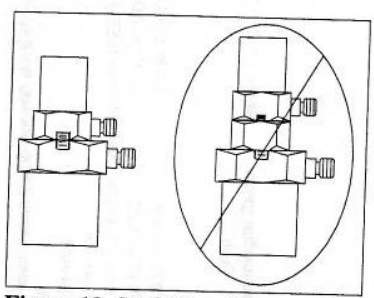

Figure 13. Stud Mounting

For adhesive mount sensors, use a thin, stiff layer of temporary adhesive such as quick-bonding gel or superglue. DO NOT use excessive amounts of glue or epoxy, as the mounting stiffness may be reduced and compromise highfrequency performance. It may also damage the sensor during removal.

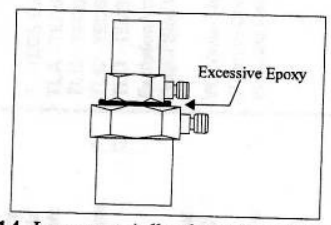

Figure 14. Incorrect Adhesive Mounting

Triaxial accelerometers should always be mounted directly to the reference standard. Unless absolutely required, DO NOT use adaptors to re-orient the sensor along the axis of motion, as the mounting stiffness may be altered. The vibration at the test sensor's sensing element may differ from the vibration at the reference standard due to "cantilever" effect, seen in Figure 15.

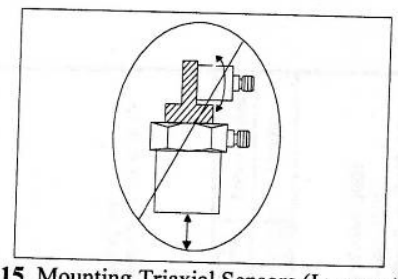

Figure 15. Mounting Triaxial Sensors (Incorrect)

Understand Back-to-Back Calibration limitations. Do not expect the uncertainty of calibration to be any better than $\pm 2 \%$. (In fact, the uncertainty may be as high as $\pm 3 \%$ or $\pm 4 \%$ for frequencies $<10 \mathrm{~Hz}$ or $>2 \mathrm{kHz}$.) Since large sensors may affect high-frequency accuracy, verify that the test sensor does not mass load the reference standard. Validate your calibration system with another accelerometer prior to each calibration session. Check with the manufacturer for exact system specifications.

\subsection{CONCLUSIONS}

Without an adequate understanding of dynamics, determining what, when, and how to test a sensor is a difficult task. Therefore, each user must weigh the cost, time, and risk associated with self-calibration versus utilizing the services of an accredited laboratory.

\subsection{SERVICE}

See the supplement sheet, contained in this manual, for information on our warranty, service, repair, and return policies and instructions.

When unexpected measurement problems arise, call our 24-hour SensorLine ${ }^{S M}$ to discuss your immediate dynamic instrumentation needs with a factory representative. Dial 716-684-0001. 


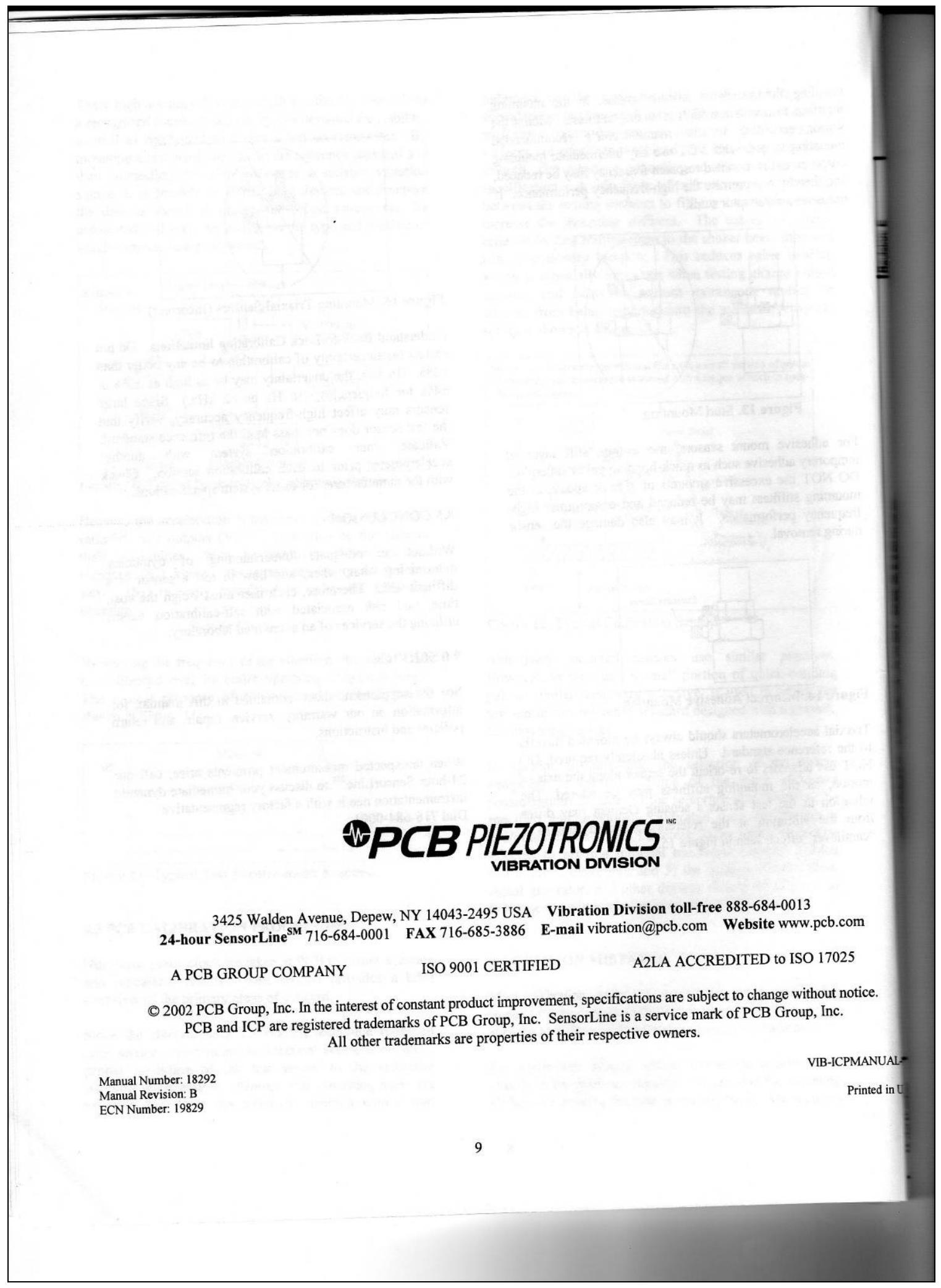




\section{A.2 Baseline Forced Vibration Testing}

\section{A.2.1 Natural Frequencies}
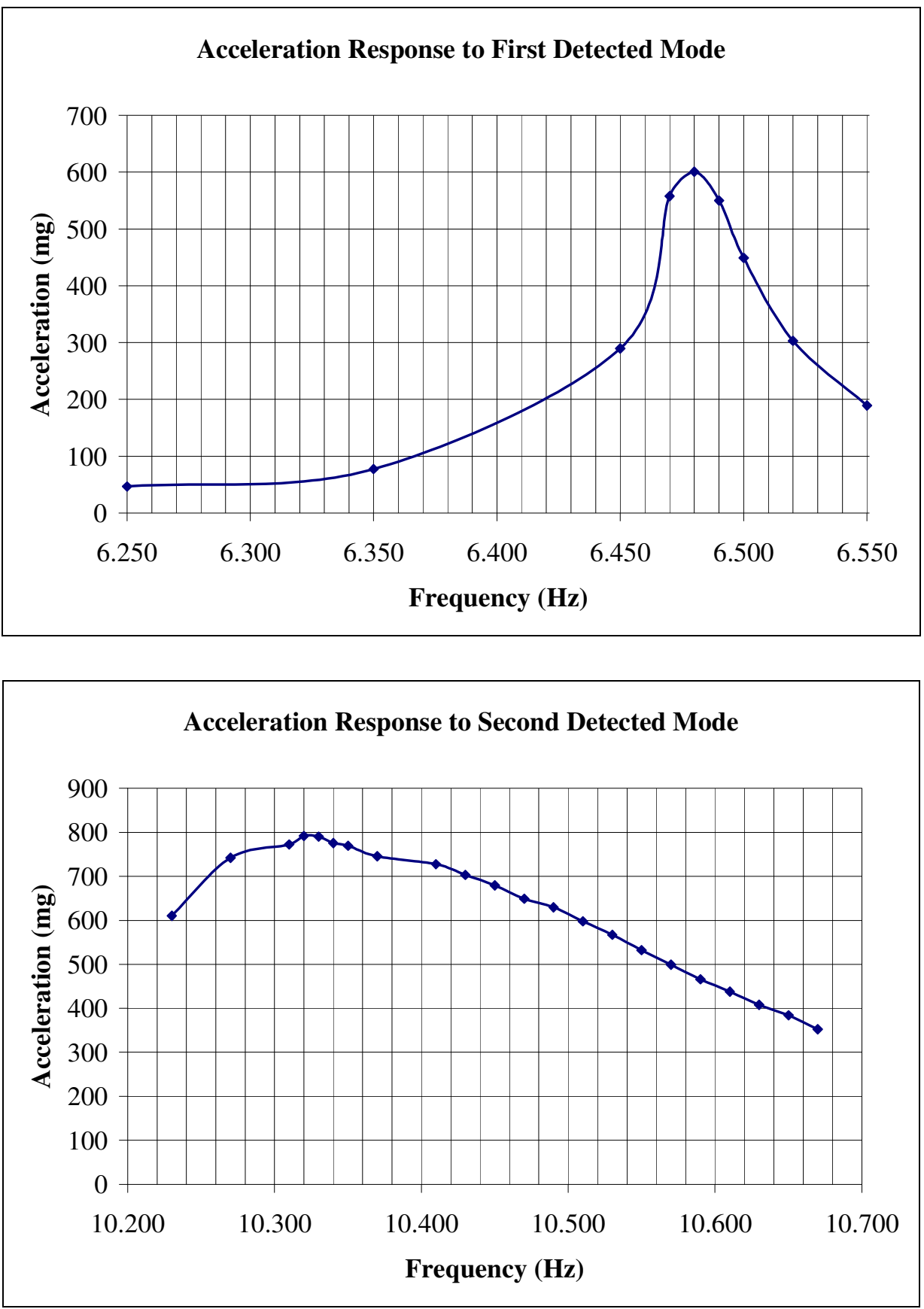

Identification of Physical Changes to a Steel Frame 

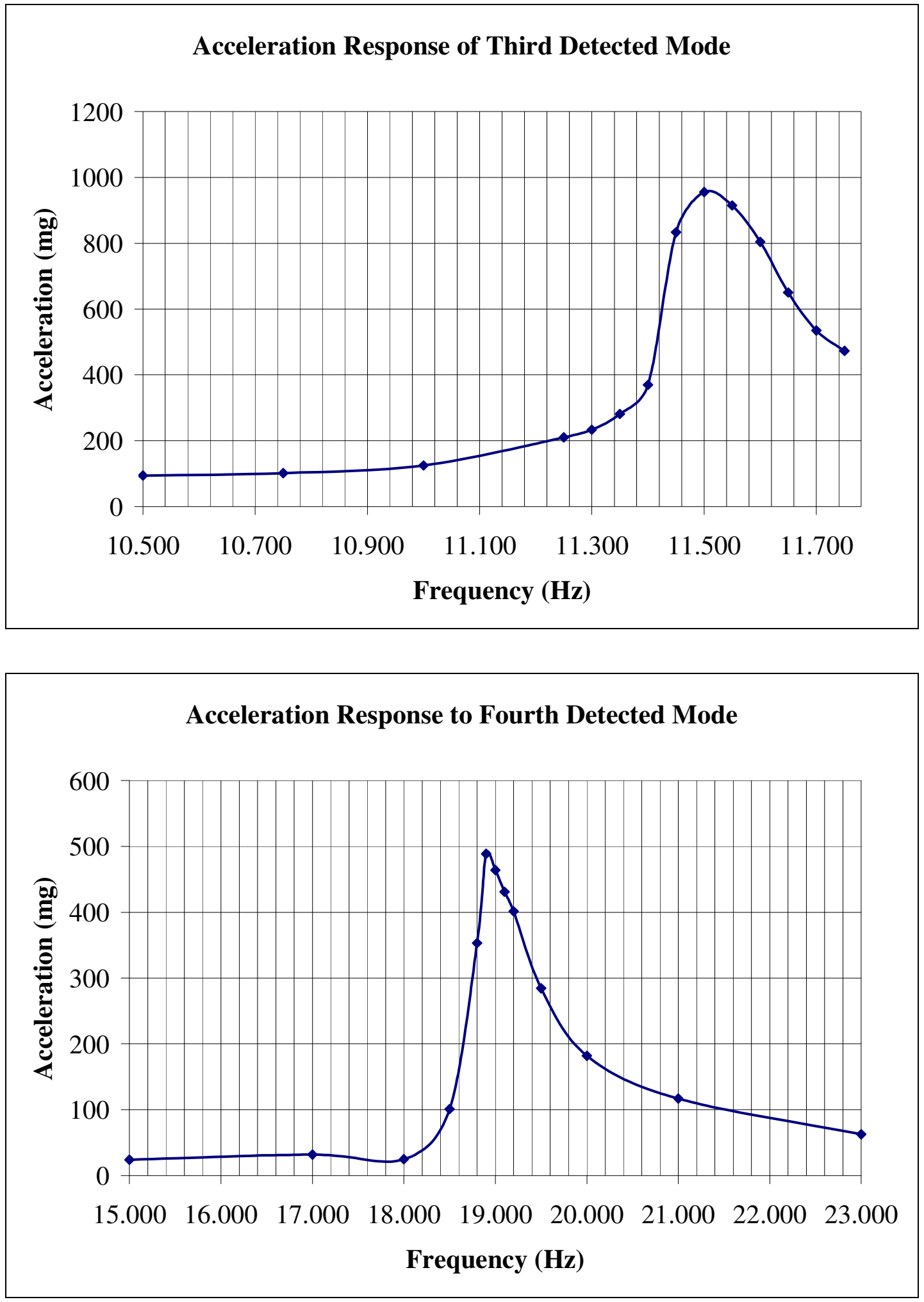

Identification of Physical Changes to a Steel Frame 


\begin{tabular}{|c|c|c|c|c|}
\hline \multicolumn{5}{|c|}{ First Detected Mode } \\
\hline $\mathrm{f}$ & $\mathrm{a} 1$ & $\mathrm{a} 2$ & $\mathrm{a} 3$ & a avg \\
\hline 6.250 & 45.2 & 47.2 & 46.2 & 46.20 \\
\hline 6.350 & 77.0 & 77.1 & 77.3 & 77.13 \\
\hline 6.450 & 293.2 & 287.4 & 290.1 & 290.23 \\
\hline 6.470 & 560.3 & 559.7 & 558.9 & 559.63 \\
\hline $\mathbf{6 . 4 8 0}$ & $\mathbf{6 0 1 . 2}$ & $\mathbf{6 0 0 . 6}$ & $\mathbf{6 0 1 . 0}$ & $\mathbf{6 0 0 . 9 3}$ \\
\hline 6.490 & 554.2 & 553.4 & 552.2 & 553.27 \\
\hline 6.500 & 450.9 & 451.2 & 448.9 & 450.33 \\
\hline 6.520 & 301.4 & 302.9 & 302.8 & 302.37 \\
\hline 6.550 & 190.5 & 188.3 & 189.9 & 189.57 \\
\hline
\end{tabular}

\begin{tabular}{|c|c|c|c|c|}
\hline \multicolumn{5}{|c}{ Second Detected Mode } \\
\hline $\mathrm{f}$ & $\mathrm{a} 1$ & $\mathrm{a} 2$ & $\mathrm{a} 3$ & $\mathrm{a}$ avg \\
\hline 10.230 & 611.5 & 609.3 & 610.1 & 610.30 \\
\hline 10.270 & 744.8 & 741.4 & 740.0 & 742.07 \\
\hline 10.310 & 770.8 & 773.8 & 772.3 & 772.30 \\
\hline $\mathbf{1 0 . 3 2 0}$ & $\mathbf{7 9 1 . 6}$ & $\mathbf{7 9 2 . 6}$ & $\mathbf{7 9 0 . 5}$ & $\mathbf{7 9 1 . 5 7}$ \\
\hline 10.330 & 793.6 & 789.8 & 787.4 & 790.27 \\
\hline 10.340 & 780.1 & 770.2 & 776.9 & 775.73 \\
\hline 10.350 & 770.6 & 770.0 & 767.9 & 769.50 \\
\hline 10.370 & 747.4 & 747.4 & 741.0 & 745.27 \\
\hline 10.410 & 730.8 & 726.9 & 725.1 & 727.60 \\
\hline 10.430 & 708.2 & 702.5 & 699.3 & 703.33 \\
\hline 10.450 & 683.1 & 678.2 & 677.6 & 679.63 \\
\hline 10.470 & 644.8 & 651.1 & 651.5 & 649.13 \\
\hline 10.490 & 630.9 & 631.4 & 626.8 & 629.70 \\
\hline 10.510 & 605.4 & 597.3 & 590.0 & 597.57 \\
\hline 10.530 & 567.6 & 566.8 & 567.5 & 567.30 \\
\hline 10.550 & 535.5 & 531.6 & 529.2 & 532.10 \\
\hline 10.570 & 500.7 & 500.1 & 497.0 & 499.27 \\
\hline 10.590 & 465.4 & 464.4 & 467.7 & 465.83 \\
\hline 10.610 & 439.5 & 438.4 & 435.9 & 437.93 \\
\hline 10.630 & 409.2 & 406.3 & 407.8 & 407.77 \\
\hline 10.650 & 383.7 & 386.8 & 381.6 & 384.03 \\
\hline 10.670 & 351.9 & 354.4 & 350.8 & 352.37 \\
\hline
\end{tabular}




\begin{tabular}{|c|c|c|c|c|}
\hline \multicolumn{5}{|c|}{ Third Detected Mode } \\
\hline $\mathrm{f}$ & $\mathrm{a} 1$ & $\mathrm{a} 2$ & $\mathrm{a} 3$ & $\mathrm{a}$ avg \\
\hline 11.25 & 207.9 & 213 & 208.6 & 209.8333 \\
\hline 11.3 & 231.5 & 234.5 & 234.1 & 233.3667 \\
\hline 11.35 & 281.5 & 281.6 & 281.5 & 281.5333 \\
\hline 11.4 & 369.7 & 371 & 367.5 & 369.4 \\
\hline 11.45 & 827.8 & 830.5 & 841 & 833.1 \\
\hline $\mathbf{1 1 . 5}$ & $\mathbf{9 5 5}$ & $\mathbf{9 5 9 . 1}$ & $\mathbf{9 5 2 . 6}$ & $\mathbf{9 5 5 . 5 6 6 7}$ \\
\hline 11.55 & 908.5 & 915.6 & 920.5 & 914.8667 \\
\hline 11.6 & 792.6 & 806.7 & 813.6 & 804.3 \\
\hline 11.65 & 642.2 & 653.5 & 656.3 & 650.6667 \\
\hline 11.7 & 531.2 & 535.6 & 538.2 & 535 \\
\hline 11.75 & 472 & 475.3 & 471.8 & 473.0333 \\
\hline
\end{tabular}

\begin{tabular}{|c|c|c|c|c|c|c|}
\hline \multicolumn{7}{|c|}{ Fourth Detectected Mode } \\
\hline $\mathrm{f}$ & $\mathrm{a} 1$ & $\mathrm{a} 2$ & $\mathrm{a} 3$ & $\mathrm{a} 4$ & $\mathrm{a} 5$ & $\mathrm{a}$ avg \\
\hline 15.000 & 23.8 & 24.0 & & & & 23.90 \\
\hline 17.000 & 32.7 & 32.7 & 30.0 & & & 31.80 \\
\hline 18.000 & 24.6 & 25.0 & 24.4 & & & 24.67 \\
\hline 18.500 & 101.8 & 100.7 & 101.2 & 100.7 & 100.3 & 100.94 \\
\hline 18.800 & 354.8 & 349.5 & 352.6 & 353.7 & 354.8 & 353.08 \\
\hline $\mathbf{1 8 . 9 0 0}$ & $\mathbf{4 8 9 . 1}$ & $\mathbf{4 8 8 . 8}$ & $\mathbf{4 8 7 . 6}$ & $\mathbf{4 8 7 . 9}$ & $\mathbf{4 8 9 . 5}$ & $\mathbf{4 8 8 . 5 8}$ \\
\hline 19.000 & 466.0 & 460.2 & 462.9 & 466.7 & 463.5 & 463.86 \\
\hline 19.100 & 425.1 & 430.1 & 430.4 & 434.9 & 434.6 & 431.02 \\
\hline 19.200 & 397.3 & 400.1 & 400.3 & 403.4 & 405.2 & 401.26 \\
\hline 19.500 & 280.7 & 282.7 & 285.2 & 286.5 & 287.7 & 284.56 \\
\hline 20.000 & 180.6 & 181.6 & 182.3 & 182.6 & 182.9 & 182.00 \\
\hline 21.000 & 116.7 & 117.3 & & & & 117.00 \\
\hline 23.000 & 63.2 & 62.0 & & & & 62.60 \\
\hline
\end{tabular}




\section{A.2.2 Recorded Mode Shapes}

\begin{tabular}{|c|c|c|c|c|c|c|c|c|c|c|}
\hline Mode Shapes & $\mathrm{V}$ & \multicolumn{3}{|c|}{ Roof } & \multicolumn{3}{|c|}{ Floor } & \multicolumn{3}{|c|}{ Ratio } \\
\hline \multirow{5}{*}{$6.48 \mathrm{~Hz}$} & \multirow{4}{*}{1} & $\mathrm{x} 1$ & $\mathrm{y} 1$ & $\mathrm{y} 2$ & $\mathrm{x} 1$ & $\mathrm{y} 1$ & $\mathrm{y} 2$ & $\mathrm{x} 1$ & $\mathrm{y} 1$ & $\mathrm{y} 2$ \\
\hline & & 62 & 396 & 420 & 29 & 264 & 288 & & & \\
\hline & & 65 & 379 & 420 & 30 & 263 & 288 & & & \\
\hline & & 54 & 405 & 421 & 29 & 262 & 286 & & & \\
\hline & Average --> & 58.5 & 392.0 & 420.8 & 29.3 & 263.0 & 287.3 & 2.0 & 1.49 & 1.46 \\
\hline \multirow{4}{*}{$18.65 \mathrm{~Hz}$} & \multirow{3}{*}{ (1) } & 5.78 & 74.7 & 94.7 & 6.6 & 139 & 141 & & & \\
\hline & & 5.82 & 74.6 & 94.9 & 18.0 & 140 & 140 & & & \\
\hline & & 5.97 & 74.7 & 95.0 & 18.4 & 141 & 140 & & & \\
\hline & Average --> & 5.868 & 74.58 & 94.53 & 13.30 & 139.5 & 140.5 & 0.44 & 0.53 & 0.67 \\
\hline \multirow{2}{*}{$18.90 \mathrm{~Hz}$} & 1 & $\mathrm{x} 1$ & $\mathrm{y} 1$ & $\mathrm{y} 2$ & $\mathrm{x} 1$ & $\mathrm{y} 1$ & $\mathrm{y} 2$ & $\mathrm{x} 1$ & $\mathrm{y} 1$ & $\mathrm{y} 2$ \\
\hline & Average -.> & 21.10 & 72.10 & 74.85 & 14.68 & 105.0 & 107.5 & 1.4 & 0.69 & 0.70 \\
\hline \multirow{6}{*}{$21.12 \mathrm{~Hz}$} & \multirow{5}{*}{ ond } & $\mathrm{x} 1$ & $\mathrm{y} 1$ & $\mathrm{y} 2$ & $\mathrm{x} 1$ & $\mathrm{y} 1$ & $\mathrm{y} 2$ & $\mathrm{x} 1$ & $\mathrm{y} 1$ & $\mathrm{y} 2$ \\
\hline & & 32.1 & 36.0 & 15.1 & 18.2 & 15.9 & 32.4 & & & \\
\hline & & 32.3 & 36.0 & 15.1 & 18.2 & 15.8 & 33.2 & & & \\
\hline & & 32.1 & 35.9 & 15.0 & 18.2 & 15.8 & 31.1 & & & \\
\hline & & 32.1 & 35.9 & 14.9 & 18.1 & 15.7 & 30.9 & & & \\
\hline & Average --> & 32.15 & 35.95 & 15.03 & 18.18 & 15.80 & 31.90 & 1.77 & 2.28 & 0.47 \\
\hline
\end{tabular}

\section{A.2.3 ETABS Mode Shapes}

\begin{tabular}{|l|r|r|r|r|r|r|r|r|}
\hline Mode & Floor NW & Floor NE & Floor SE & Floor SW & Roof NW & Roof NE & Roof SE & Roof SW \\
\hline 1 - Weak Axis & 8.96 & 8.96 & 8.96 & 8.96 & 14.1 & 14.1 & 14.1 & 14.1 \\
\hline 2 - Strong Axis & 9.2 & 9.2 & 9.2 & 9.2 & 13.5 & 13.5 & 13.5 & 13.5 \\
\hline 3- Strong Axis & -7.86 & -7.86 & 7.86 & 7.86 & -11.6 & -11.6 & 11.6 & 11.6 \\
\hline 3- Weak Axis & 10.8 & -10.8 & -10.8 & 10.8 & 15.3 & -15.3 & -15.3 & 15.3 \\
\hline 4 - Weak Axis & 13.6 & 13.6 & 13.6 & 13.6 & -8.86 & -8.86 & -8.86 & -8.86 \\
\hline 5 - Strong Axis & -10.5 & -10.5 & 10.5 & 10.5 & 8.51 & 8.51 & -8.51 & -8.51 \\
\hline 5 - Weak Axis & -14.3 & 14.3 & 14.3 & -14.3 & 11.5 & -11.5 & -11.5 & 11.5 \\
\hline 6 - Strong Axis & 13.2 & 13.2 & 13.2 & 13.2 & -9.33 & -9.33 & -9.33 & -9.33 \\
\hline
\end{tabular}




\section{A.3 Roof Mass FVT}

\section{A.3.1 Natural Frequencies}

\section{First Detected Mode}
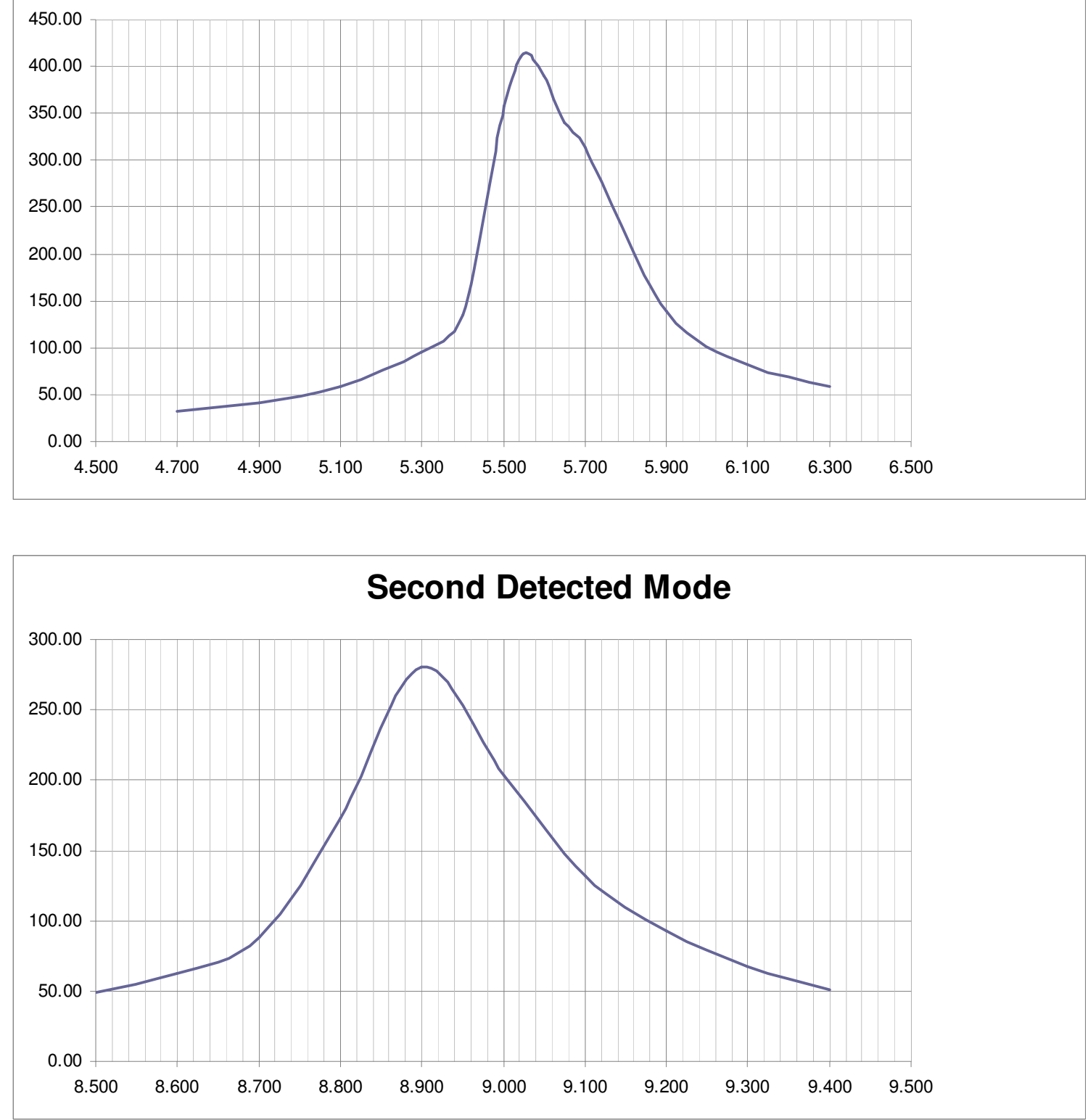

Identification of Physical Changes to a Steel Frame 


\section{Third Detected Mode}

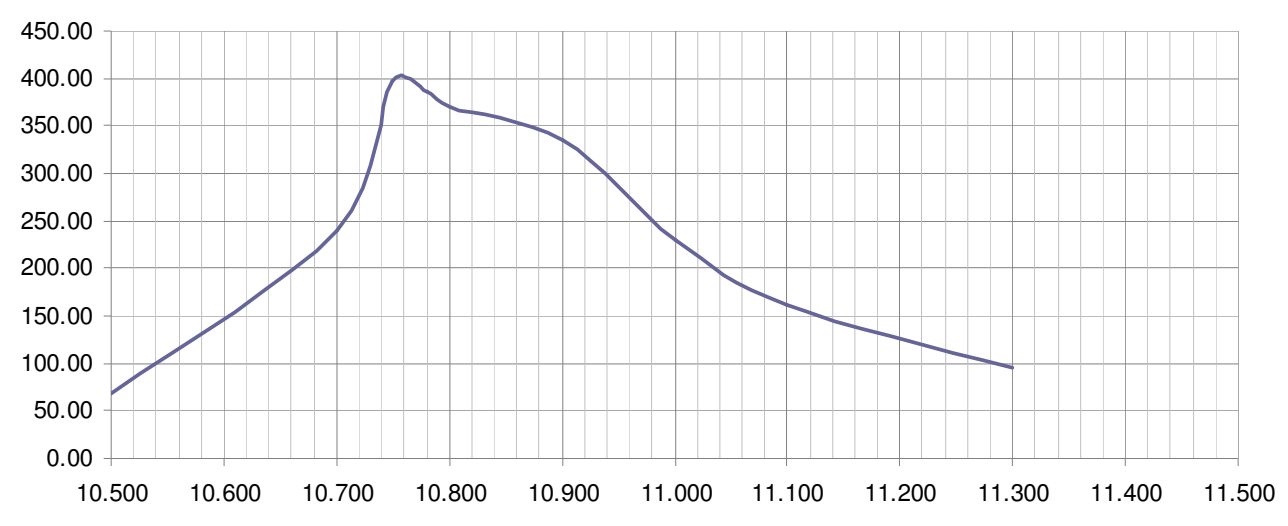

Fourth Detected Mode

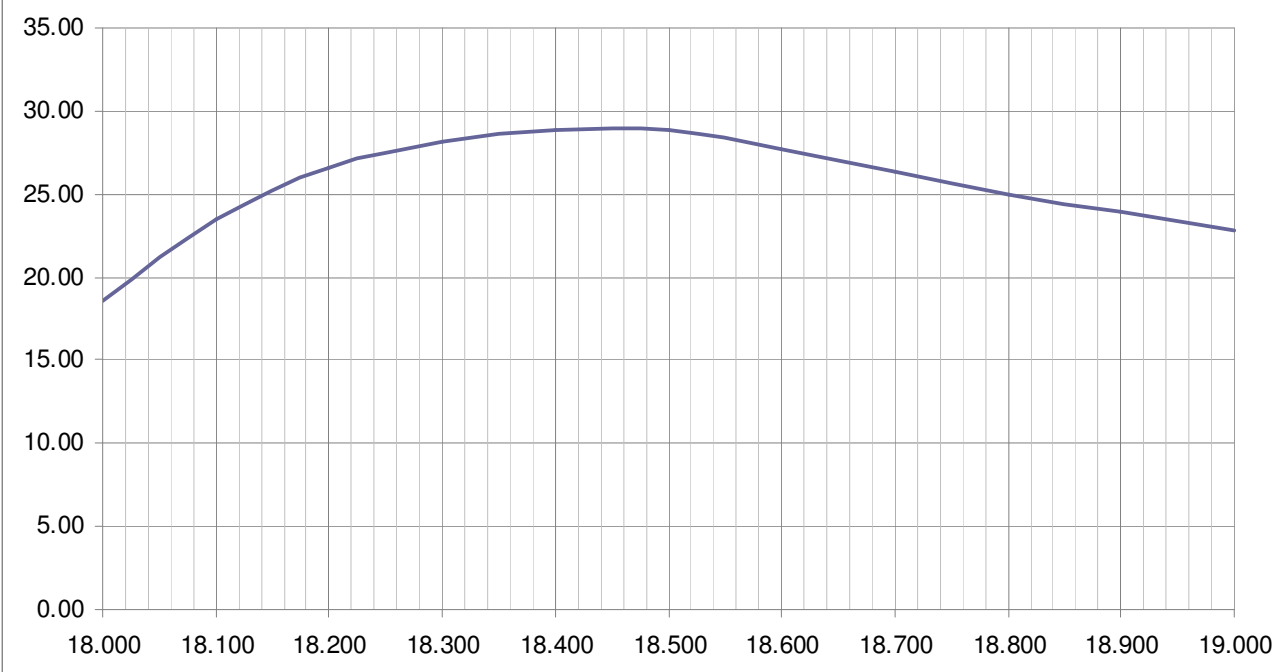




\begin{tabular}{|r|r|r|r|r|r|r|}
\hline \multicolumn{7}{|c|}{ First Detected Mode } \\
\hline \multicolumn{1}{|r|}{} & a1 & a2 & a3 & a4 & \multicolumn{1}{l|}{ a5 } & a avg \\
\hline 4.700 & 31.8 & 31.9 & 31.9 & & & 31.87 \\
\hline 4.900 & 41.4 & 41.3 & 41.2 & & & 41.30 \\
\hline 5.100 & 58.1 & 58.0 & 57.9 & 57.8 & & 57.95 \\
\hline 5.300 & 95.2 & 95.1 & 95.0 & 94.9 & 94.7 & 94.98 \\
\hline 5.400 & 135.0 & 135.0 & 135.0 & 134.0 & 134.0 & 134.60 \\
\hline 5.500 & 350.0 & 356.0 & 358.0 & 361.0 & 362.0 & 357.40 \\
\hline $\mathbf{5 . 5 5 0}$ & $\mathbf{4 1 6 . 0}$ & $\mathbf{4 1 3 . 0}$ & $\mathbf{4 1 2 . 0}$ & $\mathbf{4 1 2 . 0}$ & $\mathbf{4 1 2 . 0}$ & $\mathbf{4 1 3 . 0 0}$ \\
\hline 5.600 & 391.0 & 390.0 & 391.0 & 390.0 & 390.0 & 390.40 \\
\hline 5.650 & 337.0 & 339.0 & 341.0 & 342.0 & 341.0 & 340.00 \\
\hline 5.700 & 310.0 & 313.0 & 315.0 & 317.0 & 316.0 & 314.20 \\
\hline 5.900 & 139.0 & 140.0 & 140.0 & 140.0 & & 139.75 \\
\hline 6.100 & 81.8 & 81.9 & 82.0 & 81.9 & & 81.90 \\
\hline 6.300 & 58.3 & 58.3 & 58.3 & & & 58.30 \\
\hline
\end{tabular}

\begin{tabular}{|r|r|r|r|r|r|r|}
\hline \multicolumn{7}{|c|}{ Second Detected Mode } \\
\hline \multicolumn{1}{|r|}{} & a1 & a2 & a3 & a4 & a5 & a avg \\
\hline 8.500 & 48.8 & 48.7 & 48.6 & & & 48.70 \\
\hline 8.600 & 62.5 & 62.6 & 62.4 & & & 62.50 \\
\hline 8.700 & 88.0 & 87.8 & 87.8 & & & 87.87 \\
\hline 8.800 & 172.0 & 173.0 & 174.0 & 173.0 & & 173.00 \\
\hline $\mathbf{8 . 9 0 0}$ & $\mathbf{2 7 6 . 0}$ & $\mathbf{2 7 4 . 0}$ & $\mathbf{2 7 9 . 0}$ & $\mathbf{2 8 6 . 0}$ & $\mathbf{2 8 5 . 0}$ & $\mathbf{2 8 0 . 0 0}$ \\
\hline 9.000 & 201.0 & 203.0 & 204.0 & 204.0 & 205.0 & 203.40 \\
\hline 9.100 & 130.0 & 132.0 & 132.0 & 133.0 & & 131.75 \\
\hline 9.200 & 92.9 & 93.3 & 93.7 & & & 93.30 \\
\hline 9.300 & 67.5 & 67.7 & 68.2 & & & 67.80 \\
\hline 9.400 & 50.9 & 51.3 & 51.3 & & & 51.17 \\
\hline
\end{tabular}




\begin{tabular}{|r|r|r|r|r|r|r|}
\hline \multicolumn{7}{|c|}{ Third Detected Mode } \\
\hline f & a1 & a2 & a3 & a4 & a5 & a avg \\
\hline 10.500 & 68.3 & 68.3 & 68.2 & & & 68.27 \\
\hline 10.700 & 243.0 & 244.0 & 236.0 & 236.0 & & 239.75 \\
\hline $\mathbf{1 0 . 7 5 0}$ & $\mathbf{4 0 2 . 0}$ & $\mathbf{3 9 9 . 0}$ & $\mathbf{3 9 7 . 0}$ & $\mathbf{3 9 6 . 0}$ & $\mathbf{3 9 5 . 0}$ & $\mathbf{3 9 7 . 8 0}$ \\
\hline 10.780 & 387.0 & 385.0 & 385.0 & 385.0 & 385.0 & 385.40 \\
\hline 10.800 & 365.0 & 371.0 & 372.0 & 370.0 & 370.0 & 369.60 \\
\hline 10.900 & 331.0 & 334.0 & 336.0 & 338.0 & 336.0 & 335.00 \\
\hline 11.000 & 229.0 & 230.0 & 231.0 & 232.0 & 231.0 & 230.60 \\
\hline 11.100 & 161.0 & 162.0 & 163.0 & 164.0 & & 162.50 \\
\hline 11.300 & 94.6 & 95.1 & 95.3 & & & 95.00 \\
\hline
\end{tabular}

\begin{tabular}{|r|r|r|r|r|r|r|}
\hline \multicolumn{7}{|c|}{ Fourth Detected Mode } \\
\hline f & a1 & a2 & a3 & a4 & \multicolumn{1}{l|}{ a5 } & \multicolumn{1}{l|}{ a avg } \\
\hline 18.000 & 18.6 & 18.6 & 18.4 & & & 18.53 \\
\hline 18.100 & 24.4 & 23.2 & 23.0 & & & 23.53 \\
\hline 18.200 & 26.6 & 26.5 & 26.4 & 26.9 & & 26.60 \\
\hline 18.300 & 28.4 & 28.2 & 28.2 & 28.1 & 28.1 & 28.20 \\
\hline $\mathbf{1 8 . 4 0 0}$ & $\mathbf{2 8 . 6}$ & $\mathbf{2 8 . 8}$ & $\mathbf{2 8 . 8}$ & $\mathbf{2 8 . 9}$ & $\mathbf{2 9 . 1}$ & $\mathbf{2 8 . 8 4}$ \\
\hline $\mathbf{1 8 . 5 0 0}$ & $\mathbf{2 8 . 7}$ & $\mathbf{2 8 . 8}$ & $\mathbf{2 8 . 9}$ & $\mathbf{2 8 . 9}$ & $\mathbf{2 8 . 9}$ & $\mathbf{2 8 . 8 5}$ \\
\hline 18.600 & 27.7 & 27.7 & 27.6 & 27.7 & 27.7 & 27.68 \\
\hline 18.700 & 26.3 & 26.3 & 26.3 & 26.3 & & 26.30 \\
\hline 18.800 & 25.0 & 25.0 & 25.0 & 25.0 & & 25.00 \\
\hline 18.900 & 23.9 & 23.9 & 23.9 & & & 23.90 \\
\hline 19.000 & 22.8 & 22.9 & 22.8 & & & 22.83 \\
\hline
\end{tabular}




\section{A.3.2 Recorded Mode Shapes}

\begin{tabular}{|c|c|c|c|c|c|c|c|c|c|c|}
\hline Mode Shapes & V & \multicolumn{3}{|c|}{ Roof } & \multicolumn{3}{|c|}{ Floor } & \multicolumn{3}{|c|}{ Ratio } \\
\hline \multirow{6}{*}{$5.55 \mathrm{~Hz}$} & \multirow{5}{*}{1} & $\mathrm{x} 1$ & $\mathrm{y} 1$ & $\mathrm{y} 2$ & $\mathrm{x} 1$ & $\mathrm{y} 1$ & $\mathrm{y} 2$ & $\mathrm{x} 1$ & $\mathrm{y} 1$ & $\mathrm{y} 2$ \\
\hline & & 22.8 & 408 & 337 & 27.6 & 232 & 218 & & & \\
\hline & & 22.8 & 408 & 337 & 27.5 & 233 & 218 & & & \\
\hline & & 22.7 & 407 & 336 & 27.4 & 232 & 218 & & & \\
\hline & & 22.6 & 406 & 336 & 27.4 & 232 & 217 & & & \\
\hline & Average --> & 22.7 & 407.3 & 336.5 & 27.5 & 232.3 & 217.8 & 0.83 & 1.75 & 1.55 \\
\hline
\end{tabular}

\begin{tabular}{|c|c|c|c|c|c|c|c|c|c|c|}
\hline Mode Shapes & V & \multicolumn{3}{|c|}{ Roof } & \multicolumn{3}{|c|}{ Floor } & \multicolumn{3}{|c|}{ Ratio } \\
\hline \multirow{6}{*}{$8.91 \mathrm{~Hz}$} & \multirow{5}{*}{1} & $\mathrm{x} 1$ & $\mathrm{y} 1$ & $\mathrm{y} 2$ & $\mathrm{x} 1$ & $\mathrm{y} 1$ & $\mathrm{y} 2$ & $\mathrm{x} 1$ & $\mathrm{y} 1$ & y2 \\
\hline & & 119 & 21.9 & 56.40 & 63.30 & 11.5 & 33.4 & & & \\
\hline & & 117 & 22 & 56.00 & 63.30 & 11.5 & 33.0 & & & \\
\hline & & 117 & 22.4 & 56.00 & 65.80 & 11.6 & 32.7 & & & \\
\hline & & 118 & 21.4 & 55.60 & 64.60 & 11.7 & 32.5 & & & \\
\hline & Average --> & 117.8 & 21.9 & 56.0 & 64.3 & 11.6 & 32.9 & 1.83 & 1.89 & 1.70 \\
\hline
\end{tabular}

\begin{tabular}{|c|c|c|c|c|c|c|c|c|c|c|}
\hline \begin{tabular}{|l|} 
Mode Shapes \\
\end{tabular} & \multirow[t]{2}{*}{$\mathrm{V}$} & \multicolumn{3}{|c|}{ Roof } & \multicolumn{3}{|c|}{ Floor } & \multicolumn{3}{|c|}{ Ratio } \\
\hline \multirow{6}{*}{$10.75 \mathrm{~Hz}$} & & $\mathrm{x} 1$ & $\mathrm{y} 1$ & y2 & $\mathrm{x} 1$ & $\mathrm{y} 1$ & $\mathrm{y} 2$ & $\mathrm{x} 1$ & $\mathrm{y} 1$ & $\mathrm{y} 2$ \\
\hline & \multirow{4}{*}{1} & 261 & 402 & 553 & 250 & 142 & 300 & & & \\
\hline & & 260 & 399 & 550 & 254 & 144 & 300 & & & \\
\hline & & 258 & 397 & 548 & 252 & 144 & 301 & & & \\
\hline & & 257 & 396 & 541 & 253 & 144 & 301 & & & \\
\hline & Average -.> & 259.0 & 398.5 & 548.0 & 252.3 & 143.5 & 300.5 & 1.03 & 2.78 & 1.82 \\
\hline
\end{tabular}

\begin{tabular}{|c|c|c|c|c|c|c|c|c|c|c|}
\hline \begin{tabular}{|l|} 
Mode Shapes \\
\end{tabular} & \multirow[t]{2}{*}{$\mathrm{V}$} & \multicolumn{3}{|c|}{ Roof } & \multicolumn{3}{|c|}{ Floor } & \multicolumn{3}{|c|}{ Ratio } \\
\hline \multirow{6}{*}{$18.46 \mathrm{~Hz}$} & & $\mathrm{x} 1$ & $\mathrm{y} 1$ & y2 & $\mathrm{x} 1$ & $\mathrm{y} 1$ & $\mathrm{y} 2$ & $\mathrm{x} 1$ & $\mathrm{y} 1$ & $\mathrm{y} 2$ \\
\hline & \multirow{4}{*}{1} & 16.8 & 28.7 & 29.4 & 8.70 & 63.0 & 65.7 & & & \\
\hline & & 16.7 & 28.2 & 30.6 & 9.73 & 63.6 & 65.7 & & & \\
\hline & & 16.6 & 28.2 & 29.5 & 9.87 & 63.6 & 66.1 & & & \\
\hline & & 16.6 & 29.0 & 32.5 & 8.95 & 63.2 & 66.5 & & & \\
\hline & Average -.> & 16.7 & 28.5 & 30.5 & 9.3 & 63.4 & 66.0 & 1.79 & 0.45 & 0.46 \\
\hline
\end{tabular}




\section{A.4 Roof Mass and Braces FVT}

\section{A.4.1 Natural Frequencies}
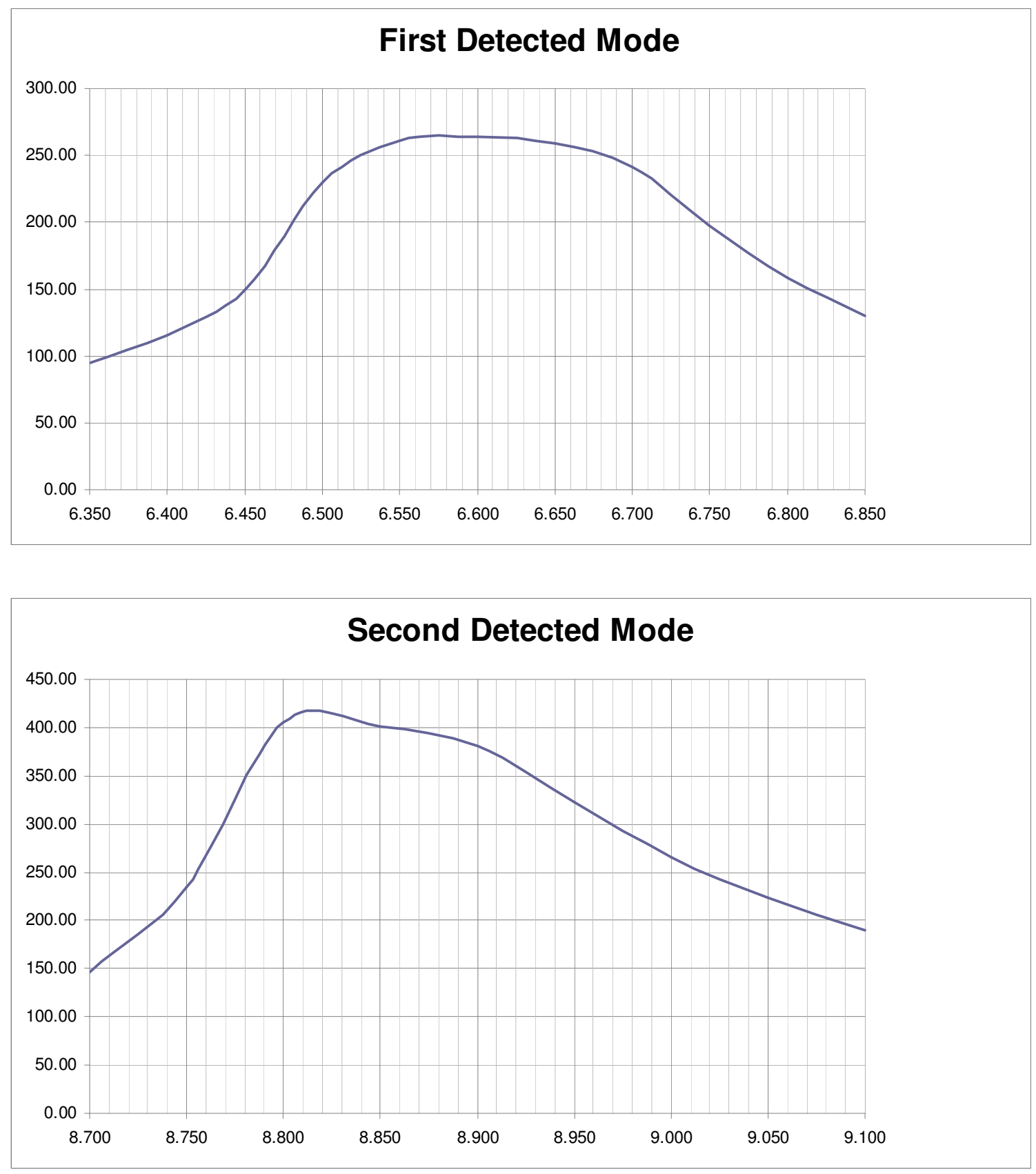

Identification of Physical Changes to a Steel Frame 

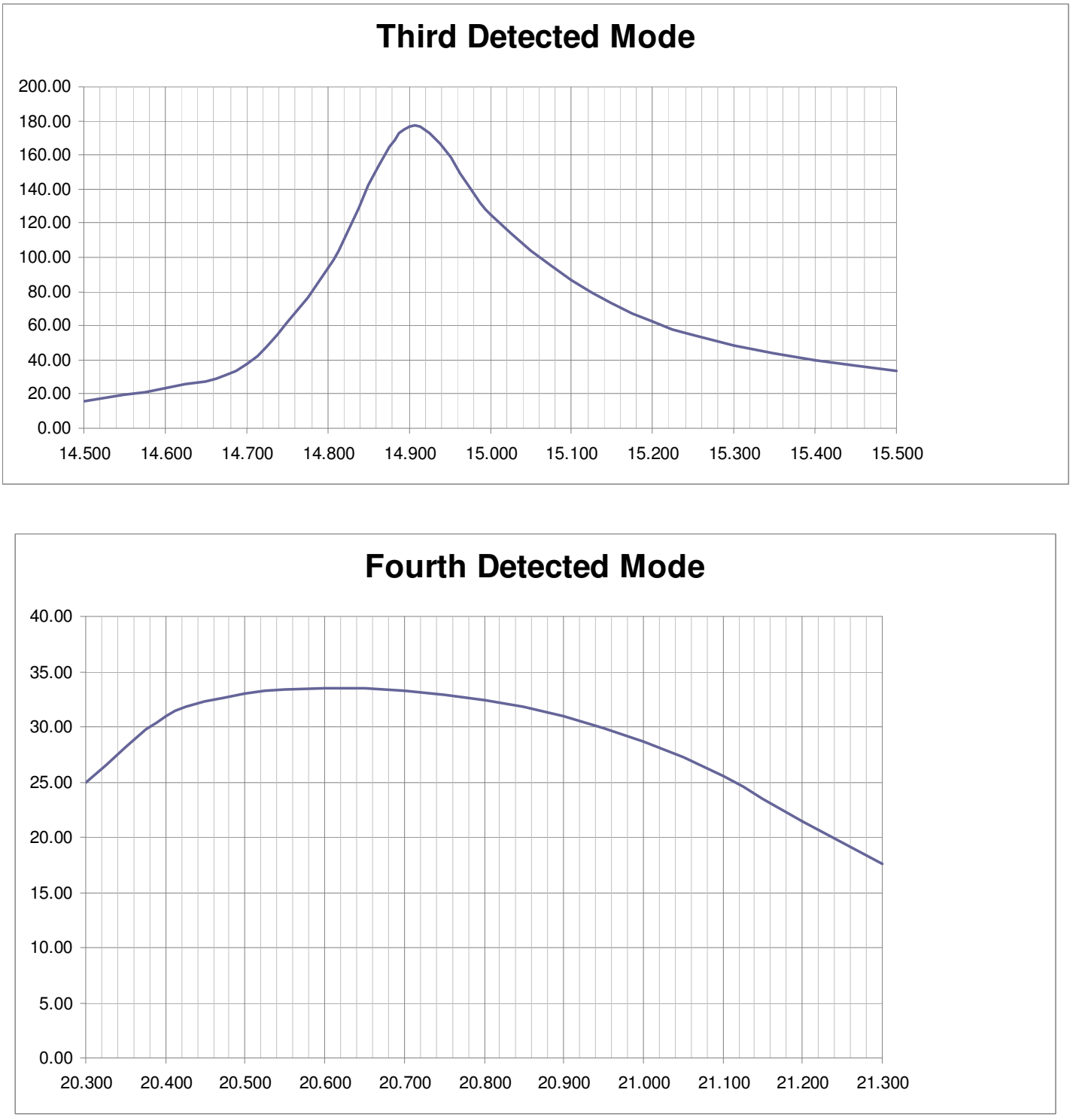


\begin{tabular}{|r|r|r|r|r|r|r|}
\hline \multicolumn{7}{|c|}{ First Detected Mode } \\
\hline f & a1 & a2 & a3 & a 4 & a5 & a avg \\
\hline 6.350 & 94.9 & 94.7 & 94.5 & & & 94.70 \\
\hline 6.400 & 116.0 & 116.0 & 115.0 & & & 115.67 \\
\hline 6.450 & 150.0 & 150.0 & 150.0 & 150.0 & & 150.00 \\
\hline 6.500 & 227.0 & 231.0 & 231.0 & 230.0 & & 229.75 \\
\hline $\mathbf{6 . 5 5 0}$ & $\mathbf{2 6 1 . 0}$ & $\mathbf{2 6 1 . 0}$ & $\mathbf{2 6 0 . 0}$ & $\mathbf{2 6 0 . 0}$ & $\mathbf{2 6 1 . 0}$ & $\mathbf{2 6 0 . 6 0}$ \\
\hline $\mathbf{6 . 6 0 0}$ & $\mathbf{2 6 4 . 0}$ & $\mathbf{2 6 2 . 0}$ & $\mathbf{2 6 5 . 0}$ & $\mathbf{2 6 5 . 0}$ & $\mathbf{2 6 4 . 0}$ & $\mathbf{2 6 4 . 0 0}$ \\
\hline 6.650 & 254.0 & 257.0 & 259.0 & 261.0 & 263.0 & 258.80 \\
\hline 6.700 & 239.0 & 241.0 & 243.0 & 244.0 & & 241.75 \\
\hline 6.750 & 198.0 & 195.0 & 198.0 & 198.0 & & 197.25 \\
\hline 6.800 & 158.0 & 159.0 & 159.0 & & & 158.67 \\
\hline 6.850 & 129.0 & 130.0 & 130.0 & & & 129.67 \\
\hline
\end{tabular}

\begin{tabular}{|r|r|r|r|r|r|r|}
\hline \multicolumn{7}{|c|}{ Second Detected Mode } \\
\hline f & a1 & a2 & a3 & a 4 & a5 & a avg \\
\hline 8.700 & 150.0 & 146.0 & 143.0 & & & 146.33 \\
\hline 8.750 & 232.0 & 236.0 & 235.0 & 235.0 & & 234.50 \\
\hline $\mathbf{8 . 8 0 0}$ & $\mathbf{4 0 1 . 0}$ & $\mathbf{3 9 9 . 0}$ & $\mathbf{4 0 2 . 0}$ & $\mathbf{4 0 7 . 0}$ & $\mathbf{4 1 4 . 0}$ & $\mathbf{4 0 4 . 6 0}$ \\
\hline $\mathbf{8 . 8 5 0}$ & $\mathbf{3 9 9 . 0}$ & $\mathbf{3 9 7 . 0}$ & $\mathbf{4 0 2 . 0}$ & $\mathbf{4 0 4 . 0}$ & $\mathbf{4 0 4 . 0}$ & $\mathbf{4 0 1 . 2 0}$ \\
\hline 8.900 & 377.0 & 380.0 & 380.0 & 383.0 & 383.0 & 380.60 \\
\hline 8.950 & 321.0 & 323.0 & 321.0 & 325.0 & & 322.50 \\
\hline 9.000 & 267.0 & 264.0 & 268.0 & & & 266.33 \\
\hline 9.050 & 221.0 & 223.0 & 225.0 & & & 223.00 \\
\hline 9.100 & 190.0 & 190.0 & 191.0 & & & 190.33 \\
\hline
\end{tabular}




\begin{tabular}{|r|r|r|r|r|r|r|}
\hline \multicolumn{7}{|c|}{ Third Detected Mode } \\
\hline \multicolumn{1}{|r|}{} & a1 & a2 & a3 & a4 & \multicolumn{1}{l|}{ a5 } & a avg \\
\hline 14.500 & 15.6 & 15.6 & 15.6 & & & 15.60 \\
\hline 14.600 & 23.1 & 23.1 & 23.1 & & & 23.10 \\
\hline 14.700 & 37.3 & 37.6 & 37.7 & & & 37.53 \\
\hline 14.800 & 92.9 & 93.9 & 93.9 & 93.9 & & 93.65 \\
\hline $\mathbf{1 4 . 9 0 0}$ & $\mathbf{1 7 9 . 0}$ & $\mathbf{1 7 6 . 0}$ & $\mathbf{1 7 6 . 0}$ & $\mathbf{1 7 6 . 0}$ & $\mathbf{1 7 6 . 0}$ & $\mathbf{1 7 6 . 6 0}$ \\
\hline 15.000 & 124.0 & 125.0 & 126.0 & 126.0 & & 125.25 \\
\hline 15.100 & 86.6 & 86.9 & 87.4 & & & 86.97 \\
\hline 15.200 & 62.0 & 62.5 & 62.7 & & & 62.40 \\
\hline 15.300 & 48.4 & 48.8 & 49.0 & & & 48.73 \\
\hline 15.400 & 39.4 & 39.4 & 39.8 & & & 39.53 \\
\hline 15.500 & 33.2 & 34.0 & 34.3 & & & 33.83 \\
\hline
\end{tabular}

\begin{tabular}{|r|r|r|r|r|r|r|}
\hline \multicolumn{7}{|c|}{ Fourth Detected Mode } \\
\hline $\mathrm{f}$ & a1 & a2 & a3 & a4 & a5 & \multicolumn{1}{l|}{ a avg } \\
\hline 20.300 & 24.9 & 24.9 & 25.1 & 25.0 & & 24.98 \\
\hline 20.400 & 31.1 & 31.0 & 31.0 & 30.9 & 30.9 & 30.98 \\
\hline 20.500 & 33.1 & 32.9 & 33.1 & 33.0 & 33.0 & 33.02 \\
\hline $\mathbf{2 0 . 6 0 0}$ & $\mathbf{3 3 . 4}$ & $\mathbf{3 3 . 4}$ & $\mathbf{3 3 . 5}$ & $\mathbf{3 3 . 5}$ & $\mathbf{3 3 . 5}$ & $\mathbf{3 3 . 4 6}$ \\
\hline 20.700 & 33.2 & 33.2 & 33.3 & 33.4 & 33.4 & 33.30 \\
\hline 20.800 & 32.4 & 32.4 & 32.4 & 32.5 & & 32.43 \\
\hline 20.900 & 30.8 & 30.9 & 31.0 & 31.0 & & 30.93 \\
\hline 21.000 & 28.7 & 28.7 & 28.7 & & & 28.70 \\
\hline 21.100 & 25.4 & 25.5 & 25.6 & & & 25.50 \\
\hline 21.200 & 21.4 & 21.4 & 21.5 & & & 21.43 \\
\hline 21.300 & 17.5 & 17.6 & 17.6 & & & 17.57 \\
\hline
\end{tabular}




\section{A.4.2 Recorded Mode Shapes}

\begin{tabular}{|c|c|c|c|c|c|c|c|c|c|c|}
\hline Mode Shapes & $\mathrm{V}$ & \multicolumn{3}{|c|}{ Roof } & \multicolumn{3}{|c|}{ Floor } & \multicolumn{3}{|c|}{ Ratio } \\
\hline \multirow{6}{*}{$6.57 \mathrm{~Hz}$} & \multirow{5}{*}{1} & $\mathrm{x} 1$ & $\mathrm{y} 1$ & $\mathrm{y} 2$ & $\mathrm{x} 1$ & $\mathrm{y} 1$ & $\mathrm{y} 2$ & $\mathrm{x} 1$ & $\mathrm{y} 1$ & $\mathrm{y} 2$ \\
\hline & & 73.8 & 363 & 147 & 59.3 & 210 & 110 & & & \\
\hline & & 73.2 & 364 & 144 & 60.4 & 208 & 109 & & & \\
\hline & & 73.2 & 362 & 151 & 61 & 210 & 111 & & & \\
\hline & & 72.9 & 366 & 150 & 59 & 210 & 110 & & & \\
\hline & Average -.> & 73.3 & 363.8 & 148.0 & 59.9 & 209.5 & 110.0 & 1.22 & 1.74 & 1.35 \\
\hline
\end{tabular}

\begin{tabular}{|c|c|c|c|c|c|c|c|c|c|c|}
\hline Mode Shapes & V & \multicolumn{3}{|c|}{ Roof } & \multicolumn{3}{|c|}{ Floor } & \multicolumn{3}{|c|}{ Ratio } \\
\hline \multirow{6}{*}{$8.82 \mathrm{~Hz}$} & \multirow{5}{*}{1} & $\mathrm{x} 1$ & $\mathrm{y} 1$ & y2 & $\mathrm{x} 1$ & $\mathrm{y} 1$ & $\mathrm{y} 2$ & $\mathrm{x} 1$ & $\mathrm{y} 1$ & y2 \\
\hline & & 321 & 20.0 & 8.33 & 156 & 24.8 & 18.4 & & & \\
\hline & & 326 & 21.4 & 10.6 & 154 & 24.9 & 17.5 & & & \\
\hline & & 315 & 21.8 & 10.7 & 153 & 24.8 & 18.2 & & & \\
\hline & & 332 & 23.8 & 11.0 & 153 & 24.9 & 18.1 & & & \\
\hline & Average --> & 323.5 & 21.8 & 10.2 & 154.0 & 24.9 & 18.1 & 2.10 & 0.88 & 0.56 \\
\hline
\end{tabular}

\begin{tabular}{|c|c|c|c|c|c|c|c|c|c|c|}
\hline \begin{tabular}{|l} 
Mode Shapes \\
\end{tabular} & \multirow[t]{2}{*}{ V } & \multicolumn{3}{|c|}{ Roof } & \multicolumn{3}{|c|}{ Floor } & \multicolumn{3}{|c|}{ Ratio } \\
\hline \multirow{6}{*}{$14.91 \mathrm{~Hz}$} & & $\mathrm{x} 1$ & $\mathrm{y} 1$ & $\mathrm{y} 2$ & $\mathrm{x} 1$ & $\mathrm{y} 1$ & $\mathrm{y} 2$ & $\mathrm{x} 1$ & $\mathrm{y} 1$ & $\mathrm{y} 2$ \\
\hline & \multirow{4}{*}{1} & 138 & 109 & 320 & 115 & 51.3 & 199 & & & \\
\hline & & 139 & 108 & 317 & 115 & 50.7 & 193 & & & \\
\hline & & 139 & 108 & 316 & 116 & 50.4 & 193 & & & \\
\hline & & 138 & 108 & 316 & 116 & 50.3 & 194 & & & \\
\hline & Average -.> & 138.5 & 108.3 & 317.3 & 115.5 & 50.7 & 194.8 & 1.20 & 2.14 & 1.63 \\
\hline
\end{tabular}

\begin{tabular}{|c|c|c|c|c|c|c|c|c|c|c|}
\hline Mode Shapes & V & \multicolumn{3}{|c|}{ Roof } & \multicolumn{3}{|c|}{ Floor } & \multicolumn{3}{|c|}{ Ratio } \\
\hline \multirow{6}{*}{$20.59 \mathrm{~Hz}$} & \multirow{5}{*}{1} & $\mathrm{x} 1$ & $\mathrm{y} 1$ & $\mathrm{y} 2$ & $\mathrm{x} 1$ & $\mathrm{y} 1$ & $y 2$ & $\mathrm{x} 1$ & $\mathrm{y} 1$ & $\mathrm{y} 2$ \\
\hline & & 9.77 & 38.9 & 31.9 & 3.97 & 95.6 & 64.9 & & & \\
\hline & & 9.95 & 39.1 & 32.0 & 3.50 & 95.9 & 65.2 & & & \\
\hline & & 10.2 & 39.2 & 32.1 & 3.82 & 96.3 & 65.4 & & & \\
\hline & & 10.3 & 39.6 & 32.1 & 3.48 & 96.5 & 65.6 & & & \\
\hline & Average -.> & 10.1 & 39.2 & 32.0 & 3.7 & 96.1 & 65.3 & 2.72 & 0.41 & 0.49 \\
\hline
\end{tabular}




\section{A.5 Properties of Each Singly Altered Model}

\begin{tabular}{|c|c|c|c|c|c|c|c|c|}
\hline Model Name & hand: & Girat? & flanes: & fresine: & & & & \\
\hline \multicolumn{9}{|l|}{ Physical Testing } \\
\hline Bustint & $6.48 \mathrm{~Hz}$ & $18.90 \mathrm{~Hz}$ & $1032 \mathrm{~Hz}$ & $1150 \mathrm{~Hz}$ & & & & \\
\hline Added Fioof Mass & $5.55 \mathrm{~Hz}$ & $18.46 \mathrm{~Hz}$ & $6.31 \mathrm{H}_{2}$ & $10.75 \mathrm{~Hz}$ & $-14.35 \%$ & -2334 & $-1366 \%$ & $-6.52 \%$ \\
\hline Added Roor Mass and Bracts & $6.57 \mathrm{~Hz}$ & $20.59 \mathrm{~Hz}$ & $8.82 \mathrm{~Hz}$ & $14.91 \mathrm{~Hz}$ & $139 \%$ & $894 \%$ & $-14.53 \%$ & $23.65 \%$ \\
\hline \multicolumn{9}{|l|}{ Computar Modsl: } \\
\hline Baseline & $6.48 \mathrm{~Hz}$ & $19.01 \mathrm{~Hz}$ & $10.34 \mathrm{~Hz}$ & $1166 \mathrm{~Hz}$ & $0.01 \%$ & $0.59 \%$ & $0.21 \%$ & $135 \%$ \\
\hline 125 Cont Roof Mass & $6.37 \mathrm{~Hz}$ & $16.90 \mathrm{~Hz}$ & $10.18 \mathrm{~Hz}$ & $1155 \mathrm{H}_{2}$ & $-166 \%$ & $-0.57 \%$ & $-1.53 \%$ & $-0.92 \%$ \\
\hline IS Coinet Pood Mass & $6.27 \mathrm{~Hz}$ & $1850 \mathrm{~Hz}$ & $1003 \mathrm{~Hz}$ & $1 \mathrm{IL4Hz}$ & $-320 \%$ & $-113 \%$ & $.301 \%$ & $-163 \%$ \\
\hline 175 Coint Roor Muss & $6.18 \mathrm{~Hz}$ & $18.69 \mathrm{~Hz}$ & $989 \mathrm{~Hz}$ & $1136 \mathrm{~Hz}$ & $-4.64 \%$ & $-168 \%$ & $-4.45 \%$ & $-2.50 \%$ \\
\hline 2 Cornet Roof Muss & $6.09 \mathrm{~Hz}$ & $18.62 \mathrm{~Hz}$ & $973 \mathrm{~Hz}$ & $1129 \mathrm{~Hz}$ & $-8.09 \%$ & $-205 \%$ & $-5.93 \%$ & $-3.18 \%$ \\
\hline 3 Corner Roof Mass & $5.75 \mathrm{~Hz}$ & $18.35 \mathrm{~Hz}$ & $9.18 \mathrm{~Hz}$ & $1104 \mathrm{~Hz}$ & $-1132 \%$ & $-3.49 \%$ & $-11.20 \%$ & $-5.30 \%$ \\
\hline 4 Cotner Roof Mass & $5.45 \mathrm{H}_{2}$ & $16.15 \mathrm{~Hz}$ & $8.70 \mathrm{H}_{2}$ & $10.86 \mathrm{~Hz}$ & $-15.67 \%$ & $-4.54 \%$ & $-15.84 \%$ & $-6.84 \%$ \\
\hline 125 Side Rool Mass & $6.27 \mathrm{H}_{2}$ & $16.50 \mathrm{~Hz}$ & $1004 \mathrm{~Hz}$ & $1143 \mathrm{~Hz}$ & $-320 \%$ & $-113 \%$ & $-291 \%$ & $-1.94 \%$ \\
\hline 15 Side Root Mass & $609 \mathrm{~Hz}$ & $18.62 \mathrm{~Hz}$ & $977 \mathrm{~Hz}$ & $1124 \mathrm{~Hz}$ & $-6.09 \%$ & $-205 \%$ & $-5.57 \%$ & $-3.60 \%$ \\
\hline 175 Side Roof Mass & $5.91 \mathrm{~Hz}$ & $18.48 \mathrm{~Hz}$ & $9.51 \mathrm{Hi}$ & $1105 \mathrm{~Hz}$ & $-881 \%$ & $277 \%$ & $-8.08 \%$ & $-5.19 \%$ \\
\hline 2 Side Roof Mass & $5.75 \mathrm{~Hz}$ & $18.35 \mathrm{~Hz}$ & $9.27 \mathrm{~Hz}$ & $10.89 \mathrm{H}_{2}$ & $-1132 \%$ & $-3.49 \%$ & $-10.38 \%$ & $-6.54 \%$ \\
\hline 25 Side Rool Mass & $5.45 \mathrm{~Hz}$ & $16.15 \mathrm{~Hz}$ & $883 \mathrm{~Hz}$ & $10.62 \mathrm{~Hz}$ & $-15.67 \%$ & $-4.54 \%$ & $+14.58 \%$ & $-8.92 \%$ \\
\hline 3 Side Roof Mass & $5.19 \mathrm{~Hz}$ & $17.99 \mathrm{H}_{2}$ & $8.48 \mathrm{~Hz}$ & $10.37 \mathrm{~Hz}_{2}$ & $-19647 /$ & $-5.40 \%$ & $-18.19 \%$ & $-1100 \%$ \\
\hline 125 Totsi Pool Muss & $6.10 \mathrm{~Hz}$ & $18.59 \mathrm{~Hz}$ & $9.77 \mathrm{~Hz}$ & iitis $\mathrm{H}$ i & $-5.31 \%$ & $-223 \%$ & $-5.57 \%$ & $-4,03 \%$ \\
\hline 15 TotilRool Muss & $593 \mathrm{~Hz}$ & $18.45 \mathrm{~Hz}$ & $951 \mathrm{~Hz}$ & $10.99 \mathrm{~Hz}$ & $-8.54 \%$ & $-295 \%$ & $-8.08 \%$ & $-5.71 \%$ \\
\hline 175 Total Roof Mass & $5.77 \mathrm{~Hz}$ & $18.32 \mathrm{~Hz}$ & $927 \mathrm{~Hz}$ & $1081 \mathrm{~Hz}$ & $-1101 \%$ & $-3.66 \%$ & $+1038 \%$ & $+724 \%$ \\
\hline 2 Tolal Roof Mass & $5.25 \mathrm{~Hz}$ & $17.86 \mathrm{~Hz}$ & $846 \mathrm{~Hz}$ & $10.07 \mathrm{H}_{2}$ & $-18.92 \%$ & $-6.07 \%$ & $-18.19 \%$ & $-13.60 \%$ \\
\hline 125 Connt Floor Mass & $6.44 \mathrm{~Hz}$ & $16.73 \mathrm{~Hz}$ & $1027 \mathrm{~Hz}$ & $1160 \mathrm{~Hz}$ & $-0.7 \mathrm{~K}$ & $-1.50 \%$ & $-0.72 \%$ & $-0.46 \%$ \\
\hline 15 Cotnet Floot Mass & $6.39 \mathrm{~Hz}$ & $16.48 \mathrm{~Hz}$ & $10.19 \mathrm{~Hz}$ & $1155 \mathrm{H}$ & $-134 \%$ & $-277 \%$ & $-1.43 \%$ & $-0.92 \%$ \\
\hline 175 Count Floot Mass & $6.35 \mathrm{~Hz}$ & $18.25 \mathrm{~Hz}$ & $10.12 \mathrm{~Hz}$ & 115:HE & $-197 \%$ & $-401 \%$ & $-213 \%$ & $-127 \%$ \\
\hline 2 Corner Floor Mass & $6.31 \mathrm{~Hz}$ & $18.02 \mathrm{~Hz}$ & $1005 \mathrm{~Hz}$ & $1145 \mathrm{~Hz}$ & $-2.65 \%$ & $-5.23 \%$ & $-2.81 \%$ & $-172 \%$ \\
\hline 125 Sids Floor Mass & $6.39 \mathrm{~Hz}$ & $16.48 \mathrm{~Hz}$ & $10.19 \mathrm{~Hz}$ & $1155 \mathrm{~Hz}$ & $-134 \%$ & $-277 x$ & $-1.43 \%$ & $-0.92 \%$ \\
\hline 15 Sude Floor Mass & $631 \mathrm{~Hz}$ & $16.02 \mathrm{~Hz}$ & $1006 \mathrm{~Hz}$ & $1144 \mathrm{~Hz}$ & $-265 \%$ & $-5.23 \%$ & $-2.72 \%$ & $-1.63 \%$ \\
\hline L75 Side Floot Mass & $623 \mathrm{~Hz}$ & $17.61 \mathrm{~Hz}$ & $932 \mathrm{H}_{2}$ & $1134 \mathrm{~Hz}$ & $-392 \%$ & $-7.39 \%$ & $-4.07 \%$ & $-272 \%$ \\
\hline 2 Side Floot Mass & $6.15 \mathrm{~Hz}$ & $1727 \mathrm{~Hz}$ & $979 \mathrm{~Hz}$ & $1124 \mathrm{~Hz}$ & $-5.15 \%$ & $-9.15 \%$ & $-5.29 \%$ & $-3.60 \%$ \\
\hline 125 Tots Floor Mast & $632 \mathrm{~Hz}$ & $1802 \mathrm{~Hz}$ & $1006 \mathrm{~Hz}$ & $1143 \mathrm{~Hz}$ & $-253 \%$ & $-5.23 \%$ & $-272 \%$ & $-194 \%$ \\
\hline 15 Tot iffloor Mass & $6.16 \mathrm{~Hz}$ & $17.21 \mathrm{~Hz}$ & $978 \mathrm{~Hz}$ & $1122 \mathrm{~Hz}$ & $-4.49 \%$ & $-947 \%$ & $.5 .29 \%$ & $-3.70 \%$ \\
\hline 175 Total Floor Muss & $6.01 \mathrm{~Hz}$ & $16.58 \mathrm{~Hz}$ & $954 \mathrm{~Hz}$ & $101 \mathrm{~Hz}$ & $.727 x$ & $-12.77 \%$ & $.7 .73 \%$ & $-5.51 \%$ \\
\hline 2 Tors floor Mass & $5.87 \mathrm{~Hz}$ & $16.10 \mathrm{~Hz}$ & $93 \mathrm{~Hz}$ & $1082 \mathrm{~Hz}$ & $-9.45 \%$ & $-15.30 \%$ & $-9.96 \%$ & $-7.14 \%$ \\
\hline 125 All Muss & $5.37 \mathrm{H}_{4}$ & $17.54 \mathrm{~Hz}$ & $9.52 \mathrm{~Hz}$ & $1100 \mathrm{H}_{2}$ & $.7 .34 \%$ & -7.728 & $.7,30 \% \%$ & -5.616 \\
\hline 15 AllMass & $5.56 \mathrm{H}_{2}$ & $16.34 \mathrm{~Hz}$ & $887 \mathrm{~Hz}$ & $1044 \mathrm{~Hz}$ & $-14.23 \%$ & $.4 .05 \%$ & $-1420 \%$ & $-10.44 \%$ \\
\hline 175 All Mass & $522 \mathrm{~Hz}$ & $1536 \mathrm{~Hz}$ & $834 \mathrm{~Hz}$ & $986 \mathrm{~Hz}$ & $-1938 \%$ & $-1320 \%$ & $-1835 \%$ & $-14.54 \%$ \\
\hline 2 Ail Mars & $494 \mathrm{~Hz}$ & $145 \mathrm{~Hz}$ & $7.89 \mathrm{~Hz}$ & $955 \mathrm{~Hz}$ & $.2373 \%$ & $.2344 \%$ & $.2368 \%$ & $.18 .21 \%$ \\
\hline
\end{tabular}


Appendix 100

\begin{tabular}{|c|c|c|c|c|c|c|c|c|}
\hline 0.125 Top Brace & $6.58 \mathrm{~Hz}$ & $19.80 \mathrm{~Hz}$ & $10.34 \mathrm{~Hz}$ & $11.71 \mathrm{~Hz}$ & $1.51 \%$ & $4.16 \%$ & $0.00 \%$ & $0.47 \%$ \\
\hline 0.250 Top Brace & $6.76 \mathrm{~Hz}$ & $21.79 \mathrm{~Hz}$ & $10.34 \mathrm{~Hz}$ & $11.82 \mathrm{~Hz}$ & $4.33 \%$ & $14.60 \%$ & $0.00 \%$ & $1.42 \%$ \\
\hline 0.375 Top Brace & $6.91 \mathrm{~Hz}$ & $24.10 \mathrm{~Hz}$ & $10.34 \mathrm{~Hz}$ & $11.89 \mathrm{~Hz}$ & $6.56 \%$ & $26.75 \%$ & $0.00 \%$ & $2.02 \%$ \\
\hline 0.500 Top Brace & $7.00 \mathrm{~Hz}$ & $26.04 \mathrm{~Hz}$ & $10.33 \mathrm{~Hz}$ & $11.95 \mathrm{~Hz}$ & $7.98 \%$ & $36.98 \%$ & $-0.10 \%$ & $2.51 \%$ \\
\hline 0.625 Top Brace & $7.06 \mathrm{~Hz}$ & $27.55 \mathrm{~Hz}$ & $10.33 \mathrm{~Hz}$ & $11.96 \mathrm{~Hz}$ & $8.89 \%$ & $44.90 \%$ & $-0.10 \%$ & $2.63 \%$ \\
\hline 0.750 Top Brace & $7.09 \mathrm{~Hz}$ & $28.57 \mathrm{~Hz}$ & $10.33 \mathrm{~Hz}$ & $11.98 \mathrm{~Hz}$ & $9.43 \%$ & $50.29 \%$ & $-0.10 \%$ & $2.75 \%$ \\
\hline 0.875 Top Brace & $7.12 \mathrm{~Hz}$ & $29.24 \mathrm{~Hz}$ & $10.32 \mathrm{~Hz}$ & $11.98 \mathrm{~Hz}$ & $9.82 \%$ & $53.80 \%$ & $-0.21 \%$ & $2.75 \%$ \\
\hline 1.000 Top Brace & $7.13 \mathrm{~Hz}$ & $29.76 \mathrm{~Hz}$ & $10.31 \mathrm{~Hz}$ & $11.96 \mathrm{~Hz}$ & $10.06 \%$ & $56.55 \%$ & $-0.31 \%$ & $2.63 \%$ \\
\hline 0.125 Bottom Brace & $6.81 \mathrm{~Hz}$ & $19.38 \mathrm{~Hz}$ & $10.34 \mathrm{~Hz}$ & $11.99 \mathrm{~Hz}$ & $5.04 \%$ & $1.94 \%$ & $0.00 \%$ & $2.88 \%$ \\
\hline 0.250 Bottom Brace & $7.39 \mathrm{~Hz}$ & $20.49 \mathrm{~Hz}$ & $10.34 \mathrm{~Hz}$ & $12.82 \mathrm{~Hz}$ & $13.96 \%$ & $7.79 \%$ & $0.00 \%$ & $10.00 \%$ \\
\hline 0.375 Bottom Brace & $7.78 \mathrm{~Hz}$ & $22.37 \mathrm{~Hz}$ & $10.34 \mathrm{~Hz}$ & $13.66 \mathrm{~Hz}$ & $20.08 \%$ & $17.67 \%$ & $0.00 \%$ & $17.21 \%$ \\
\hline 0.500 Bottom Brace & $8.01 \mathrm{~Hz}$ & $24.81 \mathrm{~Hz}$ & $10.34 \mathrm{~Hz}$ & $14.25 \mathrm{~Hz}$ & $23.54 \%$ & $30.52 \%$ & $0.00 \%$ & $22.22 \%$ \\
\hline 0.625 Bottom Brace & $8.13 \mathrm{~Hz}$ & $27.17 \mathrm{~Hz}$ & $10.34 \mathrm{~Hz}$ & $14.58 \mathrm{~Hz}$ & $25.45 \%$ & $42.93 \%$ & $0.00 \%$ & $25.07 \%$ \\
\hline 0.750 Bottom Brace & $8.21 \mathrm{~Hz}$ & $29.24 \mathrm{~Hz}$ & $10.34 \mathrm{~Hz}$ & $14.79 \mathrm{~Hz}$ & $26.68 \%$ & $53.80 \%$ & $0.00 \%$ & $26.92 \%$ \\
\hline 0.875 Bottom Brace & $8.26 \mathrm{~Hz}$ & $30.77 \mathrm{~Hz}$ & $10.34 \mathrm{~Hz}$ & $14.93 \mathrm{~Hz}$ & $27.42 \%$ & $61.85 \%$ & $0.00 \%$ & $28.06 \%$ \\
\hline 1.000 Bottom Brace & $8.29 \mathrm{~Hz}$ & $31.95 \mathrm{~Hz}$ & $10.34 \mathrm{~Hz}$ & $15.02 \mathrm{~Hz}$ & $27.84 \%$ & $68.05 \%$ & $0.00 \%$ & $28.83 \%$ \\
\hline 0.125 Double Brace & $6.91 \mathrm{~Hz}$ & $20.08 \mathrm{~Hz}$ & $10.34 \mathrm{~Hz}$ & $12.08 \mathrm{~Hz}$ & $6.63 \%$ & $5.62 \%$ & $0.00 \%$ & $3.62 \%$ \\
\hline 0.250 Double Brace & $7.69 \mathrm{~Hz}$ & $22.57 \mathrm{~Hz}$ & $10.34 \mathrm{~Hz}$ & $13.48 \mathrm{~Hz}$ & $18.60 \%$ & $18.74 \%$ & $0.00 \%$ & $15.63 \%$ \\
\hline 0.375 Double Brace & $8.22 \mathrm{~Hz}$ & $25.25 \mathrm{~Hz}$ & $10.34 \mathrm{~Hz}$ & $15.77 \mathrm{~Hz}$ & $26.79 \%$ & $32.83 \%$ & $0.00 \%$ & $35.33 \%$ \\
\hline 0.500 Double Brace & $8.49 \mathrm{~Hz}$ & $27.32 \mathrm{~Hz}$ & $10.33 \mathrm{~Hz}$ & $18.59 \mathrm{~Hz}$ & $30.98 \%$ & $43.72 \%$ & $-0.10 \%$ & $59.48 \%$ \\
\hline 0.625 Double Brace & $8.64 \mathrm{~Hz}$ & $28.74 \mathrm{~Hz}$ & $10.33 \mathrm{~Hz}$ & $21.55 \mathrm{~Hz}$ & $33.25 \%$ & $51.15 \%$ & $-0.10 \%$ & $84.91 \%$ \\
\hline 0.750 Double Brace & $8.72 \mathrm{~Hz}$ & $29.76 \mathrm{~Hz}$ & $10.32 \mathrm{~Hz}$ & $24.45 \mathrm{~Hz}$ & $34.52 \%$ & $56.55 \%$ & $-0.21 \%$ & $109.78 \%$ \\
\hline 0.875 Double Brace & $8.77 \mathrm{~Hz}$ & $30.77 \mathrm{~Hz}$ & $10.32 \mathrm{~Hz}$ & $27.03 \mathrm{~Hz}$ & $35.35 \%$ & $61.85 \%$ & $-0.21 \%$ & $131.89 \%$ \\
\hline 1.000 Double Brace & $8.80 \mathrm{~Hz}$ & $32.15 \mathrm{~Hz}$ & $10.31 \mathrm{~Hz}$ & $28.82 \mathrm{~Hz}$ & $35.83 \%$ & $69.13 \%$ & $-0.31 \%$ & $147.26 \%$ \\
\hline
\end{tabular}

Comparing the lab data to the ETABS model for single change (additional mass: 600

pounds):

\begin{tabular}{|l|r|r|r|r|}
\hline & f weak1 & f weak2 & f strong1 & f torsion 1 \\
\hline Lab Testing & $5.55 \mathrm{~Hz}$ & $18.46 \mathrm{~Hz}$ & $8.91 \mathrm{~Hz}$ & $10.75 \mathrm{~Hz}$ \\
\hline ETABS & $5.68 \mathrm{~Hz}$ & $18.67 \mathrm{~Hz}$ & $9.14 \mathrm{~Hz}$ & $10.94 \mathrm{~Hz}$ \\
\hline \% Difference & $2.32 \%$ & $1.15 \%$ & $2.59 \%$ & $1.78 \%$ \\
\hline
\end{tabular}

